\title{
Los deflactores del gasto público: El caso de la educación básica y terciaria en la Argentina
}

\section{Sabrina Reichler}

Tesis de la Maestría en Economía

Facultad de Ciencias Económicas - Universidad Nacional de La Plata

Director: Damián Bonari

Septiembre de 2005 


\section{Los deflactores del gasto público: El caso de la educación básica y terciaria en la Argentina}

1 Introducción . 1

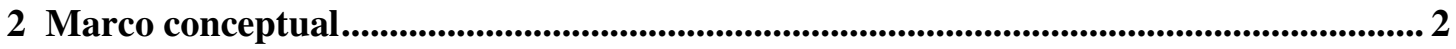

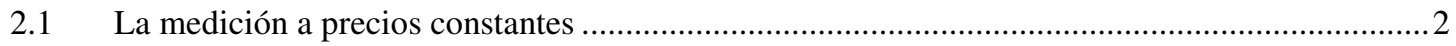

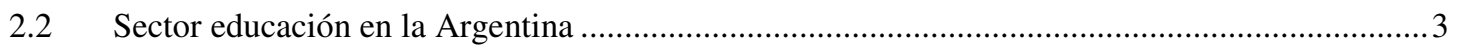

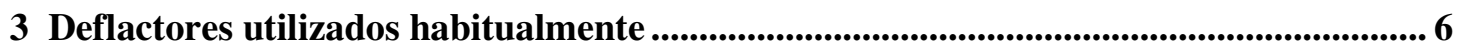

3.1 El índice de precios al consumidor y el índice de precios combinado......................................6

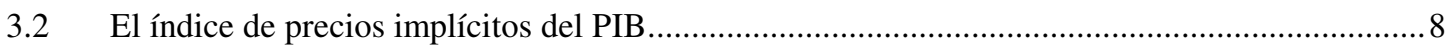

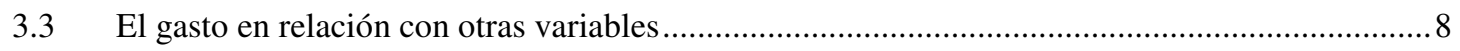

4 Medidas alternativas para la deflación ........................................................................................ 9

4.1 El índice de precios educativos de Halstead ......................................................................... 9

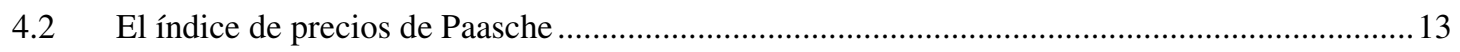

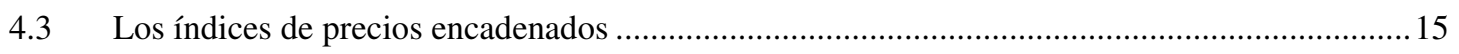

4.4 El índice de servicios neto de Rothstein y Miles ................................................................... 16

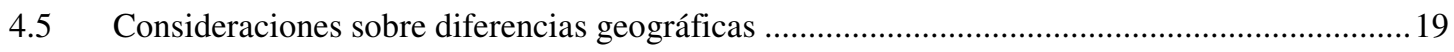

5 Deflactar el gasto a partir de los productos ............................................................................... 23

5.1 Medidas basadas en el producto: concepto y definiciones ....................................................23

5.2 Medición del producto de la educación básica y terciaria .......................................................25

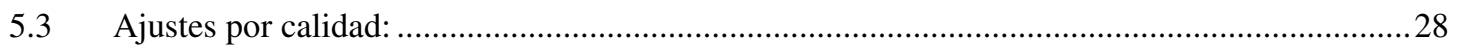

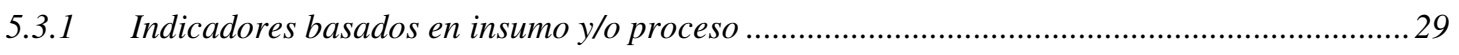

5.3.2 Aplicación de los ajustes por calidad a partir de los insumos ................................................37

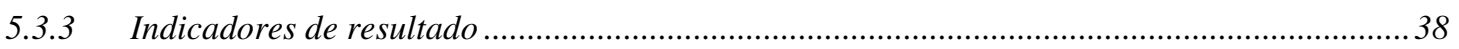

5.3.4 Aplicación de los ajustes por calidad a partir de los resultados............................................40

6 La productividad del gasto público educativo................................................................ 42

6.1 Medición directa: diferencia entre producto e insumos ........................................................42

7 Consideraciones Finales ............................................................................................................. 44

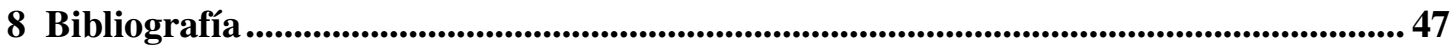

9 AnexOS .........................................................................................................................5 50

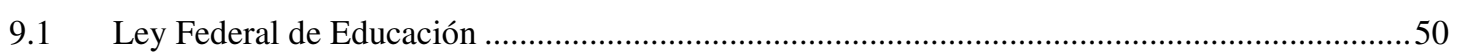

9.2 Variables utilizadas en la estimación del modelo de salarios hedónicos ...................................51 


\section{Introducción}

En 1998 el gasto público consolidado en educación básica y terciaria fue de $\$ 10.150$ millones; en 2002 este gasto creció a $\$ 10.947$ millones. Sin embargo, este aumento de 7,9\% para el período no da información sobre la variación real en el gasto que se destina al sector. Es probable que al menos parte de este incremento haya sido causado por la inflación: los precios de los diferentes insumos que adquieren los proveedores de educación varían cada año.

Si el precio de los alimentos aumenta 5\% en promedio, las familias deben aumentar sus presupuestos alimentarios en 5\% sólo para mantener su consumo de alimentos constante. De manera similar, si las escuelas se enfrentan con un $10 \%$ de aumento en el precio de los libros de texto deben aumentar el gasto en este insumo 10\% para proveer a los estudiantes del mismo número de libros de texto. Medir el crecimiento de los recursos reales en la educación requiere conocer el aumento de precios en los bienes y servicios que adquieren las escuelas. Los cambios nominales de los niveles de gasto público en educación pueden implicar modificaciones tanto de los precios de los insumos como del volumen físico de éstos.

De este modo, el análisis de los cambios en el gasto público educativo a lo largo del tiempo, tanto en contextos de planeamiento como de evaluación, debe utilizar alguna medida de inflación para convertir el gasto de 1998 en su equivalente para 2002. Así, puede considerarse el crecimiento de gasto "real" por oposición al "nominal".

Habitualmente, el gasto se expresa en términos reales transformando los valores nominales en moneda constante mediante el uso de algún deflactor. Los deflactores del gasto comúnmente empleados son el índice de precios implícitos del PIB (IPI), el índice de precios al consumidor (IPC) y un índice de precios combinado (compuesto en partes iguales por el índice de precios al consumidor y el índice de precios mayoristas) ${ }^{1}$.

A partir de utilizar cualquiera de estos indicadores el gasto público en educación en términos reales entre 1998 y 2002 presentó disminuciones muy importantes: 15,8\% en el caso del IPI, 11,5\% para el IPC y $27,1 \%$ para el índice de precios combinado.

Sin embargo, ¿presentó el sector educativo una caída en el gasto real tan significativa? ¿qué relación existe entre los bienes y servicios que se incorporan en el cálculo de los distintos indicadores y aquellos que utiliza el sector educativo?

Con respecto a estos interrogantes, el primer objetivo del trabajo se relaciona con el análisis de la utilidad de los indicadores usuales para expresar el gasto público en educación en términos constantes. La presunción es que existe una serie de dificultades asociadas a su uso y que en consecuencia la construcción de indicadores más apropiados arrojará resultados distintos. En particular, se plantea que el gasto real del sector no sólo no disminuyó en las proporciones planteadas sino que registró para el período algún incremento.

El segundo objetivo, estrechamente vinculado al primero, se basa en la relación entre los recursos reales destinados al sector educativo y el producto de este sector. En este sentido, aislar el impacto de los precios en el gasto, no resuelve el problema de la comparabilidad de las prestaciones en términos cuantitativos. Es decir, si el precio de los insumos utilizados en el proceso de producción educativo no cambia, pero se mejora3 o empeora la eficiencia del servicio a partir de utilizar las mismas cantidades de insumo, esto no se vería reflejado en el gasto nominal o real en los términos antes definidos. A su vez, contar con más recursos reales no implica necesariamente que el producto de la educación aumente. Siguiendo a Dehn, J. et al (2002), "Resulta cada vez más evidente que el nivel de recursos asignados puede resultar en un muy mal predictor de la cantidad y calidad de los servicios públicos".

Así, la segunda parte del estudio considera la evolución del gasto educativo en términos de las prestaciones asociadas a éste. Conocer la relación entre el gasto y el producto de la educación, i.e. la

${ }^{1}$ Véase CEPAL (1994). 
cantidad y calidad de servicios que surge como resultado del dinero invertido en el sector, permite analizar, por ejemplo ¿qué cantidad de alumnos fue posible "educar" con un monto determinado de gasto?, o, que el gasto aumente, ¿significa que se está educando una mayor cantidad de alumnos o que se los está educando con una mejor calidad? Al igual que en el caso anterior, se estudia si el gasto real definido de este modo presentó para el período analizado algún incremento.

El trabajo se organiza de la siguiente manera. En la sección 2 se presentan algunas definiciones relevantes con respecto a la medición a precios constantes y se realiza un breve repaso del sector educativo en la Argentina, focalizando en las características que tuvo en los últimos años en términos de organización y del gasto destinado a éste. La sección 3 analiza los deflactores empleados habitualmente, exponiendo las características y las principales dificultades que surgen al utilizar cada uno. La cuarta sección explora los métodos alternativos para aislar el efecto de la inflación sobre los recursos destinados a la educación. Adicionalmente, comprende algunas consideraciones sobre las diferencias geográficas. La sección 5 se centra en la evolución del producto de la educación; se revisa la definición y el cálculo de éste y se consideran distintas alternativas para incorporar cambios en la calidad. En la sección 6 se utilizan los resultados anteriores para obtener una aproximación hacia la productividad/ eficiencia del sector educativo. Por último, la sección 7 presenta las consideraciones finales.

\section{Marco conceptual}

\subsection{La medición a precios constantes}

De acuerdo con la teoría, la variación que experimentan las magnitudes económicas a través del tiempo está compuesta de una variación en precio y una variación en volumen. En principio, el componente "precio" debe incorporar cambios relacionados únicamente con cambios en los precios, mientras que el resto de los cambios (relacionados con cantidad, calidad y composición) deben ser incluidos en el componente "volumen" .

La posibilidad de comparar intertemporalmente distintas magnitudes presupone, por lo tanto, algún tipo de corrección de las mismas, a través de la cual pueda despejarse la variación en precio para llegar a una noción de la variación del volumen.

Las alternativas existentes para realizar este ejercicio son variadas y la elección de alguna en particular tiene que ver tanto con las características de la variable a ser corregida como con el tipo de información que se busca extraer de la misma. El problema que se presenta es que para cada variable resulta relevante sólo la variación de algunos precios, de modo que la elección del deflactor adecuado no es trivial.

El modo en que habitualmente se realiza la conversión de cualquier magnitud a precios constantes implica la utilización de índices de precios e índices de volumen.

Un índice de precios es un promedio del cambio proporcional en los precios de un conjunto de bienes y servicios entre dos períodos de tiempo. De manera similar, un índice de volumen es un promedio del cambio proporcional en las cantidades de un conjunto específico de bienes y servicios. Los cambios en precio y cantidad se refieren a bienes y servicios individuales, distinguiéndolos de grupos o productos similares. En este contexto, calidades diferentes del mismo tipo de producto deben tratarse como bienes o servicios separados.

En línea con las convenciones habituales, el período que sirve de punto de referencia se designa como período 0 y el período que se compara con éste se designa como período t. Los dos períodos pueden ser consecutivos o estar separados por períodos intermedios. La relación de precio o cantidad de un producto específico en el período t con el precio o cantidad del mismo producto en el período

\footnotetext{
${ }^{2}$ Sin embargo algunos "flujos", como las transferencias monetarias, no tienen las dimensiones precio y cantidad y no pueden por tanto descomponerse de esta forma. Este tipo de flujos no puede medirse a "precios constantes" pero se puede calcular en cambio, en "términos reales" a partir de deflactar su valor por índices de precios que permitan medir el poder de compra real sobre alguna canasta de bienes y servicios que sirva como numerario.
} 
0 , se describe como precio relativo o cantidad relativa: pt/po o qt/qo. Los precios o cantidades relativas son números puros independientes de las unidades en que los precios o las cantidades están expresados. La mayor parte de los números índices puede expresarse como, o derivarse de, promedios ponderados de estos precios o cantidades relativas. Las distintas fórmulas difieren entre sí principalmente en la ponderación que le asocian a los precios o cantidades relativas individuales y en la forma particular de los promedios que utilizan -aritmético, geométrico, armónico, etc.

Los dos índices más comúnmente utilizados son el índice de Laspeyres y el de Paasche. Ambos pueden definirse como promedios ponderados de los precios o cantidades relativas, siendo las ponderaciones los valores de los bienes o servicios individuales en uno, otro o ambos períodos que están siendo comparados.

Desde el punto de vista de la teoría económica ${ }^{3}$, las cantidades observadas en distintos períodos pueden asumirse que son funciones de los precios, tal como se especifica en algunas funciones de utilidad o de producción. Asumiendo que los gastos del consumidor se relacionan con una función de utilidad, un índice de precios puede definirse como la relación entre el gasto mínimo requerido para permitir al consumidor lograr el mismo nivel de utilidad bajo los dos conjuntos de precios. El valor del índice teórico no es el mismo para diferentes consumidores con diferentes preferencias, ni siquiera para el mismo consumidor partiendo desde distintos niveles de ingreso (no es invariante).

Por consiguiente, la fórmula del índice dependerá de la especificación de las funciones de utilidad de las que se derivan las funciones de gasto; y la exactitud con que se midan los cambios en los precios, dependerá de la aproximación que logren esas funciones al comportamiento de las unidades de decisión.

Los índices de precios sólo son invariantes cuando las funciones de preferencia son homotéticas, pues en este caso las funciones de gasto son separables en precios y niveles de bienestar ${ }^{4}$. Y debido a que éstos últimos se mantienen en las dos situaciones de equilibrio, el valor del índice sólo depende de los precios iniciales y finales.

Bajo el supuesto de preferencias homotéticas, el índice de Laspeyres provee un límite superior al índice teórico, mientras que el índice de Paasche provee un límite inferior. Si adicionalmente se supone que la función es cuadrática homogénea, el índice de Fischer -definido como la media geométrica entre los dos índices anteriores- es igual al índice teórico.

\subsection{Sector educación en la Argentina}

La Argentina cuenta con altos niveles relativos de escolarización. A partir de datos del último censo (2001), el nivel de alfabetización era de $97 \%$ y las tasas netas de escolarización en educación primaria y media $97,9 \%$ y $71,5 \%$ respectivamente. Asimismo, las tasas de escolarización por grupo de edad indican que asistían a establecimientos educativos 98,3\% de los niños entre 6 y 11 años y 93,6\% de los niños entre 12 y 14 años. De acuerdo con las encuestas permanentes de hogares (EPH) que realiza periódicamente el INDEC, la tasa de niños en edad de escolaridad obligatoria que asisten a la escuela se ha mantenido constante alrededor del $98 \%$ durante el período 1998-2002 ${ }^{5}$. En 2002, el sistema contaba con un total de 9,95 millones de estudiantes (54\% en educación primaria) y más de 516.000 cargos docentes; $75 \%$ de la matrícula total se registraba en instituciones públicas.

La responsabilidad sobre la educación primaria y media ha sido descentralizada hacia las provincias (el nivel primario mayormente a partir de $1978^{6}$ y la educación media a partir de 19937). En 1993 la

\footnotetext{
${ }^{3}$ Sobre la teoría económica de los números índices y las pruebas de consistencia que supera cada uno, ver United Nations (1993) cap. 16 y Delfino (2002).

${ }^{4}$ Una función homotética es una transformación monótonamente creciente de una función homogénea de primer grado, del tipo $\mathrm{F}[\mathrm{f}(\mathrm{X})]$ tal que $\mathrm{F}[0]=0$ y $\mathrm{F}[\mathrm{X}] \rightarrow \infty$ en tanto $\mathrm{X} \rightarrow \infty$. Las curvas de indiferencia de las funciones de preferencia homotéticas se obtienen por expansión radial de cualquiera de ellas. Además, todas las funciones ordinarias de demanda que derivan de esas funciones tienen elasticidad-ingreso unitaria.

${ }_{6}^{5}$ El dato se refiere al porcentaje de alumnos de 6 a 14 años que declaran asistir a la escuela.

${ }^{6}$ Las leyes $\mathrm{N}^{\circ} 21.809$ y N 21.810 transfirieron a las provincias y a la Ciudad de Buenos Aires las escuelas primarias $\mathrm{y}$ algunas escuelas secundarias.
} 
Ley Federal de Educación (Ley $\mathrm{N}^{\circ}$ 24.195) reguló la distribución de responsabilidades entre los niveles de gobierno ${ }^{8}$. A partir de ésta las provincias tienen a su cargo gran parte de las responsabilidades financieras, pedagógicas y administrativas, así como también asumen las cuestiones vinculadas con las relaciones laborales y el desarrollo de la carrera docente. El gobierno nacional por su parte tiene a cargo la definición del currículum, la evaluación del sistema, la implementación de programas compensatorios y la promoción - junto con las provincias - de los programas de formación docente. El rol preponderante de los gobiernos provinciales, en contraposición con las responsabilidades a nivel municipal o nacional en el manejo del sistema educativo, es muy importante en términos internacionales. Dado que la mayor parte de las escuelas dependen del nivel de gobierno provincial, los presupuestos educativos, los salarios docentes y las condiciones de trabajo y regulaciones se deciden en este nivel.

Con respecto a la educación superior, en 1995 se firmó la Ley de Educación Superior No 24.521. Dicha Ley estableció que las provincias y la Ciudad de Buenos Aires son responsables del gobierno y la organización de la educación superior no universitaria ${ }^{9}$. Por su parte, la enseñanza superior universitaria está a cargo de las universidades nacionales y provinciales, y de los institutos universitarios que tienen autonomía académica e institucional y son evaluadas por la Comisión Nacional de Evaluación y Acreditación Universitaria ${ }^{10}$.

Durante la última década el gasto público consolidado en educación aumentó más de 70\%, pasando de $\$ 6.368$ millones en 1992 a $\$ 10.947$ millones en 2002. Los datos disponibles indican que este incremento en el gasto total se ha mantenido durante los años 2003 y 2004.

En términos del PIB, se registró una participación promedio para el período de $3,5 \%$ y con respecto al gasto total se destinó a la educación $10,8 \%$ en promedio. La desagregación por niveles de gobierno indica que el gasto ejecutado por la Nación

Gráfico I

Gasto público consolidado en educación básica y terciaria, 1992-2002

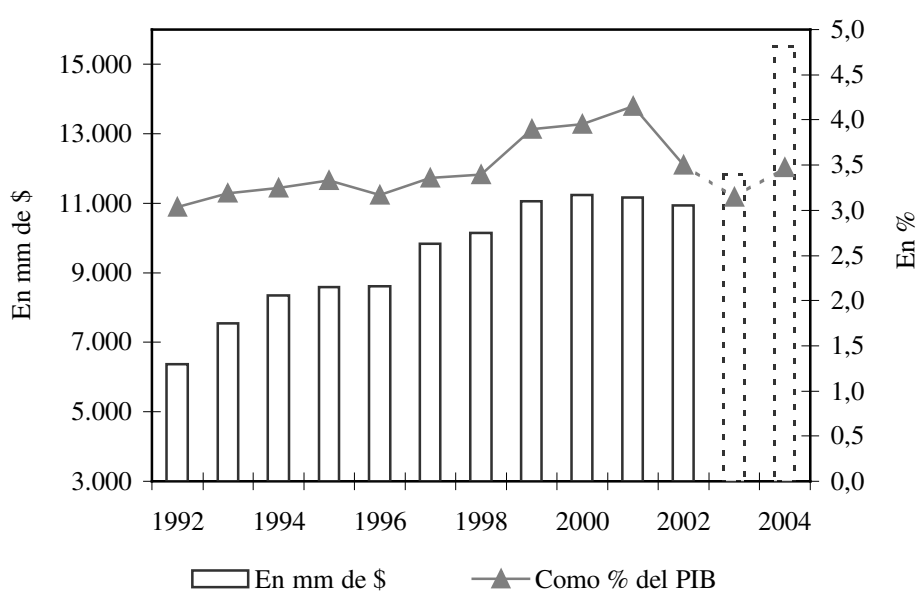

Fuente: elaboración propia sobre la base de DAGPyPS. disminuyó a partir de 1992, cuando se profundizó el proceso de descentralización del sistema educativo. Su peso relativo -superior a $20 \%$ durante la segunda parte de la década del ochenta y hasta 1991- descendió en promedio, para el período 1992-2002, a alrededor de 3,2\%. Como contrapartida, la participación de las provincias aumentó de $76,3 \%$ a $93,3 \%$ y los municipios incrementaron su participación de $2,5 \%$ a 3,5\%.

\footnotetext{
${ }^{7}$ La Ley No 24.049 facultó al Poder Ejecutivo a transferir a partir de 1992 a las provincias y a la Ciudad de Buenos Aires, todos los servicios educativos administrados por el Ministerio de Educación, Ciencia y Tecnología, y las responsabilidades y funciones inherentes a los establecimientos privados.

${ }^{8}$ Esta Ley también modificó la estructura del sistema educativo. Ver anexo 9.1.

${ }^{9}$ La educación terciaria comprende diversos campos: Institutos superiores de formación docente, Institutos de Formación Técnica, educación artística y distintas carreras cortas (que duran entre 1 y 4 años). Este sector involucra más de 1.750 instituciones.

${ }^{10}$ De acuerdo con la Ley, la Administración Nacional debe asegurar el aporte financiero para sostener el funcionamiento y desarrollo de las instituciones universitarias nacionales. En virtud de su autarquía económico-financiera, estas instituciones pueden administrar su patrimonio, aprobar su presupuesto y generar recursos adicionales a los aportes del Tesoro Nacional. Dadas las características particulares de estas instituciones, se excluye del análisis el gasto relacionado con el financiamiento de las universidades nacionales.
} 
Durante el período 1998-2002 el gasto creció 7,9\% y la participación promedio de cada nivel de gobierno fue de 2,5\% para el gobierno nacional, 93,9\% para las provincias y el 3,6\% restante para los gobiernos municipales.

\section{Cuadro I}

Gasto público consolidado en educación básica y terciaria por nivel de gobierno, 1998-2002

En millones de pesos

\begin{tabular}{lrrrrr}
\hline $\begin{array}{c}\text { Nivel de } \\
\text { gobierno }\end{array}$ & $\mathbf{1 9 9 8}$ & $\mathbf{1 9 9 9}$ & $\mathbf{2 0 0 0}$ & $\mathbf{2 0 0 1}$ & $\mathbf{2 0 0 2}$ \\
\hline Nación & 437 & 296 & 184 & 139 & 298 \\
Provincias & 9.363 & 10.337 & 10.642 & 10.617 & 10.262 \\
Municipios & 350 & 415 & 410 & 401 & 387 \\
Total & $\mathbf{1 0 . 1 5 0}$ & $\mathbf{1 1 . 0 4 8}$ & $\mathbf{1 1 . 2 3 7}$ & $\mathbf{1 1 . 1 5 7}$ & $\mathbf{1 0 . 9 4 7}$ \\
\hline
\end{tabular}

Fuente: elaboración propia sobre la base de DAGPyPS.

Los principales componentes del gasto nacional para este período fueron: salarios para terciarios transferidos; Fondo de Incentivo Docente -FONID-; programas de infraestructura, equipamiento y materiales didácticos; programas de información y eficiencia; y acciones asistenciales. El Cuadro II muestra los fondos asignados a tales destinos incluyendo las transferencias destinadas a gobiernos subnacionales que en el gasto consolidado aparecen imputadas en los niveles de gobierno provincial y municipal ${ }^{11}$.

\section{Cuadro II}

Gasto público de la Administración Nacional, 1998-2002

En millones de pesos

\begin{tabular}{lrrrrr}
\hline Programa & $\mathbf{1 9 9 8}$ & $\mathbf{1 9 9 9}$ & $\mathbf{2 0 0 0}$ & $\mathbf{2 0 0 1}$ & $\mathbf{2 0 0 2}$ \\
\hline Transferencias para salarios & 188,2 & 493,9 & 817,1 & 714,3 & 13,7 \\
Terciarios transferidos & 188,2 & 170,1 & 157,1 & 54,3 & 13,7 \\
Fondo de Incentivo Docente & 0,0 & 323,8 & 660,0 & 660,0 & 0,0 \\
Formación docente & 46,3 & 18,7 & 23,1 & 33,9 & 14,4 \\
Calidad educativa & 7,8 & 8,2 & 11,3 & 6,1 & 4,0 \\
Acciones Compensatorias & 165,8 & 131,0 & 88,2 & 63,0 & 208,0 \\
Infraestructura y Equipamiento & 192,7 & 67,0 & 43,9 & 71,2 & 68,4 \\
Otros programas & 137,4 & 119,1 & 79,1 & 62,5 & 75,1 \\
Total & $\mathbf{7 3 8 , 3}$ & $\mathbf{8 3 8 , 0}$ & $\mathbf{1 . 0 6 2 , 7}$ & $\mathbf{9 5 1 , 1}$ & $\mathbf{3 8 3 , 7}$ \\
\hline
\end{tabular}

Fuente: elaboración propia sobre la base de DAGPyPS.

Es importante resaltar dos aspectos que surgen del análisis del cuadro:

-En el año 1999 se incorporó el FONID, lo cual implicó un devengamiento de \$660 millones anuales en 2000 y 2001. La mitad de lo imputado al ejercicio 2001 no fue abonado y quedó como deuda a los docentes a ser cancelada durante 2002. Por su parte, en 2002 no se devengaron fondos por este concepto $^{12,13}$.

\footnotetext{
${ }^{11}$ En el proceso de consolidación del gasto público el criterio adoptado consiste en imputar las erogaciones en el nivel de gobierno que las ejecuta y no en el que las financia, así a los efectos de evitar duplicaciones, las transferencias del gobierno nacional a gobiernos provinciales y municipales se descuentan de la jurisdicción financiadora para ser incluidas en la que las ejecuta (gobiernos provinciales y municipales respectivamente).

${ }^{12}$ De acuerdo con la Ley Complementaria Permanente de Presupuesto y Reglamentos Parciales de la Ley No 24.156, el gasto devengado se refiere a la afectación definitiva de los créditos presupuestarios correspondientes al pago por la recepción de conformidad de bienes contratados oportunamente, mientras la percepción o recaudación de los recursos se produce en el momento en que los fondos ingresan o se ponen a disposición de una oficina recaudadora, de un agente del Tesoro o de cualquier otro funcionario facultado para recibirlos. Por tal motivo, es factible que una transferencia del gobierno nacional destinada a los gobiernos provinciales o municipales se devengue durante un período fiscal, y que el pago y, por lo tanto, la percepción por parte de los gobiernos subnacionales se haga efectiva en el período siguiente. Este es el caso de las transferencias correspondientes al FONID, que el gobierno nacional devengó en 2001 por un monto de $\$ 660$ millones, pero sólo registró \$331 millones como pagado en el año.
} 
-Durante 2002 se reasignaron fondos nacionales incrementando las partidas destinadas a acciones asistenciales. Ante el agravamiento de la crisis social se amplió el alcance del programa de becas y se agilizó su ejecución. Este componente implicó \$155 millones más que lo ejecutado el año anterior.

En cuanto al gasto de los gobiernos provinciales, este se ve concentrado en el pago de salarios. Tradicionalmente, el rango de la participación del gasto en la partida de Personal del sector ha oscilado entre un $80 \%$ y un $90 \%$ (según la provincia). En promedio, en el año 2002, el gasto salarial dentro del gasto educativo fue del $83,6 \%$, pero agregando los subsidios a las escuelas de gestión privada exclusivamente destinados al pago de salarios docentes-, el promedio superó el 93\%. Los presupuestos educativos provinciales no variaron de manera importante durante 2002. En términos generales, los valores nominales de gasto provincial no se alteraron significativamente, ni se alteró la tendencia decreciente en el financiamiento de los rubros no salariales. La información presupuestaria disponible permite identificar claramente que se repitieron -en términos nominales- los niveles de gasto de 2001, con la importante excepción de la provincia de Buenos Aires que anunció una fuerte disminución a inicios del año, relativizada posteriormente (la disminución estuvo en el orden de $\$ 200$ millones sobre un total de $\$ 3.785$ ejecutados el año anterior).

El problema más serio que se registró entre 2001 y 2002 ha sido el financiamiento en provincias altamente endeudadas, que derivaron en atrasos en los pagos de sus obligaciones por falta de disponibilidad de dinero, o en el uso de bonos provinciales con menor valor que el peso. Otra consecuencia fue una mayor concentración hacia el gasto salarial, sufriendo una fuerte caída en algunas provincias, el financiamiento de infraestructura y otros rubros de inversión no salarial.

\section{Deflactores utilizados habitualmente}

\subsection{El índice de precios al consumidor y el índice de precios combinado}

Cuando se habla de inflación es común asumir que se está haciendo referencia a cambios en los precios reflejados por el índice de precios al consumidor. La inflación en los precios al consumidor, sin embargo, no es necesariamente similar a la de cambios en los costos de la educación a lo largo del tiempo.

La razón para esto es que el índice de precios al consumidor es un promedio ponderado de los cambios en los precios de todos los productos que adquiere un consumidor urbano típico. Esta "canasta de mercado" es diferente de la canasta que compran los prestadores de servicios educativos. Los consumidores urbanos adquieren habitualmente servicios de vivienda, alimentos, indumentaria, transporte, etc. Sin embargo, los distritos escolares adquieren estos productos y servicios sólo en pequeñas cantidades y en cambio, gastan la mayor parte de sus presupuestos en "comprar" trabajo profesional. Estos servicios son adquiridos por los consumidores urbanos sólo en pequeñas cantidades.

Dado que cada producto o servicio cambia su precio a una tasa única, un índice que asume que estos cambios en precios deben ser ponderados en proporción a su importancia relativa con respecto a las canastas de los consumidores urbanos, no reflejará el promedio real de inflación que enfrentan los prestadores de servicios educativos. Los movimientos en los precios de los bienes y servicios que adquieren las escuelas pueden ser significativamente diferentes de los observados en los precios al consumidor. Un argumento similar resulta válido para el caso del índice de precios combinado, que se compone en partes iguales por el índice de precios al consumidor y el índice de precios mayoristas nivel general.

El cuadro III reproduce las tasas de inflación para un conjunto de bienes y servicios, y distintos índices utilizados habitualmente para deflactar el gasto público. Estos datos muestran que el cambio en el precio de categorías particulares puede ser diferente de los cambios en el precio para el promedio de las categorías que se incluyen en las canastas de bienes y servicios que se utilizan para calcular

\footnotetext{
${ }^{13}$ Sin embargo, a partir de 2003 se reestablece la ejecución de este fondo.
} 
los índices. Así, la inflación en los productos importados fue considerablemente mayor que el promedio para todas las categorías, mientras que la inflación en los servicios fue menor. Dado que la tasa de inflación varía considerablemente entre categorías particulares, es importante determinar con cuidado el índice de inflación apropiado que se utiliza para convertir gasto nominal en gasto real.

\section{Cuadro III}

Indices de precios y tasas de inflación seleccionadas, 1998-2002

\begin{tabular}{lccr}
\hline & \multicolumn{2}{c}{ Indices (2001=100) } & Inflación \\
& $\mathbf{1 9 9 8}$ & $\mathbf{2 0 0 2}$ & $\mathbf{9 8 - 0 2}$ \\
\cline { 2 - 4 } Indice de precios al consumidor & $\mathbf{1 0 3 , 2}$ & $\mathbf{1 2 5 , 9}$ & $\mathbf{2 1 , 9}$ \\
Bienes & 106,7 & 143,9 & 34,8 \\
Servicios & 99,6 & 106,2 & 6,6 \\
Indice de precios mayoristas & $\mathbf{1 0 2 , 3}$ & $\mathbf{1 7 7 , 1}$ & $\mathbf{7 3 , 1}$ \\
Primarios & 99,4 & 206,8 & 108,2 \\
Manufacturados y energía eléctrica & 102,5 & 162,4 & 58,4 \\
Productos importados & 108,5 & 260,2 & 139,7 \\
Indice de precios combinado & $\mathbf{1 0 2 , 8}$ & $\mathbf{1 5 1 , 5}$ & $\mathbf{4 7 , 4}$ \\
\hline
\end{tabular}

Fuente: elaboración propia sobre la base del INDEC.

Por otro lado, el método para calcular el índice de precios al consumidor utiliza información de precios proveniente únicamente del Gran Buenos Aires. Es por ello que la representatividad para el total del país de este índice es cuestionable. En este sentido, un cálculo realizado por el INDEC, revela que adquirir la canasta básica de consumo en abril de 2001 costaba en la región Noroeste el 86,5\% del valor de la misma canasta en el Gran Buenos Aires ${ }^{1415}$.

El cuadro IV muestra el gasto público consolidado en educación en millones de pesos de 2001 a partir de utilizar el IPC y el Indice de precios combinado. En ambos casos se observa una caída muy importante del gasto entre 1998 y 2002. Esta disminución en el gasto se explica principalmente por el alza registrada durante 2002 en el precio de algunos de los ítems que componen cada uno de los índices. Por ejemplo, se registra para los bienes de consumo que componen el IPC una inflación de $43,9 \%$ y para los productos primarios y productos importados del IPM $106,8 \%$ y $160,2 \%$ respectivamente. Sin embargo, el consumo de bienes no supera el 5\% del gasto total en educación, y aún más, la proporción que de ese consumo se destina a productos primarios y a bienes importados resulta despreciable.

\section{Cuadro IV}

Gasto público consolidado en educación básica y terciaria, 1998-2002 Deflactor: IPC e índice de precios combinado

\begin{tabular}{lrrrrrr}
\hline & $\mathbf{1 9 9 8}$ & $\mathbf{1 9 9 9}$ & $\mathbf{2 0 0 0}$ & $\mathbf{2 0 0 1}$ & $\mathbf{2 0 0 2}$ & $\mathbf{9 8 - 0 2}$ \\
\cline { 2 - 7 } En mill.\$ & 10.150 & 11.048 & 11.237 & 11.157 & 10.947 & \\
En mill.\$ 2001 & & & & & & \\
IPC nivel general & 9.831 & 10.828 & 11.117 & 11.157 & 8.697 & \\
\% var. anual & & 10,1 & 2,7 & 0,4 & $-22,0$ & $-11,5$ \\
En mill.\$ 2001 & & & & & & \\
Indice combinado & 9.877 & 11.029 & 11.046 & 11.157 & 7.196 & \\
$\%$ var. anual & & 11,7 & 0,2 & 1,0 & $-35,5$ & $-27,1$ \\
\hline
\end{tabular}

Fuente: elaboración propia sobre la base de DAGPyPS e INDEC.

\footnotetext{
${ }^{14}$ Dirección de Indices de Precios de Consumo (2002).

${ }^{15} \mathrm{El}$ IPC o alguno de sus componentes se utiliza en distintas instancias del trabajo, por lo que este cuestionamiento debe ser considerado al momento de evaluar los resultados en cada caso.
} 
El empleo del IPC como deflactor del gasto en educación tendría sentido en la medida en que fuese posible estimar el valor de los servicios prestados en su equivalente en ingresos, esto es, como si los servicios se otorgaran en la forma de un ingreso monetario. El gasto deflactado de esta manera representaría el poder adquisitivo de los recursos en términos de la población beneficiaria.

En este sentido, un uso apropiado del IPC en educación sería en la estimación del valor real de la asistencia prestada a los estudiantes (becas); aunque en este caso puede cuestionarse si los items incluidos en el IPC reflejan o no adecuadamente la canasta de consumo de los estudiantes que reciben los subsidios ${ }^{16}$.

\subsection{El índice de precios implícitos del PIB}

El índice de precios implícitos del PIB mide la inflación promedio en el consumo, la inversión y las exportaciones netas de la economía. Utilizando este índice el gasto público real en educación básica y terciaria entre 1998 y 2002 disminuyó en 15,8\%.

Este índice resulta apropiado para estimar, por ejemplo, cuál es el impacto de una decisión sobre el gasto en educación en el nivel de producto proyectado en la etapa en que se presupuesta dicho gasto. Hanushek y Rivkin (1996) lo expresan de esta forma "si el gasto en educación se deflacta a partir de un deflactor de producto - como el deflactor del PIB - los cambios en las series de gasto real indican cambios en los recursos que la sociedad destina a la educación." Esto, agregan, "representa una medida de los recursos totales que la sociedad invierte en la educación".

Cuadro V

Gasto público consolidado en educación básica y terciaria, 1998-2002

Deflactor: Indice de precios implícitos del PIB

\begin{tabular}{lrrrrrr}
\hline & $\mathbf{1 9 9 8}$ & $\mathbf{1 9 9 9}$ & $\mathbf{2 0 0 0}$ & $\mathbf{2 0 0 1}$ & $\mathbf{2 0 0 2}$ & $\mathbf{9 8 - 0 2}$ \\
\cline { 2 - 7 } En mill.\$ & 10.150 & 11.048 & 11.237 & 11.157 & 10.947 & \\
En mill.\$ 2001 & 9.956 & 11.040 & 11.114 & 11.157 & 8.385 & \\
IPI del PIB & & 10,9 & 0,7 & 0,4 & $-24,8$ & $-15,8$ \\
\% var. anual & & &
\end{tabular}

Fuente: elaboración propia sobre la base de DAGPyPS y DNCN.

Sin embargo, existen algunas dificultades con esta metodología en la medida en que en el deflactor implícito del PIB tienen particular peso algunos componentes que pueden distorsionar este concepto, al incluir, por ejemplo, las exportaciones, que tienen un tratamiento tributario muy distinto al resto del producto interno. Una limitación importante de este deflactor, al utilizarlo en series de gasto en educación, es que incluye muchas actividades no relevantes para la acción pública y en particular muchas actividades que no se relacionan con la prestación del servicio educativo.

\subsection{El gasto en relación con otras variables}

Otra de las alternativas comúnmente utilizadas para evaluar la evolución del gasto en educación es investigar como varía relativamente este gasto con respecto a otras variables de la actividad pública o macroeconómica, en cuyo caso se vincula el gasto en educación al gasto total, o al PIB, respectivamente. Estos indicadores se interpretan habitualmente como medidas de la importancia relativa del sector dentro de las finanzas públicas en el primer caso, y de la porción de la riqueza generada en una economía que se invierte en el sector, en el segundo. Sin embargo, si los distintos componentes que forman el gasto o el PIB presentan cambios en los precios de los insumos de distintas magnitudes, entonces la porción de los recursos reales destinados a la educación puede subestimarse o sobreestimarse según sea el caso. A modo de ejemplo, el sector salud destina alrededor de $14 \%$ del gasto total al consumo de bienes, mientras que en educación esta proporción no supera el 5\%. En esta circunstancia cualquier cambio en el precio de los bienes afectará naturalmente más al sector salud,

\footnotetext{
${ }^{16}$ Sobre los sesgos en el índice de precios, ver Jorgenson y Slesnick (1983) y Lodola, Busso y Cerimedo (2001)
} 
con lo cual la proporción de este sector sobre el gasto total o sobre el PIB estará sobreestimada mientras que seguramente la proporción del gasto educativo estará subestimada.

\section{Medidas alternativas para la deflación}

\subsection{El índice de precios educativos de Halstead}

Halstead (1983) construyó un índice de precios de la educación a partir de examinar los cambios en los precios de una canasta de 42 categorías típicamente consumidas por las escuelas primarias y secundarias de Estados Unidos en 1975. En ese año las escuelas primarias y secundarias gastaban 47,68\% de sus presupuestos en salarios docentes, $3,75 \%$ en transporte escolar, $0,7 \%$ en libros de texto, $1,1 \%$ en electricidad, etc. Asociando una serie de precios a cada una de esas categorías, Halstead calculó cuánto le costaría a las escuelas comprar una canasta idéntica de bienes y servicios en cada año subsiguiente e identificó estos cambios como la tasa de inflación de la educación, con lo que cualquier gasto por encima de esta tasa representaría incrementos reales en el gasto.

Es posible realizar un ejercicio similar al desarrollado por Halstead para la Argentina a partir de los datos obtenidos para la construcción de la matriz insumo-producto llevada a cabo en 1997 (MIP97). En esa oportunidad la Dirección Nacional de Cuentas Nacionales (DNCN), realizó una estimación de la composición del gasto público en el sector educación para cada uno de los tres niveles de gobierno. Esta estimación permite desagregar el gasto en bienes y servicios de cada nivel en más de 80 categorías.

Por otra parte, para calcular cómo se distribuye el gasto en educación entre las restantes partidas que conforman el objeto del gasto se utiliza para el nivel nacional información proveniente del Sistema Integrado de Información Financiera de la Secretaría de Hacienda (SIDIF); y para el nivel provincial información suministrada por la Dirección de Análisis de Gasto Público y Programas Sociales (DAGPyPS). En el primer caso la desagregación puede realizarse con el mismo nivel de apertura que el disponible a partir de la MIP97 (inciso, partida principal, partida parcial). En el caso de las provincias, la información está disponible a nivel de inciso, aunque se cuenta con información adicional para un conjunto de provincias que permite ajustar las estimaciones con mayor nivel de detalle ${ }^{17}$. En el caso de los municipios la información de la MIP97, se complementa con estimaciones de la Dirección Nacional de Coordinación Fiscal con las Provincias (DNCFP) y de la DAGPyPS.

Sobre la base de estos datos, se obtuvo en primer lugar la estructura del gasto público consolidado en educación básica y terciaria para 1997. Además de las categorías habituales de gasto en personal y en bienes y servicios, aparece una porción importante de gasto destinado a transferencias corrientes y de capital (18\%). Dentro del gasto en transferencias corrientes están incluidos, entre otros conceptos, los subsidios que los gobiernos provinciales entregan a escuelas de gestión privada y las transferencias que el gobierno nacional realiza a las instituciones públicas provinciales de enseñanza para adquirir distintos bienes de consumo, principalmente material didáctico. En el caso de los primeros se optó por incorporarlos en la partida personal, ya que el destino de este gasto es el pago de los salarios docentes de esos establecimientos; en el segundo caso el gasto se incorporó en la partida bienes de consumo.

Entre las transferencias de capital se identifican aquellas que realiza el gobierno nacional a los institutos provinciales de enseñanza, para infraestructura y equipamiento y, transferencias que los gobiernos provinciales efectúan con el mismo fin. En ambos casos se optó por incorporar el gasto en la partida bienes de uso.

\footnotetext{
${ }^{17}$ El conjunto de provincias para el que se cuenta con información más desagregada representa alrededor de $80 \%$ del gasto total provincial en este sector.
} 


\section{Cuadro VI}

Estructura del gasto público consolidado en educación básica y terciaria, 1997 En porcentaje

\begin{tabular}{lcc}
\hline \multicolumn{1}{c}{ Inciso } & $\begin{array}{c}\text { Proporción del gasto Proporción del gasto } \\
\text { total }\end{array}$ & $\begin{array}{c}\text { total - ajustado } \\
\text { Personal }\end{array}$ \\
Bienes de consumo & 75,2 & 86,8 \\
Servicios no personales & 0,9 & 2,0 \\
Transferencias corrientes & 3,0 & 3,0 \\
Transferencias a Institutos privados de enseñanza & 14,0 & 1,4 \\
Acciones compensatorias e infraestructura & 11,5 & \\
Otras transferencias corrientes & 1,1 & 1,4 \\
Bienes de uso & 1,4 & 6,6 \\
Transferencias de capital & 2,8 & 0,2 \\
Acciones compensatorias e infraestructura & 4,0 & 0,2 \\
Otras transferencias de capital & 3,8 & 0,0 \\
Activos financieros & 0,2 & 100,0 \\
Total & 0,0 & \\
\hline
\end{tabular}

Fuente: elaboración propia sobre la base de MIP97, DNCN, DNCFP y DAGPyPS.

Luego de definida la estructura del gasto, se identificó para cada categoría un índice de precios apropiado. El índice de precios al consumidor comprende una cantidad de componentes separados que pueden utilizarse para deflactar los distintos tipos de bienes y servicios que conforman el gasto en educación básica y terciaria ${ }^{18}$. Existen también categorías del índice de precios mayoristas y del índice del costo de la construcción que resultan apropiados para algunos conceptos. El cuadro VII presenta las principales categorías asociadas a cada inciso del gasto.

Cuadro VII

Incisos del gasto y categorías seleccionadas de índices de precios

\begin{tabular}{lll}
\hline Inciso & Categorías principales & Fuente \\
\hline \multirow{2}{*}{ Bienes de Consumo } & Alimentos y bebidas & IPC-1 \\
& Equipamiento del hogar & IPC-4.1 \\
& Indumentaria & IPC-2 \\
& Diarios, revistas y libros & IPC-7.3 \\
& Textos y útiles escolares & IPC-8.2 \\
& Combustibles y lubricantes & IPC-6.131 \\
& Servicios básicos y combustibles para la vivienda & IPC-3.2 \\
& Servicios para el hogar & IPC-4.23 \\
& Transporte público de pasajeros & IPC-6.11 \\
& Transporte por turismo & IPC-7.11 \\
& Alojamiento y excursiones & IPC-7.12 \\
& Servicios diversos & IPC-9.3 \\
& Máquinas y equipos & IPM-29 \\
Construcción & ICC-nivel general \\
\hline
\end{tabular}

Fuente: elaboración propia sobre la base de INDEC.

\footnotetext{
${ }^{18}$ Para obtener series de precios para las distintas categorías del IPC entre 1997 y 2002 se realizó un empalme de las series actuales base 1999 con las series previas base 1988 a partir de información con apertura a 8 dígitos suministrada por el INDEC.
} 
En el caso del gasto en personal, el índice más habitual para aislar de éste el efecto de los precios es un índice de salarios, tal como utiliza Halstead ${ }^{19}$. El cálculo requiere que tanto el gasto como el índice de salarios puedan desagregarse según distintas características que permitan agrupar a los trabajadores del área educativa en categorías homogéneas.

A partir de la información disponible, el gasto puede desagregarse según el nivel de gobierno, la jurisdicción y según el nivel de educación en el que está empleado el personal. A su vez, es posible distinguir en las provincias que proporción del gasto se destina al personal docente y cuál al no docente $^{20}$.

Así, para el gasto en personal del gobierno nacional, se utiliza la evolución del salario corriente promedio de la ocupación principal para trabajadores del ámbito público. Esta variable se construye a partir del promedio para las ondas mayo y octubre de esta categoría en la Encuesta Permanente de Hogares del INDEC para el total de aglomerados urbanos relevados ${ }^{21,22}$.

En el caso de los gobiernos provinciales y municipales se utiliza para el personal docente, la evolución de un conjunto de salarios "testigo" que releva el Ministerio de Educación, Ciencia y Tecnología (MECyT). Las series resultantes incluyen para el nivel primario, el salario bruto de docentes con 10 años de antigüedad para maestros de grado y directores de primera categoría de jornada simple en escuelas de educación común; y para el nivel medio, el salario bruto de docentes con 10 años de antigüedad de profesores hora cátedra y directores de primera categoría en escuelas de educación común $^{23}$.

Si bien la información disponible permite distinguir el salario asociado a algunas categorías relevantes, no permite identificar enteramente cambios en la composición y/o en la calidad de la planta docente. Estos cambios pueden provenir de diferencias en años de experiencia, formación o preparación del docente, dedicación, satisfacción, entre otras características.

El cuadro que sigue presenta un ejemplo simple de los sesgos que pueden presentarse a partir de estas limitaciones. Se consideran 2 categorías de docentes con idénticas características excepto en cuanto a los años de antigüedad. Entre el período t y $t+1$ se produce un aumento en los salarios de $\$ 20$ uniforme para toda la grilla. El cálculo sobre gasto salarial en pesos constantes para t+1 resultará $\$ 1.100 /(1+0,20)=\$ 916,67$ ya que el salario testigo se refiere al docente con 10 años de antigüedad que obtuvo un $20 \%$ de aumento en su salario. Sin embargo, resulta evidente a partir del cuadro que no se ha producido cambio alguno en la cantidad de docentes, por lo cual si contáramos con la información suficiente el cálculo sería: $\$ 500 / 1,25+\$ 600 / 1,20=\$ 900$ y el cambio se reflejaría en el componente precio y no en el volumen como ocurre en el caso anterior ${ }^{24}$.

\footnotetext{
${ }^{19}$ Es importante aclarar que los sueldos y salarios se consideran aquí como insumos de la educación, es decir como parte del proceso de producción de este rubro, con lo cual el objetivo es obtener el valor del insumo trabajo a precios constantes y resulta necesario deflactarlos por una tasa constante de sueldos y salarios. Sin embargo, cuando estos sueldos y salarios se registran como recibidos (por ejemplo para analizar o comparar el poder adquisitivo en distintas ocupaciones) deberán ser medidos en términos del poder de compra sobre una canasta de consumo final de bienes y servicios de los hogares.

${ }^{20}$ En la información del MECyT sobre cantidad de cargos también es posible distinguir a los docentes según la función educativa: Dirección, Frente a alumnos, Apoyo y Personal Único.

${ }^{21}$ La decisión de utilizar esta serie se basa en el hecho de que el personal empleado por el gobierno nacional en relación con la función educación es en su mayoría personal administrativo que presta servicios distintos de los docentes.

${ }^{22}$ En 2002, y en virtud de lo dispuesto por el Decreto No 762/02 del Poder Ejecutivo Nacional, el INDEC comenzó a elaborar un Coeficiente de Variación Salarial (CVS). El Índice de Salarios (IS), sobre el que se basa el cálculo del CVS, estima a partir de la comparación de meses sucesivos las variaciones de los salarios tanto del sector público, como del privado en cada mes. El Índice es del tipo Laspeyres, con período de referencia en el cuarto trimestre de 2001 y una estructura de ponderación por ocupación y por rama de actividad. Lamentablemente, está disponible únicamente a partir del mes de octubre de 2001 por lo que no fue posible incorporarlo en este trabajo.

${ }^{23}$ Para obtener el salario bruto docente para el total del país se realiza un promedio del salario registrado en las 24 jurisdicciones ponderado por el número de docentes.

${ }^{24}$ Este tipo de cambios en la grilla docente fue y es habitual en la política salarial de las distintas provincias argentinas. En 2002 más de la mitad de las jurisdicciones contaban, entre los componentes del salario bruto, con adicionales de suma fija no remunerativos y no bonificables que se aplicaban a todos los docentes.
} 


\section{Cuadro VIII}

Ejemplo de sesgo en la medición del gasto en personal

\begin{tabular}{lrrrrrr}
\hline & \multicolumn{3}{c}{$\mathrm{t}$} & & $\mathrm{t}+1$ & \\
& Salario & Docentes & Costo total & Salario & Docentes & Costo total \\
\cline { 2 - 7 } 5 años antigüiedad & 80 & 5 & 400 & 100 & 5 & 500 \\
10 años antigüedad & 100 & 5 & 500 & 120 & 5 & 600 \\
Total & & $\mathbf{1 0}$ & $\mathbf{9 0 0}$ & & $\mathbf{1 0}$ & $\mathbf{1 . 1 0 0}$ \\
\hline
\end{tabular}

Los cambios en salarios de distinta magnitud para salarios testigo y otros no incluidos dentro de este conjunto se traducirá, al menos en parte, en cambios en el volumen de docentes aún cuando éste permanezca inalterado. De la misma manera, si no se registran cambios en el salario testigo, cualquier alteración en el gasto total será atribuida a cambios en el volumen.

El nivel de desagregación con el que se cuenta para registrar el gasto resulta relevante especialmente en el caso del insumo "personal" ya que en el límite cada docente puede considerarse como un "bien" diferente. En este sentido, los docentes difieren en características observables que pueden o no estar disponibles, pero además resulta importante para evaluar la calidad del insumo, algunas características no observables relacionadas por ejemplo con la satisfacción del docente con respecto a la tarea que desempeña o la interrelación del docente con el ámbito en el que desarrolla su actividad (probablemente no es el mismo insumo un docente en un ambiente hostil que en uno con diversas comodidades).

De este modo puede argumentarse por ejemplo que los cambios en el poder adquisitivo del salario afectan la satisfacción del docente y a través de ésta a la calidad del insumo. El problema en este caso es determinar cuánto más o menos "vale" un docente con mejor o peor poder adquisitivo de su salario. Para los salarios testigo relevados se observa entre 1997 y 2002 una caída en el poder adquisitivo del salario de alrededor de $12 \%$ que es apenas inferior al aumento en el IPC para el período.

Gráfico II

Evolución del salario bruto y poder adquisitivo del salario, 1997-2002 (1997=100)

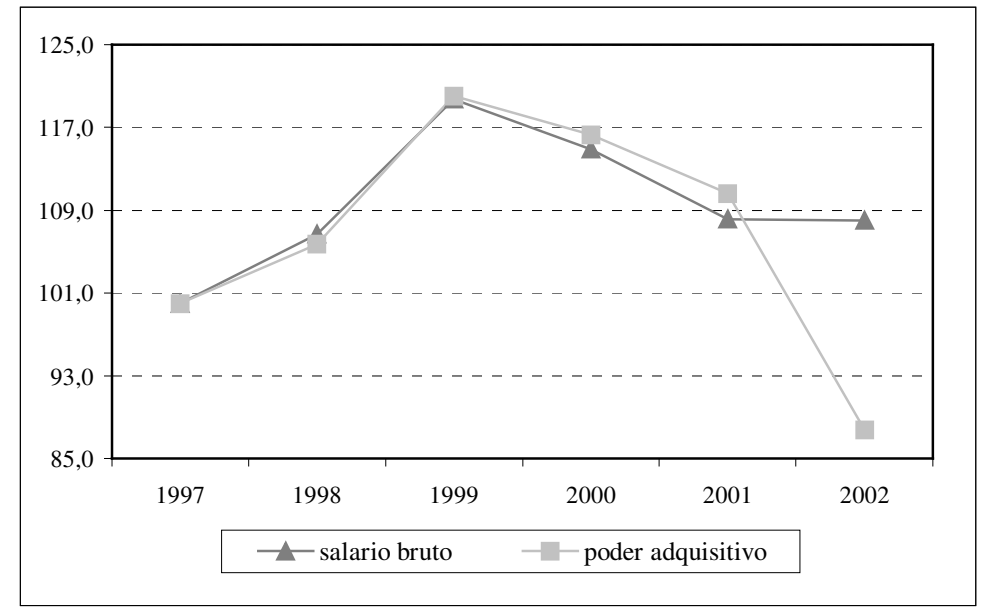

Fuente: elaboración propia sobre la base de MECyT e INDEC.

La principal dificultad consiste en determinar cuáles características deberían estar reflejadas y de qué modo (cuáles determinan cambios en el volumen) y cuáles lo están o podrían estarlo. Luego, las características docentes relevantes que no aparezcan reflejadas en diferencias salariales se convierten en un problema, dado que cualquier cambio en éstas no se manifestará en el gasto. Cuanto más información se obtenga sobre esta medida, mejor podrá aislarse el efecto precio y, de esta forma cualquier cambio en la calidad quedará dentro de los cambios en la cantidad y no de cambios en el precio, como es factible que ocurra ${ }^{25}$.

Una vez definidos los precios que se asocian a cada porción del gasto se calcula el gasto a precios constantes utilizando un índice de precios de Laspeyres, donde el año base es 1997. El índice que

\footnotetext{
${ }^{25}$ Las principales características del sistema de conformación del salario docente en la Argentina pueden consultarse en Morduchowicz (1997) y Dirie et al (2001).
} 
surge de este proceso se recalcula con los precios de 2001=1 para hacer comparables los resultados a lo largo del trabajo ${ }^{26}$.

Indice de precios de Laspeyres $=P L=\frac{\sum\left(p_{t} \times q_{0}\right)}{\sum\left(p_{0} \times q_{0}\right)}$

Un índice de precios con estas características mide la variación producida en los precios de una canasta (en función de las cantidades del año base), respecto de los valores del año de referencia. Dicho de otra forma, el numerador que constituye el elemento de comparación representa cuánto cuesta a precios de los distintos períodos la canasta del año base.

Si se multiplica y divide el numerador de cada término de la suma por $p_{0}$, se reordenan los factores y se define $a_{0}=\frac{\left(p_{0} \times q_{0}\right)}{\sum\left(p_{0} \times q_{0}\right)}$ como la participación que tiene el gasto en un bien con respecto al total en el período 0 se llega a la expresión: $P L=\sum a_{0}\left(\frac{p_{t}}{p_{0}}\right)$

Esta ecuación permite interpretar el índice como la suma de los cambios en los precios de todos los bienes, ponderados por la participación que tuvo el gasto realizado en cada uno de ellos dentro del gasto total en el período 0 .

\section{Cuadro IX}

Gasto público consolidado en educación básica y terciaria, 1998-2002 Deflactor: Indice de precios educativos de Halstead

\begin{tabular}{lrrrrrr}
\hline & $\mathbf{1 9 9 8}$ & $\mathbf{1 9 9 9}$ & $\mathbf{2 0 0 0}$ & $\mathbf{2 0 0 1}$ & $\mathbf{2 0 0 2}$ & $\mathbf{9 8 - 0 2}$ \\
\cline { 2 - 7 } En mill.\$ & 10.150 & 11.048 & 11.237 & 11.157 & 10.947 & \\
En mill.\$ 2001 & 10.183 & 10.018 & 10.591 & 11.157 & 10.422 & \\
IPE de Halstead & & $-1,6$ & 5,7 & 5,3 & $-6,6$ & 2,3 \\
\% var. anual & & &
\end{tabular}

Deflactar el gasto corriente por un índice con estas características permite conocer cuantas "canastas de 1997" es posible adquirir con el gasto ejecutado y a los precios vigentes en cada período.

Los resultados del cálculo se reproducen en el cuadro IX. Surge de allí, que el gasto a precios constantes aumentó a lo largo del período 2,3\%. Entre 1999 y 2001 se registraron variaciones positivas, mientras que en 2002 se evidenció una caída significativa del 6,6\%.

Es importante destacar que una serie construida a partir de este tipo de índices tiene la ventaja de que los valores de los distintos períodos son comparables entre sí, dado que las variaciones siempre están referidas al valor de la misma canasta en el período base. Además, el costo de construcción de este índice no es muy importante por cuanto se utiliza siempre la misma canasta base y se modifican solamente los precios en los períodos posteriores. No obstante, este último hecho implica una desventaja, dado que a medida que pasa el tiempo, las ponderaciones de cantidades que se fijan para el período base se van alejando progresivamente de la realidad y el índice pierde confiabilidad.

\subsection{El índice de precios de Paasche}

Como alternativa al cálculo propuesto por Halstead sobre el índice de Laspeyres y, considerando particularmente el último punto de la exposición anterior, se construyó un índice de precios de Paasche.

\footnotetext{
${ }^{26}$ Es importante distinguir entre el año base de referencia que es al que se relacionan las ponderaciones del número índice (1997) y el año de referencia del índice que es el año (elegido arbitrariamente) al que el índice se normaliza, esto es se iguala a 1 (2001).
} 
Indice de precios de Paasche $=P P=\frac{\sum\left(p_{t} \times q_{t}\right)}{\sum\left(p_{0} \times q_{t}\right)}$

Un índice de precios con estas características mide la variación entre el período base y los restantes, en función de la estructura de cantidades de cada año. Dicho de otra forma, para realizar la comparación con los valores transados (numerador), permite determinar cuánto hubiera costado la canasta (de cantidades) de cada período, a precios del año base.

En este caso se estima para cada año, y para cada nivel de gobierno la apertura del gasto en educación básica y terciaria según el objeto del gasto. Luego, se asocia a cada una de las categorías identificadas un índice de precios representativo. Se toma como base para este procedimiento el índice calculado en el apartado anterior, aunque en este caso la cantidad de items en que puede dividirse el gasto es menor.

Para el gobierno nacional, la información permite distinguir para todos los años la totalidad de los items relevantes (a partir de información del SIDIF). En las provincias a la apertura según el objeto del gasto (a partir de información de la DAGPyPS) pudo adicionarse información sobre transferencias a institutos privados, becas, gasto en construcciones y maquinaria y equipo, entre otros de relevancia. En el caso de los gobiernos municipales la apertura se estima a partir de información de la MIP97 e información suministrada por la DNCFP.

Al igual que en el cálculo del Indice de Halstead, se realiza la estimación del índice de Paasche a partir de la información disponible y con las consideraciones mencionadas para el caso del gasto en personal. En esta oportunidad, se utiliza como año base de referencia el 2001.

A partir del cuadro siguiente se observan los cambios registrados en la estructura del gasto público consolidado en educación para el período analizado. Es interesante destacar que se registra, tal como se mencionó en la sección II, un aumento en la importancia relativa del gasto en personal y de las transferencias a institutos privados de enseñanza, que se ve compensado por la disminución en los restantes componentes, en especial en las construcciones y las transferencias de capital.

\section{Cuadro X}

Estructura del gasto público consolidado en educación básica y terciaria, 1998-2002 En porcentaje

\begin{tabular}{|c|c|c|c|c|c|}
\hline & 1998 & 1999 & 2000 & 2001 & 2002 \\
\hline Personal & 75,3 & 76,1 & 78,2 & 79,6 & 78,5 \\
\hline Bienes de consumo & 0,6 & 0,5 & 0,7 & 0,5 & 0,6 \\
\hline Servicios no personales & 3,4 & 3,4 & 2,7 & 3,1 & 2,7 \\
\hline Transferencias corrientes & 14,2 & 14,7 & 15,4 & 14,5 & 16,3 \\
\hline Transferencias a Institutos privados de enseñanza & 11,6 & 11,9 & 12,3 & 12,7 & 12,6 \\
\hline Acciones compensatorias e infraestructura & 1,0 & 0,4 & 0,2 & 0,1 & 0,3 \\
\hline Becas & 0,5 & 1,5 & 1,8 & 0,4 & 1,8 \\
\hline Otras transferencias corrientes & 1,2 & 1,0 & 1,1 & 1,2 & 1,7 \\
\hline Bienes de uso & 3,0 & 3,9 & 2,1 & 1,9 & 1,1 \\
\hline Construcciones & 2,5 & 3,4 & 1,9 & 1,7 & 1,0 \\
\hline Otros bienes de uso & 0,5 & 0,4 & 0,2 & 0,2 & 0,1 \\
\hline Transferencias de capital & 3,5 & 1,5 & 0,8 & 0,3 & 0,7 \\
\hline Infraestructura & 3,5 & 1,4 & 0,8 & 0,3 & 0,7 \\
\hline Otras transferencias de capital & 0,1 & 0,1 & 0,1 & 0,1 & 0,1 \\
\hline Inversión financiera & 0,0 & 0,0 & 0,0 & 0,0 & 0,0 \\
\hline Total & 100,0 & 100,0 & 100,0 & 100,0 & 100,0 \\
\hline
\end{tabular}

Fuente: elaboración propia sobre la base de SIDIF, DAGPyPS, DNCN y DNCFP.

Del mismo modo puede notarse la importancia que reviste considerar estos cambios para la construcción de un índice de precios adecuado. En especial se evidencia, a partir del cuadro, de qué ma- 
nera la estructura del gasto de los primeros años del período resulta poco representativa de la estructura para el último tramo.

El cálculo que surge de aplicar el índice de Paasche se presenta en el cuadro XI. Deflactar el gasto corriente por este índice permite conocer cuántas "canastas de cada año" hubiera sido posible adquirir si los precios fueran los vigentes en 2001.

\begin{tabular}{|c|c|c|c|c|c|c|}
\hline \multicolumn{7}{|c|}{$\begin{array}{c}\text { Cuadro XI } \\
\text { Gasto público consolidado en educación básica y terciaria, 1998-2002 } \\
\text { Deflactor: Indice de precios de Paasche }\end{array}$} \\
\hline & 1998 & 1999 & 2000 & 2001 & 2002 & 98-02 \\
\hline mill.\$ & 10.150 & 11.048 & 11.237 & 11.157 & 10.947 & \\
\hline $\begin{array}{l}\text { in mill.\$ } 2001 \\
\text { d. de Paasche }\end{array}$ & 10.214 & 10.022 & 10.583 & 11.157 & 10.760 & \\
\hline 6 var. anual & & $-1,9$ & 5,6 & 5,4 & $-3,6$ & 5,3 \\
\hline
\end{tabular}

Fuente: elaboración propia sobre la base de SIDIF, DAGPYPS, DNCN, DNCFP e INDEC.

Para el período 1998-2001 no se registran diferencias muy significativas entre este cálculo y el que surge a partir del índice de Laspeyres. Esto puede explicarse principalmente a partir de que el cambio en los precios para este período no resulta muy diferente entre los distintos componentes del gasto, especialmente entre aquellos con mayor representatividad.

Sin embargo, la diferencia entre ambos cálculos resulta importante para el período 2001-2002. Esto se debe fundamentalmente a la diferencia en la ponderación que cada índice otorga a los distintos componentes del gasto y al cambio en los precios asociado a cada uno en 2002. En este sentido, el índice de Laspeyres otorga en todo el período una ponderación algo inferior a $7 \%$ al conjunto de los bienes de uso y las transferencias de capital destinadas a infraestructura -que corresponde a la estructura vigente en 1997-; mientras que estas categorías, que representan en 2002 un porcentaje inferior al 2\%, registraron un aumento considerable en los índices de precios asociados a cada una de aproximadamente $30 \%$. A su vez, para el gasto en personal, que recibe en Laspeyres una ponderación de $75 \%$ y representa en 2002 78,5\% del gasto, el cambio en el precio para ese año es prácticamente nulo.

El índice de Paasche, respecto del de Laspeyres, cuenta con la ventaja de estar más actualizado dado que utiliza la canasta de cada año. Sin embargo, este índice tiene la dificultad de que las variaciones calculadas no solamente representan cambios de precios, sino también de la estructura de ponderaciones de las cantidades. A partir de esto, no resultan comparables los índices de los distintos períodos entre sí, sino solamente con el año base. Adicionalmente, su construcción resulta más costosa ya que requiere un permanente relevamiento para su actualización.

\subsection{Los índices de precios encadenados}

Tal como se comentara, en el transcurso del tiempo el patrón de cantidades en el período base tiende a ser progresivamente menos relevante a las situaciones económicas de períodos separados en el tiempo.

Si el objetivo es medir el movimiento de los precios de un período a otro los índices deberían compilarse sólo entre períodos consecutivos. De este modo, es posible obtener los cambios en precios entre períodos que están separados en el tiempo a partir de acumular los movimientos de corto plazo, esto es, a partir de asociar los índices entre períodos consecutivos para formar índices encadenados. Estos índices encadenados tienen una serie de ventajas tanto teóricas como prácticas. Por ejemplo, es posible obtener una mucho mejor asociación entre productos para períodos consecutivos que entre períodos alejados en el tiempo.

El índice de precios encadenado de Laspeyres se obtiene a partir de la siguiente ecuación: 


$$
P L^{e}=\frac{\sum\left(p_{1} \times q_{0}\right)}{\sum\left(p_{0} \times q_{0}\right)} \cdot \frac{\sum\left(p_{2} \times q_{1}\right)}{\sum\left(p_{1} \times q_{1}\right)} \cdot \ldots \frac{\sum\left(p_{t} \times q_{t-1}\right)}{\sum\left(p_{t-1} \times q_{t-1}\right)} \cdot \cdots \frac{\sum\left(p_{n} \times q_{n-1}\right)}{\sum\left(p_{n-1} \times q_{n-1}\right)}
$$

A su vez, el índice de precios encadenado de Paasche se obtiene a partir de sumar 1 a cada uno de los subíndices de cantidades en la ecuación anterior.

A partir de los datos mencionados en las secciones previas se calculó el gasto público consolidado en educación básica y terciaria en pesos constantes utilizando como deflactores los índices de precios encadenados.

\section{Cuadro XII}

Gasto público consolidado en educación básica y terciaria, 1998-2002 Deflactor: Indices de precios encadenados

\begin{tabular}{lrrrrrr}
\hline & $\mathbf{1 9 9 8}$ & $\mathbf{1 9 9 9}$ & $\mathbf{2 0 0 0}$ & $\mathbf{2 0 0 1}$ & $\mathbf{2 0 0 2}$ & $\mathbf{9 8 - 0 2}$ \\
\cline { 2 - 7 } En mill.\$ & 10.150 & 11.048 & 11.237 & 11.157 & 10.947 & \\
$\begin{array}{l}\text { En mill.\$ 2001 } \\
\text { Ind. de Laspeyres encadenado }\end{array}$ & 10.191 & 10.000 & 10.576 & 11.157 & 10.767 & \\
\% var. anual & & $-1,9$ & 5,8 & 5,5 & $-3,5$ & 5,7 \\
En mill.\$ 2001 & 10.210 & 10.012 & 10.583 & 11.157 & 10.760 & \\
Ind. de Paasche encadenado & & $-1,9$ & 5,7 & 5,4 & $-3,6$ & 5,4 \\
\% var. anual & & & & & & \\
\hline
\end{tabular}

Fuente: elaboración propia sobre la base de SIDIF, DAGPyPS, DNCN, DNCFP e INDEC.

Como puede observarse a partir del cuadro, en el caso de los índices encadenados las diferencias que surgen de utilizar las ponderaciones asociadas a períodos previos, corrientes o a una combinación de ambos se reducen considerablemente ${ }^{27}$. Esto se debe a que estos índices se aproximan a un índice teórico para el que las ponderaciones cambian continuamente ${ }^{28}$.

Este tipo de índices sin embargo, cuenta con una desventaja asociada al costo de su construcción, ya que resulta necesario contar con la información referida a cantidades y precios para cada uno de los períodos bajo análisis.

\subsection{El índice de servicios neto de Rothstein y Miles}

Rothstein y Miles (1995) desarrollan una serie de trabajos relacionados con el gasto en educación y la deflación de éste a través del tiempo. Una de las ideas principales de estos documentos es la discusión, en el intento de aislar la inflación en el sector educativo, del hecho de asociar los diferentes insumos educativos, particularmente los salarios, con series de precios basadas en los cambios efectivos de los precios de los insumos en general y de los salarios docentes en particular.

En este sentido, los autores plantean la cuestión de si los incrementos en los precios reflejan necesariamente inflación.

La idea central es investigar cuánto del incremento en los precios educativos es "culpa" de los responsables de la política educativa y cuánto está fuera de su control. Si el precio de la educación aumenta porque los administradores escolares "deben" pagar más por los insumos educativos, la respuesta natural es aumentar la cantidad de dinero que se destina a la educación, para compensar a las instituciones educativas por sus mayores gastos. Pero si el precio de la educación aumenta porque los administradores escolares deciden gastar más dinero, entonces deberán demostrar mejores resultados para justificar el incremento en el gasto ${ }^{29}$.

\footnotetext{
${ }^{27}$ El cálculo a partir del índice encadenado de Fischer arrojó resultados similares.

${ }^{28}$ Sobre las propiedades de los índices encadenados ver United Nations (1993), cap. 16

${ }^{29}$ Un desarrollo muy interesante sobre la idea de diferenciar "costo" de "gasto" puede hallarse en el documento de Fowler y Monk (2001).
} 
La complicación que aparece en este caso, sin embargo, es definir que significa "elegir" gastar más dinero. Por ejemplo, si el gasto aumenta porque los responsables del área educativa deciden pagar a los docentes por encima de las tasas del mercado, los mayores salarios pueden resultar superiores a los necesarios para atraer la calidad deseada de graduados hacia la profesión docente. En un caso como este, puede decirse que los docentes reciben "rentas" adicionalmente a sus salarios de mercado.

En la visión de Rothstein y Miles, las "rentas", debido a que éstas están dentro del control de las instituciones educativas y no son costos mayores impuestos externamente, deberían contabilizarse como gasto real, no atribuible a la inflación.

$\mathrm{El}$ argumento que siguen es que lo que las escuelas pagan a sus docentes refleja las decisiones de cada jurisdicción sobre si pagar a los docentes por encima o por debajo de los trabajadores comparables con éstos. Estas decisiones pueden estar influenciadas no sólo por los responsables de cada jurisdicción, sino también por los legisladores y los sindicatos docentes ${ }^{30}$. Cuando los salarios docentes aumentan en relación con los salarios de trabajadores comparables en otras áreas, en términos de educación y experiencia, puede presumirse que las escuelas están aumentando los niveles de excelencia de su fuerza de trabajo (en otras palabras, están generando insumos adicionales, más recursos "reales" para los estudiantes). Por el contrario si los salarios docentes caen con relación a profesionales con niveles de educación comparables, entonces los distritos escolares tendrán dificultades para atraer docentes mejor calificados, y se verificará un deterioro en el nivel de los insumos. En el primer caso, puede interpretarse que los gremios docentes utilizan su poder de monopolio para ganar "rentas" a los docentes; en el segundo, que las escuelas utilizan su poder de monopsonio para "subpagar" a los docentes.

De este modo, los autores postulan que sería más apropiado basar el índice de precios en un grupo comparable a los docentes, por ejemplo de trabajadores con formación terciaria: "Ante la ausencia de un índice conceptualmente correcto, una aproximación al gasto real de las escuelas debe basarse en alguna combinación de los índices disponibles. Una elección razonable, es utilizar la medida de inflación para "servicios" del índice de precios al consumidor, ya que las escuelas son industrias de servicios con características de baja productividad (o "enfermedad de los costos")." Así, el grado en que cada jurisdicción paga a sus docentes u otro personal escolar por encima de la tasa de mercado no se verá oscurecido por un índice de precios escolares que ignora los salarios de trabajadores comparables. A la inversa, una caída en el pago docente relativamente a los trabajadores comparables resultará en una caída en los recursos reales que se proveen a los estudiantes ${ }^{31}$.

A partir de este argumento, Rothstein y Miles (1995) desarrollan el "Indice de servicios neto" (ISN) que surge de excluir del sector "servicios" del IPC las categorías relacionadas con alquiler de vivienda y salud. La supresión de estos conceptos se fundamenta en el importante peso relativo dentro del índice y su no relevancia con respecto al sector educativo. Las categorías incluidas son en general servicios trabajo-intensivos con bajo crecimiento de la productividad, donde resulta difícil obtener eficiencias crecientes en los costos.

Sobre la base de los trabajos de Rothstein y Miles se realizan distintos ejercicios para la Argentina. En primer lugar, se reproduce el Indice de Servicios Neto a partir de excluir del IPC las categorías "alquiler de la vivienda" y "servicios para la salud".

A efectos de visualizar los resultados de la aplicación del ISN, el gráfico III reproduce la evolución del salario bruto de docentes con 10 años de antigüedad para maestros de grado, del índice de servicios neto y del gasto en millones de pesos de 2001 utilizando como deflactor el ISN. Puede observarse que en 1999 se verifica un importante aumento en el salario docente que no encuentra correlato

\footnotetext{
${ }^{30}$ Sobre la influencia de los gremios docentes en la educación argentina, ver Murillo et al (2001).

${ }^{31}$ La interpretación de los salarios docentes expuesta en los trabajos de Rothstein y Miles $(1995,1996)$ puede vincularse a la discusión en la sección anterior sobre la consideración de la calidad del insumo docente a partir de los salarios que estos reciben, en este caso a partir de compararlos con trabajadores de características similares.
} 
en el índice de servicios neto, el gasto real refleja este hecho como un aumento, ya que en este caso los salarios docentes estarían por encima de los trabajadores comparables y esto debería traducirse

Gráfico III

Evolución del salario docente, índice de servicios neto y gasto en $\$ 2001,1998-2002(1998=100)$

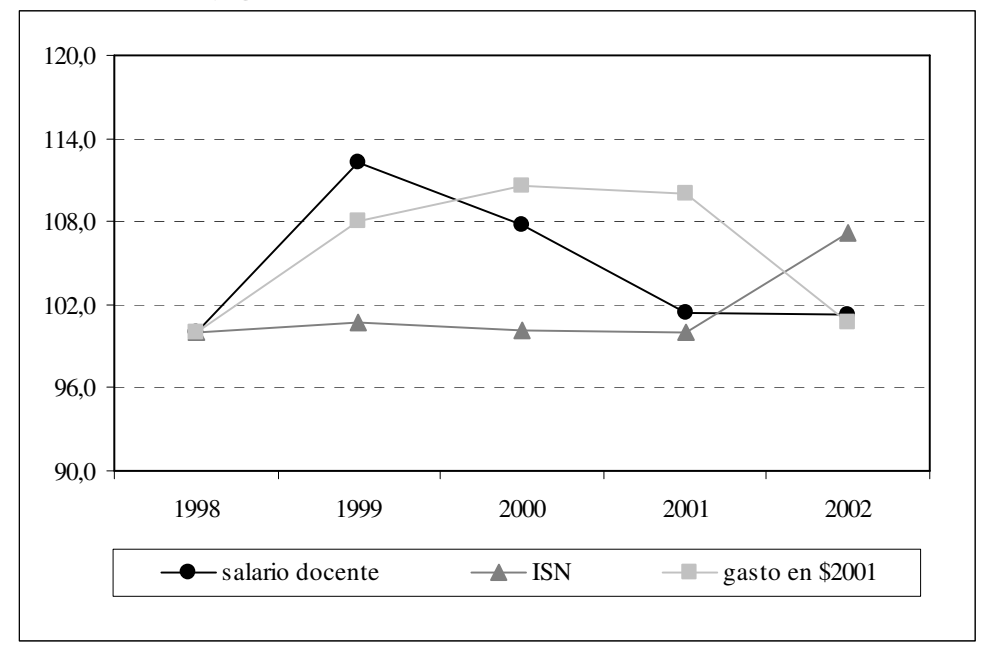

Fuente: elaboración propia sobre la base de DAGPyPS e INDEC. en mayores recursos reales destinados a la educación A la inversa, en 2002 se verifica una disminución (aunque leve) del salario docente al mismo tiempo que aumenta considerablemente el índice de servicios neto. En este caso, el gasto real refleja una importante caída ya que se interpreta que los insumos educativos que pueden contratarse considerando que el mercado paga mejor, serían de peor calidad.

Existen, sin embargo, algunos problemas asociados a

la aplicación del ISN tal como está definido. En primer lugar, al igual que se mencionara en el caso del IPC el índice no resulta representativo a nivel nacional dado que se releva únicamente en el Gran Buenos Aires y a su vez, está basado en una canasta de mercado.

\section{Cuadro XIII}

Gasto público consolidado en educación básica y terciaria, 1998-2002 Deflactor: Indice de Servicios Neto

\begin{tabular}{lrrrrrr}
\hline & $\mathbf{1 9 9 8}$ & $\mathbf{1 9 9 9}$ & $\mathbf{2 0 0 0}$ & $\mathbf{2 0 0 1}$ & $\mathbf{2 0 0 2}$ & $\mathbf{9 8 - 0 2}$ \\
\cline { 2 - 7 } En mill.\$ & 10.150 & 11.048 & 11.237 & 11.157 & 10.947 & \\
En mill.\$ 2001 & & & & & & \\
Ind. de Serv. Neto & 10.148 & 10.966 & 11.226 & 11.157 & 10.217 & \\
\% var. anual & & 8,1 & 2,4 & $-0,6$ & $-8,4$ & 0,7 \\
\hline
\end{tabular}

Fuente: elaboración propia sobre la base de DAGPyPS e INDEC.

En particular para 2002, el aumento en el ISN tiene gran influencia de categorías que no necesariamente se comportan de modo similar al sector educativo. En este sentido, se registraron durante el período aumentos muy importantes en los servicios de correo y en servicios relacionados con el turismo que probablemente no reflejan incrementos relevantes en cuanto a su comparación con el sector educativo.

De este modo, siguiendo el razonamiento de Rothstein y Miles (1995), se lleva a cabo un segundo cálculo que consiste en la construcción de un índice basado en la evolución de los salarios de trabajadores comparables a los docentes. Sobre datos de la EPH se calcula para todos los aglomerados urbanos relevados el promedio entre las ondas de mayo y octubre del salario corriente promedio de la ocupación principal para trabajadores en la rama "Servicios comunales, sociales y personales" y para trabajadores con nivel educativo "superior o universitario".

Los resultados en ambos casos muestran un aumento sostenido a lo largo del período en los recursos reales destinados a la educación. En el caso del índice construido a partir del salario de trabajadores en la rama "servicios comunales, sociales y personales", el gasto real aumenta entre 1998 y 2002 más de 28\%; en el caso de los trabajadores con educación superior o universitaria el aumento entre las puntas es algo inferior, y alcanza $21,6 \%$. 


\section{Cuadro XIV}

Gasto público consolidado en educación básica y terciaria, 1998-2002

Deflactor: Indice de Servicios Neto

\begin{tabular}{lrrrrrr}
\hline & $\mathbf{1 9 9 8}$ & $\mathbf{1 9 9 9}$ & $\mathbf{2 0 0 0}$ & $\mathbf{2 0 0 1}$ & $\mathbf{2 0 0 2}$ & $\mathbf{9 8 - 0 2}$ \\
\cline { 2 - 7 } En mill.\$ & 10.150 & 11.048 & 11.237 & 11.157 & 10.947 & \\
$\begin{array}{l}\text { En mill.\$ 2001 } \\
\text { Ind. de salarios en serv. sociales }\end{array}$ & 9.428 & 10.482 & 10.941 & 11.157 & 12.080 & \\
\% var. anual & & 11,2 & 4,4 & 2,0 & 8,3 & 28,1 \\
En mill.\$ 2001 & 9.541 & 10.853 & 11.103 & 11.157 & 11.601 & \\
$\begin{array}{l}\text { Ind. de salarios c/educ. superior } \\
\text { \% var. anual }\end{array}$ & & 13,8 & 2,3 & 0,5 & 4,0 & 21,6 \\
\hline
\end{tabular}

Fuente: elaboración propia sobre la base de DAGPyPS e INDEC.

El gráfico IV presenta la evolución de los salarios docentes, de los salarios de trabajadores en servicios comunales y del gasto en términos reales calculado a partir del índice que involucra a estos últimos (los resultados son similares en el caso de trabajadores con educación superior o universitaria). A diferencia del caso anterior, aquí, en 2002 se registra una caída en el salario de los trabajadores comparables a los docentes. Esto implica que el gasto en recursos reales para la educación aumente en este caso considerablemente. En esta circunstancia puede suponerse que los trabajadores del gremio docente vieron resentidos en menor medida su salario que los trabajadores comparables, por lo que la diferencia entre éstos puede interpretarse como una renta que deberían justificar con mejor calidad, es decir mayores recursos reales ${ }^{32}$.

Gráfico IV:

Evolución del salario docente, salario de servicios y gasto en $\$ 2001$, 1998-2002 (1998=100)

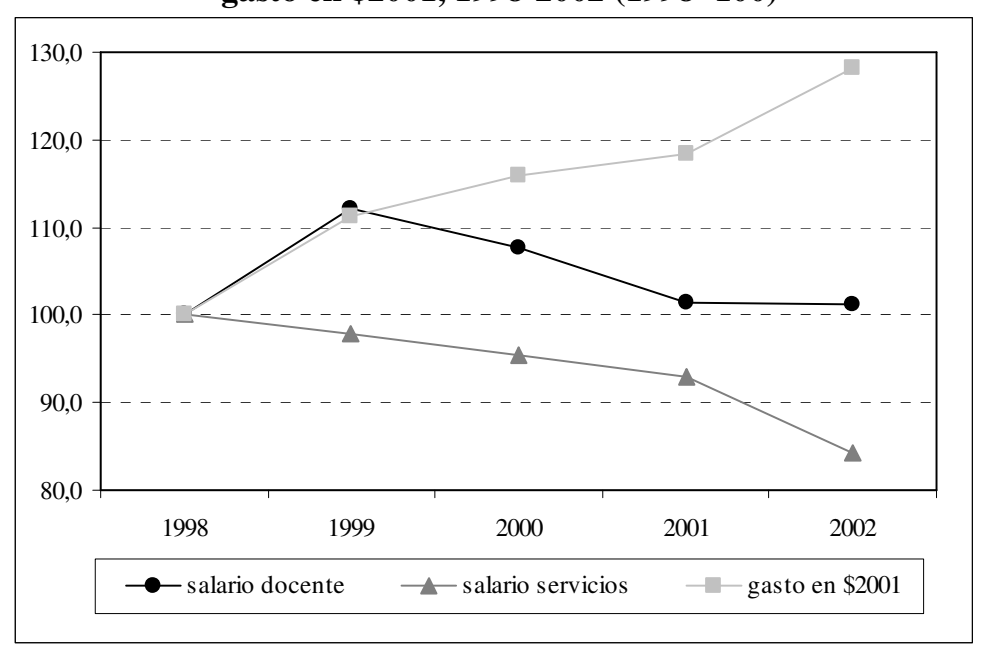

Fuente: elaboración propia sobre la base de DAGPyPS e INDEC.

\subsection{Consideraciones sobre diferencias geográficas}

Hasta aquí se ha trabajado básicamente sobre un problema "longitudinal": ajustar los pesos nominales para poder comparar el poder de compra real del gasto entre diferentes puntos del tiempo para la misma localización geográfica. Sin embargo, además de este problema, existe otro que se refiere a la comparación horizontal y se trata de ajustar los pesos nominales para poder comparar el poder de compra real del gasto entre diferentes jurisdicciones en un momento dado del tiempo. En este sentido si el costo de la educación en distintas jurisdicciones difiere, entonces una cantidad dada de gasto en una localidad comprará diferentes cantidades de recursos reales que el mismo gasto en otra localidad. Con lo cual, resulta relevante intentar investigar cuánto más o menos se paga en jurisdicciones diferentes por recursos educativos comparables, tanto humanos como materiales.

\footnotetext{
${ }^{32}$ La relación entre el aumento o la disminución de los recursos reales y el producto de la educación se analiza en la sección que sigue.
} 
En la mayoría de los casos, la información publicada con respecto al gasto en educación y a los salarios del personal de las escuelas a través de las jurisdicciones está basada en los valores corrientes. Sin embargo, dadas las variaciones existentes en los costos de recursos educativos comparables a través de las provincias, resulta difícil hacer comparaciones del nivel de gasto en cada una. Con el objetivo de realizar dichas comparaciones, es necesario ajustar los datos relacionados con los gastos educativos promedios y salarios docentes por diferencias en el poder de compra del dinero invertido en educación a través de las jurisdicciones.

Dado que el gasto en personal da cuenta de más del $80 \%$ del presupuesto educativo, la mayor parte de los estudios sobre diferencias en los costos educativos entre jurisdicciones focalizan la atención en el análisis del costo de los recursos humanos. El estudio de estas diferencias intenta investigar cuánto más o menos cuesta en jurisdicciones diferentes emplear personal educativo con características similares, en empleos y tareas similares.

En esta línea de investigación Chambers y Fowler (1995) postulan que para capturar las variaciones en el costo docente es necesario un análisis comprehensivo de los patrones de la compensación a los docentes. Se requiere para ello un modelo que incorpore las complejidades de las transacciones laborales entre el docente individual y el distrito escolar: esto es un modelo que de cuenta de las preferencias de los distritos escolares por las calificaciones de los docentes y de las preferencias de los docentes por las condiciones en las que desean trabajar y vivir, en las diferentes localidades.

Los autores proponen utilizar el "modelo de salarios hedónicos" que provee el esquema conceptual planteado para entender y ordenar los numerosos factores que determinan las variaciones en los patrones de compensación de los docentes. Este modelo resulta útil para aislar el impacto de las características regionales y el costo de vida en el salario docente mientras se controla por distintas características de los docentes y del trabajo.

Los parámetros del modelo se estiman a partir de una regresión de mínimos cuadrados clásica y los coeficientes estimados proveen las bases para determinar los diferenciales salariales (positivos o negativos) asociados con características personales, laborales o de localización.

La forma reducida del modelo de salarios hedónicos utilizada para el análisis del costo docente puede expresarse de la siguiente manera:

$$
\text { 1. } \ln \left(\text { salario }_{i j}\right)=\hat{\alpha}+\hat{\beta}_{D} \bullet D_{i}+\hat{\beta}_{A} \bullet A_{i}+\hat{\beta}_{E} \bullet E_{i}+\hat{\beta}_{J} \bullet J_{j}+u_{i j}
$$

donde i se refiere al docente i-ésimo y j se refiere a la jurisdicción j-ésima. La variable dependiente es el logaritmo natural del salario. El conjunto de variables independientes puede dividirse en factores discrecionales y factores asociados a los costos. Entre los primeros, se incluyen D: variables relacionadas con las características de los docentes; A: variables asociadas al aula y E: variables relacionadas con la escuela. Algunos ejemplos de éstas variables son: sexo, calificación y esfuerzo docente y ambiente de trabajo.

En cuanto a los factores asociados a los costos se incorporan en la variable $\mathrm{J}$ características relacionadas con la jurisdicción. Algunos ejemplos son: la competencia por docentes en el mercado (mercados de trabajo docente muy competitivos o bajas tasas de desempleo), factores asociados a diferencias en el costo de vida, las facilidades de la vida urbana (áreas más densamente pobladas, áreas con tasas mayores de criminalidad) y las condiciones climáticas de la jurisdicción.

El índice del costo docente (ICD) se calcula sobre la base de los parámetros estimados que se derivan de la ecuación anterior. A partir de la ecuación log-lineal, puede demostrarse que es factible calcular el ICD utilizando únicamente los coeficientes estimados y los valores para los factores asociados a los costos. La expresión utilizada para el cálculo del ICD es:

2. $I C D_{j}=\exp \left[\hat{\beta}_{J} \bullet\left(J_{j}-\bar{J}\right)\right]$ 
Para llevar a cabo este estudio, Chambers y Fowler cuentan con una encuesta a docentes de representatividad nacional para Estados Unidos. El cuestionario incorpora una gran cantidad de preguntas relacionadas con distintos aspectos personales y laborales, incluyendo el salario de cada docente.

Con el objetivo de investigar las diferencias geográficas en el caso de la Argentina, se intenta reproducir el método aplicado por los autores citados. Dado que no se dispone de una encuesta con características similares a la utilizada en el estudio original, se trabaja sobre la base de distintas fuentes de información que brindan datos a nivel provincial.

De este modo para capturar los factores discrecionales se utiliza el promedio por provincia de distintas características de los docentes. En cuanto a los factores asociados a los costos se evalúan conceptos tales como: la paridad de poder de compra del consumidor (PPCC $)^{33}$, densidad de población, tasa de desempleo, tasa de crimen, temperatura media, presencia sindical ${ }^{34}$ y distancia de la Capital. La variable dependiente "In (salario)" se define a partir del salario bruto de docentes de nivel primario y medio ${ }^{35}$.

La estimación del modelo de salarios hedónicos para los niveles primario y medio se reproduce en el cuadro XV.

\section{Cuadro XV}

Estimación del modelo de salarios hedónicos

\begin{tabular}{|c|c|c|c|c|c|}
\hline \multicolumn{3}{|c|}{ Primaria } & \multicolumn{3}{|c|}{ Media } \\
\hline Variable & Coeficiente & & Variable & Coeficiente & \\
\hline PPCC & 0,04941 & $* * *$ & PPCC & 0,02708 & $* * *$ \\
\hline Densidad & $-0,04684$ & $* * *$ & Distancia de CBA & 0,00021 & $* * *$ \\
\hline Distancia de CBA & 0,00022 & $* * *$ & Experiencia docente & 0,08587 & $* * *$ \\
\hline Experiencia docente & 0,18545 & $* * *$ & & & \\
\hline $\mathrm{R}^{2}$ & 0,99930 & & $\mathrm{R}^{2}$ & 0,99710 & \\
\hline $\mathrm{R}^{2}$ ajustado & 0,99920 & & $\mathrm{R}^{2}$ ajustado & 0,99670 & \\
\hline F-statistic & $7.183,29$ & $* * *$ & F-statistic & $2.410,40$ & $* * *$ \\
\hline
\end{tabular}

Se incorporan únicamente las estimaciones que arrojan mejores niveles de ajuste. Las variables que no están incluidas en el cuadro a pesar de no resultar significativas, arrojaron los signos esperados.

El índice del costo docente (ICD) se calcula sobre la base de los parámetros obtenidos en las regresiones de acuerdo con la ecuación 2. El cuadro XVI presenta las estimaciones por provincia del ICD primario y medio. El valor promedio de ambos índices para el total del país se fija en $100^{36}$. Utilizando el ICD primario, el costo varía desde un mínimo de 65,5 a un máximo de 242,5. Esto significa que el costo docente en la jurisdicción con el menor costo es el 65,5\% del que pagan las jurisdicciones que atienden al estudiante promedio.

Las jurisdicciones con mayores niveles de ICD coinciden para el caso de primaria y media: Río Negro, Neuquén, Chubut, Santa Cruz y Tierra del Fuego. Este conjunto de provincias comparte distintas características, entre ellas: pertenecen a la región sur del país, tienen baja densidad de población y se encuentran alejadas de la Ciudad de Buenos Aires.

\footnotetext{
${ }^{33}$ Este índice mide la relación entre el costo de una canasta de bienes y servicios representativos del consumo de la población urbana de una región determinada y el costo que esa misma canasta tendría si se pudiera adquirir a los precios medios de otra región que se toma como base para las comparaciones. El cálculo lo realizó el INDEC para el mes de abril de 2001. Si bien existe la intención por parte del Instituto de extender el cálculo a otros períodos, en la actualidad el dato para 2001 es el único disponible con respecto a la relación de precios entre las distintas regiones del país.

${ }^{34}$ De acuerdo con la literatura referida a este tema se espera que los sindicatos, en términos de la presencia y el grado de efectividad tengan un impacto positivo sobre los salarios y los beneficios que reciben los trabajadores de la educación. Murillo et al (2001) y Fowler y Monk (2001).

${ }^{35}$ En el anexo 9.2 se presenta el listado de las variables incorporadas en el análisis: descripción, principales estadísticas y fuentes de información.

${ }^{36}$ Los valores de los ICD se ponderan por la matrícula en cada jurisdicción, de este modo cada índice se calcula relativamente a la jurisdicción que atiende al alumno promedio.
} 


\section{Cuadro XVI}

ICD primario y medio por provincia, 2002

\begin{tabular}{lcr}
\hline \multicolumn{1}{c}{ Jurisdicción } & ICD primario & ICD medio \\
\hline Buenos Aires & 86,68 & 90,06 \\
Catamarca & 103,81 & 103,01 \\
Ciudad de Bs. As. & 65,46 & 88,94 \\
Córdoba & 104,33 & 103,39 \\
Corrientes & 105,47 & 105,65 \\
Chaco & 105,28 & 105,16 \\
Chubut & 172,51 & 137,78 \\
Entre Ríos & 92,02 & 94,08 \\
Formosa & 111,28 & 109,02 \\
Jujuy & 108,54 & 113,78 \\
La Pampa & 113,05 & 101,22 \\
La Rioja & 103,49 & 102,66 \\
& & \\
\hline
\end{tabular}

\begin{tabular}{lcc}
\hline \multicolumn{1}{c}{ Jurisdicción } & ICD primario & ICD medio \\
\hline Mendoza & 99,44 & 102,76 \\
Misiones & 100,47 & 106,05 \\
Neuquén & 154,86 & 129,98 \\
Río Negro & 150,99 & 123,40 \\
Salta & 110,28 & 112,94 \\
San Juan & 102,81 & 104,08 \\
San Luis & 97,34 & 97,15 \\
Santa Cruz & 231,15 & 175,82 \\
Santa Fe & 98,15 & 98,36 \\
Stgo. del Estero & 100,06 & 102,12 \\
Tierra del Fuego & 242,47 & 199,25 \\
Tucumán & 93,03 & 105,65 \\
Total país & $\mathbf{1 0 0 , 0 0}$ & $\mathbf{1 0 0 , 0 0}$ \\
\hline
\end{tabular}

El cuadro XVII provee un ejemplo de cómo puede utilizarse el ICD para presentar información sobre los salarios docentes. Las columnas 1 y 2 del cuadro contienen el salario bruto vigente en 2002 para cada jurisdicción. En las columnas siguientes se presenta este salario ajustado por el ICD. Las últimas columnas muestran el ranking de provincias con respecto a los salarios vigentes y a los salarios ajustados por ICD.

\section{Cuadro XVII}

Comparación de salarios docentes vigentes y ajustados, 2002

\begin{tabular}{|c|c|c|c|c|c|c|c|c|}
\hline \multirow{3}{*}{ Jurisdicción } & \multirow{2}{*}{\multicolumn{2}{|c|}{ Salario bruto }} & \multirow{2}{*}{\multicolumn{2}{|c|}{ Salario ajustado }} & \multicolumn{4}{|c|}{ Ranking } \\
\hline & & & & & \multicolumn{2}{|c|}{ Sal. bruto } & \multicolumn{2}{|c|}{ Sal. ajustado } \\
\hline & primaria & media & primaria & media & prim & med & prim & med \\
\hline Buenos Aires & 481,21 & 32,07 & 555,14 & 35,61 & 9 & 11 & 18 & 18 \\
\hline Catamarca & 651,90 & 38,22 & 627,97 & 37,10 & 18 & 19 & 20 & 21 \\
\hline Ciudad de Bs. As. & 536,13 & 33,46 & 819,04 & 37,62 & 15 & 13 & 24 & 22 \\
\hline Córdoba & 763,25 & 33,00 & 731,56 & 31,92 & 22 & 12 & 23 & 14 \\
\hline Corrientes & 466,59 & 27,22 & 442,41 & 25,76 & 8 & 2 & 10 & 4 \\
\hline Chaco & 424,30 & 28,24 & 403,02 & 26,85 & 2 & 6 & 6 & 7 \\
\hline Chubut & 520,65 & 27,70 & 301,80 & 20,10 & 13 & 4 & 1 & 1 \\
\hline Entre Ríos & 463,23 & 26,61 & 503,38 & 28,28 & 7 & 1 & 15 & 10 \\
\hline Formosa & 425,50 & 28,43 & 382,38 & 26,08 & 3 & 7 & 3 & 6 \\
\hline Jujuy & 451,68 & 35,10 & 416,13 & 30,85 & 6 & 16 & 9 & 13 \\
\hline La Pampa & 522,00 & 34,86 & 461,74 & 34,44 & 14 & 15 & 12 & 16 \\
\hline La Rioja & 726,71 & 46,21 & 702,23 & 45,01 & 21 & 22 & 21 & 23 \\
\hline Mendoza & 491,20 & 37,44 & 493,96 & 36,43 & 10 & 18 & 14 & 20 \\
\hline Misiones & 409,86 & 27,43 & 407,95 & 25,86 & 1 & 3 & 7 & 5 \\
\hline Neuquén & 714,96 & 45,30 & 461,69 & 34,85 & 20 & 20 & 11 & 17 \\
\hline Río Negro & 491,70 & 28,02 & 325,65 & 22,71 & 11 & 5 & 2 & 2 \\
\hline Salta & 434,08 & 30,70 & 393,60 & 27,18 & 4 & 10 & 5 & 8 \\
\hline San Juan & 565,60 & 34,31 & 550,14 & 32,97 & 16 & 14 & 17 & 15 \\
\hline San Luis & 690,12 & 49,36 & 708,95 & 50,81 & 19 & 23 & 22 & 24 \\
\hline Santa Cruz & 952,83 & 53,47 & 412,21 & 30,41 & 24 & 24 & 8 & 12 \\
\hline Santa Fe & 509,52 & 29,19 & 519,13 & 29,68 & 12 & 8 & 16 & 11 \\
\hline Stgo. del Estero & 603,33 & 36,66 & 602,99 & 35,89 & 17 & 17 & 19 & 19 \\
\hline Tierra del Fuego & 938,10 & 46,03 & 386,89 & 23,10 & 23 & 21 & 4 & 3 \\
\hline Tucumán & 445,26 & 29,75 & 478,64 & 28,16 & 5 & 9 & 13 & 9 \\
\hline Total & 519,61 & 32,59 & 519,61 & 32,59 & & & & \\
\hline
\end{tabular}

Fuente: elaboración propia sobre la base de MECyT. 


\section{Deflactar el gasto a partir de los productos}

\subsection{Medidas basadas en el producto: concepto y definiciones}

Los ejercicios realizados hasta aquí intentan aislar el efecto de los precios para obtener una medida de los recursos reales destinados a la educación. En este sentido, resulta bastante frecuente utilizar estos últimos como indicadores de la oferta de servicios públicos, de la presencia y/o el compromiso del estado en la materia.

Sin embargo, ¿qué ocurriría si con la misma cantidad de recursos reales se produce un aumento y/o una mejora en el servicio público brindado, o si, a pesar de duplicar la cantidad de recursos reales destinados a esta área, la cantidad y la calidad de la educación brindada al público no se modifica?

El hecho de que los servicios que provee el estado se valúen sobre la base del costo de los insumos necesarios para su producción no significa que no puedan distinguirse físicamente de éstos. Tampoco implica que cambios en las prestaciones a través del tiempo no puedan distinguirse de cambios en los insumos. Los cambios en la productividad pueden ocurrir en cualquier tipo de producción, incluida la producción de servicios del Estado. Medir la producción utilizando índices de precios para deflactar insumos elimina los cambios en precios pero no tiene en cuenta ninguna ganancia o pérdida relacionada con la productividad.

El volumen de producto no necesariamente varía de manera lineal con el gasto dedicado a él. Son conceptos diferentes. El gasto paga por los insumos, mientras que el producto se crea como resultado de la combinación de éstos.

En el sector manufacturero, el valor agregado real surge del residuo entre las compras de insumos reales y las ventas reales. Sin embargo, en el sector de servicios públicos como la educación o los servicios de promoción social, no hay ingresos generados a partir de las ventas de los que los insumos adquiridos puedan deducirse. Es importante notar que la metodología en el sector privado depende de la valuación de ambos, los insumos comprados y los productos vendidos. Con lo cual, aún cuando fuera posible estimar con precisión el cambio en los precios nominales de los recursos reales adquiridos por el sector educativo, y pudiera distinguirse entre el componente "real" (aumento de recursos) y el componente que representa el aumento del precio para el mismo recurso, haría falta una estimación del valor agregado real y ese cálculo requiere la valuación de las ventas o del producto de los servicios educativos.

De este modo, se plantean dos cuestiones centrales: cuál es el producto de la educación y cómo se mide este producto. La definición y la medición del producto de la educación resulta difícil aún considerando que se trata de una actividad cercana al mercado ${ }^{37}$. La educación es un servicio con una cantidad muy significativa de insumos que están fuera del mercado, como el tiempo de los estudiantes y sus padres; y el resultado de la educación, depende de factores que están fuera del control de los proveedores de servicios educativos, como la habilidad de los estudiantes, la familia, el grupo de pares y distintos factores relacionados con el entorno (Rivkin, 2000).

Consecuentemente, aislar la contribución de los proveedores de educación resulta complejo. Sumado a esto, no todos los beneficios de la educación pueden medirse, ya que ésta tiene efectos más allá de simplemente aumentar los ingresos sobre el bienestar de los individuos y de la sociedad.

Utilizar un enfoque basado en el producto para analizar los servicios que brinda el Estado en materia educativa es parte de una tendencia general en la comunidad estadística internacional hacia el uso de medidas basadas en el producto para evaluar la producción del gobierno en las cuentas nacionales. La Oficina Nacional de Estadística (ONS) en el Reino Unido, con cerca del $70 \%$ del gasto del gobierno computado a partir de medidas directas de volumen, resulta la más avanzada en la materia.

\footnotetext{
${ }^{37}$ Es relevante aquí diferenciar entre bienes y servicios individuales (como educación, salud) y servicios colectivos (defensa seguridad, etc.). Para estos últimos resulta evidentemente más difícil medir la producción, dado que no es posible observar y registrar la provisión de estos servicios. Muchos servicios colectivos son de naturaleza preventiva: proteger los hogares u otras unidades institucionales de actos de violencia, o protegerlos de otras contingencias, como accidentes de autos, polución, incendio.
} 
Nueva Zelanda, Australia, Italia y Holanda también han seguido esta línea, cada una midiendo más del $50 \%$ del gasto del gobierno a partir de este enfoque.

\section{Cuadro XVIII}

Situación internacional en la introducción de medidas de producto para educación (a Septiembre de 2004)

\begin{tabular}{ll}
\hline País & Estimación del producto de la educación \\
\hline Reino Unido & $\begin{array}{l}\text { Utilizan el número de alumnos equivalentes ponderado por el costo } \\
\text { de distintos tipos de educación ajustado por calidad a partir de } \\
\text { resultados en exámenes estandarizados. }\end{array}$ \\
Australia & $\begin{array}{l}\text { Utilizan el número de alumnos equivalentes ponderado por el costo } \\
\text { de distintos tipos de educación. }\end{array}$ \\
Italia & $\begin{array}{l}\text { Utilizan el número de alumnos ponderado por el costo, ajustado por } \\
\text { calidad a partir del tamaño de la clase. }\end{array}$ \\
Holanda & $\begin{array}{l}\text { Utilizan el número de alumnos ponderado por el costo, ajustado por } \\
\text { calidad a partir del número de alumnos que pasan al nivel siguiente. }\end{array}$ \\
\hline
\end{tabular}

Fuente: elaboración propia sobre la base de Fraumeni et al (2004) y Tuke (2004).

Otros países, como Canadá, Alemania, Noruega, Finlandia, Suecia, Estados Unidos, Francia e Israel también han desarrollado medidas del producto real, y en algunos casos las han implementado recientemente para una porción menor del gasto del gobierno, mientras que en otros casos están considerando hacerlo en un futuro cercano. A nivel global, las dos funciones que recibieron mayor atención en cuanto al desarrollo de medidas basadas en el producto son educación y salud.

En la Argentina, esta perspectiva no está generalizada en el desarrollo de las cuentas nacionales aunque existen algunas actividades particulares que utilizan para medir la producción a precios constantes índices de volumen físico relacionados con el producto de las áreas involucradas.

Es interesante destacar aquí, un esfuerzo que en este sentido se desarrolla desde hace algunos años en el ámbito de la Oficina Nacional de Presupuesto (ONP). El trabajo: "Indicadores de la Administración Pública Nacional", basado en el seguimiento físico financiero realizado por la Dirección de Evaluación Presupuestaria de la ONP, presenta un conjunto de indicadores que se elaboran a partir de la medición de los productos (bienes y servicios) que provee cada organización, de su relación con los insumos utilizados y de los resultados logrados. A pesar de la utilidad que supone un relevamiento de estas características, el sistema cuenta con ciertas falencias: algunos indicadores se presentan "sin información" para distintos períodos y en otros la unidad de medida no permanece constante a lo largo del tiempo. Existen además indicadores que pueden resultar relevantes que no aparecen reflejados en el informe y existe también un importante defasaje con respecto al período relevado y su publicación. Además, teniendo en cuenta el objetivo de este trabajo se trata de información relacionada únicamente con las acciones que se desarrollan en el ámbito nacional, y considerando el alto grado de descentralización de los distintos servicios que provee el Estado, en especial en el sector educación, los datos relevados resultan insuficientes para su utilización en medidas que pretenden realizar un análisis global sobre las prestaciones estatales. De hecho, prácticamente ninguno de los indicadores informados resulta relevante a los fines del análisis que pretende efectuarse en esta sección.

En cuanto a la situación internacional, gran parte de los avances sobre esta materia surgieron y se desarrollan actualmente tanto en el ámbito de la Oficina Estadística de la Unión Europea (Eurostat), como en las oficinas y reuniones relacionadas con la Organización para la Cooperación y el Desarrollo Económico (OCDE).

En este sentido, en 1998 Eurostat organizó distintos grupos de trabajo dedicados a la medición del volumen de los servicios del gobierno, uno de los cuales se dedicó específicamente al área educativa. El objetivo de este último grupo de trabajo fue investigar los métodos existentes y potenciales de estimar el producto educativo a precios constantes. El equipo contó con la colaboración de especia- 
listas de distintos países miembros de la Unión Europea y en el transcurso de su labor fueron consultados especialistas en índices de precios armonizados, paridades del poder de compra, estadísticas funcionales para la educación y estadísticas estructurales de negocios, con el objetivo de tener en cuenta los desarrollos en cada una de las áreas. En su reporte final el grupo de trabajo planteó una definición del producto de la educación que puede tomarse como punto de partida:

"El producto de la educación es la cantidad de enseñanza recibida por los alumnos, ajustada por la calidad del servicio provisto, para cada tipo de educación. Las cantidades deben ser ponderadas utilizando datos referidos a los costos (o los precios) de la educación provista.",38

En cuanto a la implementación de esta definición, el grupo de trabajo expresó que la medida más adecuada para el producto de la educación es el número de horas que los estudiantes dedican al aprendizaje; y la medición de éstas puede realizarse a partir del número de alumnos en vez del número de horas-alumno. En este caso, se supone que el número de horas en las que un alumno recibe educación es constante a través del tiempo, o al menos no cambia sustancialmente.

Considerando la definición propuesta, reviste especial importancia la estratificación de los datos sobre el número de alumnos. Así, los tipos de educación que presentan costos por alumno significativamente diferentes - lo que sirve de ponderación para agregar el número de alumnos de los diferentes tipos de educación- tienen que ser distinguidos. De este modo, un incremento en el número de estudiantes en educación terciaria tendrá una influencia mayor en el cambio total de volumen que un incremento similar en la educación primaria.

Si las cantidades elementales son homogéneas una porción del efecto de la calidad se toma en consideración directamente. La estratificación debería tener en cuenta por ejemplo, distintas modalidades en la educación secundaria y terciaria, y distintos tipos de educación como la educación a distancia, la educación especial, de adultos.

Dado que las ponderaciones a utilizar para combinar los indicadores serán los costos promedio por estudiante-hora en el año base para cada categoría, la disponibilidad de datos sobre los costos unitarios será en la práctica crucial para determinar qué estratificación se utilizará.

\subsection{Medición del producto de la educación básica y terciaria}

El cálculo para la Argentina se realiza en primer lugar considerando simplemente la matrícula total. Se utiliza un índice de volumen de Laspeyres: $V L=\frac{\sum\left(p_{0} \times q_{t}\right)}{\sum\left(p_{0} \times q_{0}\right)}$ para obtener el gasto para cada año
medido a precios de 2001 .

\section{Cuadro XIX}

Gasto público consolidado en educación básica y terciaria, 1998-2002 Deflactor: matrícula total - sin ponderar por costos, sin ajustes por calidad

\begin{tabular}{lrrrrrr}
\hline & $\mathbf{1 9 9 8}$ & $\mathbf{1 9 9 9}$ & $\mathbf{2 0 0 0}$ & $\mathbf{2 0 0 1}$ & $\mathbf{2 0 0 2}$ & $\mathbf{9 8 - 0 2}$ \\
\cline { 2 - 7 } En mill.\$ & 10.150 & 11.048 & 11.237 & 11.157 & 10.947 & \\
En mill.\$ 2001 & 10.567 & 10.689 & 11.042 & 11.157 & 11.242 & \\
Matrícula total & & 1,2 & 3,3 & 1,0 & 0,8 & 6,4 \\
\% var. anual & & & &
\end{tabular}

Fuente: elaboración propia sobre la base de DAGPyPS y MECyT.

\footnotetext{
${ }^{38}$ Es importante señalar que esta definición relaciona el servicio que presta el Estado con la matrícula y de este modo, sólo vincula la prestación con la demanda efectiva haciendo abstracción de la potencial. Si bien éstas pueden no resultar muy distantes en algunos países -particularmente los de la Unión Europea- es probable que en países menos desarrollados "garantizar el acceso a la educación" sea uno de los principales objetivos del servicio educativo y deba entonces, la capacidad del Estado en atraer a la población en edad escolar hacia el sistema, considerarse como parte del producto de éste. En el caso de la Argentina, incorporar esta consideración no parece relevante para el tramo de educación obligatoria aunque si lo sería en los tramos superiores donde los niveles de deserción se convierten en un problema.
} 
Este cálculo se presenta únicamente con fines expositivos ya que la metodología utilizada para obtener esta medida es cuestionable: un indicador que no pondera por costos y no considera ajustes por calidad asume que todos los alumnos en los diferentes niveles de educación reciben la misma cantidad de educación, esto es que el producto de la escuela es el mismo si se está educando a un niño del nivel inicial o un alumno en el sistema de educación terciaria. Del mismo modo, se asume que la cantidad de educación representada por un alumno-año no cambia a través del tiempo. Naturalmente estos son supuestos simplificadores. La metodología utilizada en los ejercicios que siguen, que ponderan por el costo de distintos tipos de educación, es superadora de la recientemente presentada ya que, bajo ciertos supuestos, incluyendo que los sistemas públicos de educación distribuyen sus presupuestos entre los distintos niveles para maximizar el producto, la contribución de los distintos costos (cost-shares) refleja el producto marginal relativo de los recursos dedicados a cada nivel.

El siguiente ejercicio consiste en ajustar el indicador calculado para considerar los distintos costos involucrados. En este sentido se realizan dos tipos de ajustes: en primer lugar, con el objetivo de tener en cuenta las diferencias relacionadas con el número de horas que cada alumno dedica a la educación, se toma como medida de alumno el número de alumnos equivalentes en función de la cantidad de horas que pasa cada uno en la escuela. A partir de datos provenientes del MECyT es posible distinguir la cantidad de alumnos que cursan en jornada simple (habitualmente entre 4 y 5 horas) y en jornada completa (entre 7 y 8 horas). A partir de estos datos un alumno en jornada simple se transforma en alumno equivalente en jornada completa multiplicando por un factor que se fija en 0,7 .

En segunda instancia, se diferencia el costo asociado a cada nivel educativo ${ }^{39}$. Lamentablemente, esta es la máxima estratificación que puede lograrse a partir de los datos de gasto disponibles. Idealmente sería útil contar con el costo asociado a, por ejemplo, distintas modalidades dentro del nivel de educación medio -Agropecuaria, Bachillerato, Comercial o Técnica- ${ }^{40} \mathrm{y} / \mathrm{o}$ con el costo asociado a tipos de educación común, artística, especial, de adultos.

Si bien, más del 93\% de los alumnos participan en la educación común, el costo asociado a distintos tipos de educación puede variar significativamente. Por ejemplo, para el caso de la Provincia de Buenos Aires y la Ciudad de Buenos Aires, donde es posible distinguir el gasto correspondiente a la educación especial, el gasto por alumno en este tipo de educación es en 2002, \$3.860 y \$4.923 respectivamente. Estos montos resultan muy superiores al promedio provincial de gasto por alumno que no supera en ningún caso $\$ 1.500$ en cada una de estas jurisdicciones.

Los cálculos que incluyen ponderaciones por costos se determinan a partir de utilizar un índice encadenado de cantidades de Laspeyres:

$q_{t}^{i}$ representa la cantidad de alumnos matriculados en el año $t$ para el nivel de educación $i$, con $i=e, m, s$ según se trate del nivel elemental, medio o superior. A su vez, se define $p_{t}^{i}$ como la participación en el año $t$ del gasto en el nivel de educación $i\left(x_{t}^{i}\right)$ sobre el gasto en educación de los tres niveles: $p_{t}^{i}=\frac{x_{t}^{i}}{x_{t}^{e}+x_{t}^{m}+x_{t}^{s}}$

El índice encadenado de cantidades de Laspeyres queda definido por la siguiente ecuación:

$$
C L^{e}=\sum_{i} P_{0}{ }^{i} \times \frac{q_{1}^{i}}{q_{0}^{i}} \cdot \sum_{i} P_{1}{ }^{i} \times \frac{q_{2}^{i}}{q_{1}^{i}} \cdot \ldots \sum_{i} p_{t-1}^{i} \times \frac{q_{t}^{i}}{q_{t-1}^{i}} \cdot \ldots \sum_{i} p_{n-1}^{i} \times \frac{q_{n}^{i}}{q_{n-1}^{i}}
$$

\footnotetext{
${ }^{39}$ Sobre este punto se presenta una dificultad relacionada con la definición de los niveles educativos ya que la información referida al gasto educativo está disponible con la apertura correspondiente al sistema anterior (elemental que incluye el nivel inicial y el primario-, medio y superior) mientras que los datos sobre los participantes del proceso educativo se presentan sobre la base de la nueva estructura definida a partir de la Ley Federal de Educación (inicial, EGB, polimodal y superior). En este sentido, se desarrolló una equivalencia entre ambas estructuras que permite incorporar a los alumnos de cada año del nuevo sistema en la estructura del sistema anterior. Ver anexo 9.1.

${ }^{40}$ En la modificación de la estructura del sistema educativo, el nivel polimodal que comprende a los alumnos de los últimos 3 años de educación media cuenta con las siguientes modalidades: Ciencias naturales, Comunicación, artes y diseño, Economía y gestión de las organizaciones, Humanidades y ciencias sociales, Producción de bienes y servicios
} 
Alternativamente se realiza el cálculo considerando un índice de cantidades de Laspeyres y un índice encadenado de cantidades de Fisher. En todos los casos los resultados son muy similares ${ }^{41}$.

\section{Cuadro XX}

Gasto público consolidado en educación básica y terciaria, 1998-2002

Deflactor: matrícula total-ponderando por costos, sin ajustes por calidad

\begin{tabular}{lrrrrrr}
\hline & $\mathbf{1 9 9 8}$ & $\mathbf{1 9 9 9}$ & $\mathbf{2 0 0 0}$ & $\mathbf{2 0 0 1}$ & $\mathbf{2 0 0 2}$ & $\mathbf{9 8 - 0 2}$ \\
\cline { 2 - 7 } En mill.\$ & 10.150 & 11.048 & 11.237 & 11.157 & 10.947 & \\
En mill.\$ 2001 & 10.495 & 10.636 & 11.030 & 11.157 & 11.256 & \\
$\begin{array}{l}\text { Matrícula discriminada } \\
\% \text { var. anual }\end{array}$ & & 1,3 & 3,7 & 1,1 & 0,9 & 7,3 \\
\hline Fuente: elaboración propia sobre la base de DAGPyP y $\mathrm{MECy} T$ & &
\end{tabular}

El índice encadenado de cantidades de Fisher permite calcular la contribución de cada nivel de educación en el porcentaje de variación anual ${ }^{42}$. El cuadro XXI presenta estos resultados.

Como puede observarse el nivel con mayor participación en las variaciones registradas durante el período 1998-2001 es el medio, luego el nivel elemental y por último el superior. Contrariamente, para el período 2001-2002 el nivel que más contribuye al cambio es el superior. Dado que los niveles con mayor contribución en el incremento para los distintos períodos son los que resultan relativamente "más caros" (mayor gasto $\mathrm{x}$ alumno) es esperable que con respecto al cálculo anterior -sin ajustar por costos- se registre un aumento en el índice de volumen. Esto se evidencia en el gráfico que sigue, donde se presentan ambos índices.

\section{Cuadro XXI}

Contribución de cada nivel de gobierno a la variación \% anual, 1998-2002

\begin{tabular}{lrrrr}
\hline & $\mathbf{9 8 - 9 9}$ & $\mathbf{9 9 - 0 0}$ & $\mathbf{0 0 - 0 1}$ & $\mathbf{0 1 - 0 2}$ \\
\cline { 2 - 5 } elemental & 0,3 & 1,2 & 0,4 & 0,3 \\
media & 0,9 & 1,7 & 0,5 & 0,2 \\
superior & 0,1 & 0,8 & 0,2 & 0,4 \\
total & 1,3 & 3,7 & 1,1 & 0,9
\end{tabular}

Fuente: elaboración propia sobre la base de DAGPyPS y MEC $y T$.

\section{Gráfico V}

Evolución índices de volumen 1998-2002 (1998=100)

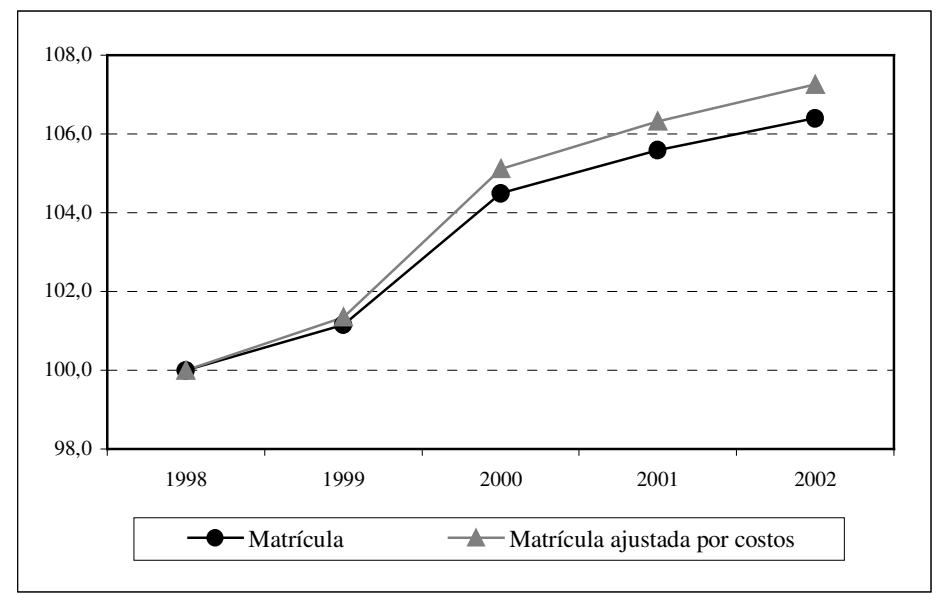

Fuente: elaboración propia sobre la base de DAGPyPS y MECyT.

\footnotetext{
${ }^{41}$ En la experiencia internacional revisada se utilizan distintos índices: En Italia se utiliza un índice de cantidades de Laspeyres, en Australia un índice de Laspeyres encadenado, en Estados Unidos un índice de Fisher encadenado y en Holanda se pondera por costos a partir de la participación en t-1 de cada nivel para el cambio entre t-1 y t.

${ }^{42}$ Para obtener la explicación de como se construyen y una discusión sobre las propiedades de los índices encadenados de Fisher, ver United Nations (1993)
} 


\subsection{Ajustes por calidad ${ }^{43}$ :}

La necesidad de tener en cuenta cambios en la calidad para el caso de los servicios educativos aparece reflejada en todos los trabajos relacionados con la medición del producto de la educación. El ejemplo más utilizado para ilustrar la importancia de los ajustes por calidad es el de una reducción en el tamaño de la clase. Si el producto de la educación se definiera únicamente como el número de alumnos, entonces una reducción en el tamaño de la clase (por ejemplo a partir de un incremento en el número de docentes) se registraría como una caída en la productividad (considerando que la productividad puede definirse como la relación alumnos/ docentes si todo lo demás permanece constante). Sin embargo, las reducciones en el tamaño de la clase pueden resultar en cambios de la calidad en el servicio prestado.

De este modo si una reducción en el tamaño de la clase promedio deriva en mejor enseñanza, esto debe reflejarse en los logros de los estudiantes; los alumnos deberían haber aprendido más en el mismo período de tiempo ${ }^{44}$. Con lo cual, podría decirse que la calidad de la educación se determina por la eficiencia en la transferencia de conocimientos a los alumnos y la definición del producto de la educación podría replantearse de esta forma: El producto de la educación es igual a la cantidad total de conocimiento que se transfiere a los alumnos a través del sistema educativo en un cierto período.

En la práctica no es posible medir directamente la transferencia de conocimiento, por lo que la mejor aproximación resulta de ponderar por costos e incluir ajustes por cambios en la calidad. Sin embargo, qué indicadores de calidad incluir y cómo especificar las ecuaciones para contemplar sus efectos son cuestiones sobre las que la literatura especializada no ha logrado acuerdo.

Existen distintas aproximaciones para realizar ajustes por calidad:

Medición directa de la calidad del producto. Por ejemplo, un informe sobre la calidad de los servicios públicos puede dar pautas sobre los cambios en la calidad de los productos en el tiempo. En Inglaterra, la Oficina de Estándares de Educación es responsable de inspeccionar las escuelas y de estimar la proporción de clases que resultan "muy buenas", "satisfactorias" o "no satisfactorias". La ventaja de esta alternativa es que se trata de una medida directa de la calidad. Sin embargo, existen algunas dificultades que deben considerarse. La información que se obtiene puede ser subjetiva y puede no ser consistente en el tiempo o entre unidades. Por otra parte, resulta difícil convertir la información en una función de calidad que pueda utilizarse para ajustar los datos de la cantidad de educación brindada. Además, existe el riesgo de que se evalúe la calidad del proceso de producción en vez de la calidad del producto.

Medir la calidad de los insumos y/o de los procesos. Por ejemplo, con respecto a los insumos puede argumentarse que mayor cantidad de computadoras o cambios cualitativos en la fuerza de trabajo como los años de educación o experiencia derivan en mayor calidad educativa. Con respecto a los procesos, algunos factores que pueden incidir sobre la calidad de la educación son: el número de alumnos en el aula, la proporción de profesores titulares respecto de los suplentes o la cantidad de tiempo de clase dedicada a la disciplina vs. la dedicada a la instrucción, la cantidad de tareas para el hogar, entre otros.

En este caso resulta necesario establecer qué tipo de relación existe entre los cambios en la calidad de los insumos o de los procesos y los cambios en la calidad de la educación. Por ejemplo si el número de computadoras en el aula aumenta un 10\%, ¿significa que el producto crecerá un $10 \%$ ? Y, aún si se pudiese estimar el impacto de los insumos sobre el producto, cambios en otros factores, como la composición del conjunto de estudiantes, pueden alterar esta relación.

\footnotetext{
${ }^{43}$ Incorporar ajustes que contemplen cambios en la calidad para medir el producto de la educación, puede interpretarse como un intento por aproximar el "D" output al "C" output. El primero se refiere a los bienes y servicios producidos en forma directa, mientras que el segundo a aquellos que son demandados por los ciudadanos. Para profundizar este concepto consultar Porto (2002), pág. 116.

${ }^{44}$ El efecto del tamaño de la clase en los logros de los alumnos fue sujeto de muchos estudios, sin embargo los resultados son materia de controversia.
} 
Utilizar el resultado. La calidad de los productos se refleja en sus resultados. Por ejemplo si el número de egresados aumenta, mientras que el número total de estudiantes no cambia, puede suponerse que las escuelas están desempeñando mejor su tarea. En estos casos será siempre necesario investigar detenidamente si existe alguna otra razón para tales cambios, por ejemplo cambios en el nivel de exigencia de la escuela o en distintos factores relacionados con el entorno.

En las secciones siguientes se revisan las dos aproximaciones expuestas en última instancia. En primer lugar se trabaja sobre el enfoque de medir la calidad a partir de los insumos y/o procesos involucrados en la educación y luego se revisan las posibilidades de contemplar los cambios en la calidad a partir de indicadores relacionados con los resultados. En cada caso se ensaya la aplicación de los distintos ajustes propuestos para el caso de la Argentina.

\subsubsection{Indicadores basados en insumo y/o proceso}

La atención hacia la relación entre insumos y productos de la educación comienza con Equality of Educational Opportunity (el "Reporte Coleman"), una publicación del gobierno de Estados Unidos que apareció en 1966. El aspecto que derivó en la atención y la controversia que siguieron a la aparición de este estudio fue que éste parecía demostrar que las diferencias entre las escuelas tenían poca relación con el desempeño de los alumnos y que en cambio resultaban muy importantes para explicar este último, el entorno familiar y las características de otros estudiantes en la misma escuela.

El Reporte Coleman, originalmente concebido para observar la existencia de discriminación racial en la provisión pública de educación, necesitaba una medida de la importancia de distintos insumos en el proceso educativo. Este requerimiento permitió a los investigadores volcarse a medir el desempeño de los estudiantes y a relacionar varios insumos directamente con éste. Este enfoque (el enfoque de la función de producción educativa -FPE-), que no estaba muy difundido en la educación o en otras áreas de servicios provistos por el gobierno, cambió radicalmente la forma básica del análisis, dado que la mayor parte de la discusión sobre las escuelas hasta el momento, tendía a utilizar los términos calidad y recursos como equivalentes.

A partir de allí, la mayor parte de los estudios sobre la efectividad de las escuelas sigue el enfoque de la FPE tratando de averiguar qué insumos manipulables pueden aumentar el producto: considerando como insumos las características personales, el entorno socio-económico y la estructura y ambiente del aula o la escuela y como producto el desempeño de los estudiantes.

$D_{i j t}=G\left(H_{i j t-1}, F_{i j t}, D_{j t}, E_{j t}, P_{i j t}\right)$

donde $i=1, \ldots, N_{j}$ representa a los estudiantes $\quad j=1, \ldots, J$ representa las aulas

y donde $H_{i j t}$ denota la habilidad del estudiante en el tiempo t, $F$ se refiere a los insumos familiares y a las características personales, $D$ insumos docentes, $E$ los insumos de la escuela y $P$ el efecto del grupo de pares.

La forma funcional de la FPE es un factor importante que sin embargo no está clarificado en la literatura. En general la función se asume como homotética y en particular aditiva, aunque algunos estudios utilizan funciones de producción translogarítmicas en vez lineales.

Una de las características de este enfoque es que la función de producción es desconocida y debe ser estimada utilizando información imperfecta. Además, el decisor de política no tiene injerencia sobre algunos insumos importantes con lo que cualquier estimación de la función de producción será sujeto de considerable incertidumbre.

Los insumos de la FPE pueden ser clasificados según el siguiente esquema:

- $F=$ sexo, asistencia a educación inicial, repitencia, cambio de escuela, densidad en el hogar, índice de salud, educación de los padres.

- $D=$ educación, experiencia, dedicación, situación de revista, entrenamiento, ingreso/ salario, ausentismo.

- $E=$ tamaño de la clase, tamaño de la escuela, estructura, días de clase, asistencia social. 
- $P=$ variables del grupo de pares.

Para analizar la producción de la educación es esencial emplear una medida adecuada de resultados. Esta no es una tarea sencilla, dado que la educación tiene múltiples objetivos, muchos de los cuales son difíciles de medir. La mayor parte de los estudios de la FPE tradicionalmente mide el producto a partir de resultados en pruebas estandarizadas, mientras que otros han empleado diferentes medidas como las tasas de asistencia a la escuela, y tasas de continuidad en la educación superior o tasas de abandono.

El problema en términos estadísticos es describir la relación entre los resultados y los procesos de la escuela y los docentes, y las características de los alumnos que asisten. En este sentido, deben considerarse al menos dos dificultades que aparecen asociadas a la regresión de una medida de logros sobre los insumos disponibles. En primer lugar, no resulta fácil hallar medidas que reflejen adecuadamente las habilidades innatas de los alumnos. En segundo lugar, mientras que la educación es un proceso acumulativo, frecuentemente sólo están disponibles medidas de insumos contemporáneas, dando lugar a errores de medición y especificación. Cada uno de estos problemas deriva en errores en la estimación de los efectos de los insumos educativos.

A continuación se exponen los principales insumos y procesos que han sido relacionados en la literatura con el desempeño de los alumnos. En cada caso se revisan los resultados de los principales estudios para Estados Unidos, para América Latina y por último para la Argentina ${ }^{45}$. Luego se intenta incorporar los distintos factores al análisis del caso argentino como posibles ajustes en la calidad del producto educativo.

En cuanto a la evidencia para Estados Unidos los trabajos que se consideran son: "Monitoring School Quality: An Indicators Report" de 2000 que presenta una completa revisión sobre una gran cantidad de estudios en la materia, y los trabajos de Krueger (2002), Rivkin, Hanushek y Kain (1998-2001), Hanushek (1995, 2000, 2002), Pritchett y Filmer (1997) y Pritchard, I. (1999).

Para América Latina, se revisa la evidencia que surge principalmente de los trabajos de Velez, Schiefelbein y Valenzuela (1994), Wolf, Schiefelbein y Valenzuela (1995), UNESCO (2000) y Hanushek $(1995,2002)^{46}$.

Velez, Schiefelbein, Valenzuela (1994) revisan 88 modelos de regresión estimados para países de América Latina a lo largo de 20 años con el objetivo de examinar la evidencia surgida de la investigación en aquellos insumos que resultan más efectivos para elevar el rendimiento de los estudiantes en la educación primaria.

El trabajo de Unesco (2000) por su parte, surge de pruebas aplicadas durante 1997 a 13 países de Latinoamérica. Estas pruebas se destinaron a 54.417 alumnos de Tercer y Cuarto grado de educación básica, y se administraron cuestionarios diseñados para recabar información sobre las condiciones en que se realiza el aprendizaje a 48.688 estudiantes, 41.088 tutores, 3.675 profesores, 1.387 directores y a 1.509 establecimientos educacionales. El estudio realiza un análisis multinivel y considera no sólo la relación de los resultados con los insumos, sino que incorpora distintas variables de proceso que resultan de especial importancia.

Por último, Hanushek $(1995,2002)$ presenta los efectos sobre el desempeño de los alumnos de distintos insumos educativos en países en desarrollo sobre la base de 96 estudios.

Para la Argentina, existe una serie de estudios basados en los resultados y cuestionarios que surgen de los Operativos Nacionales de Evaluación (ONE). Estos operativos, que comienzan a desarrollarse

\footnotetext{
${ }^{45}$ Con respecto a la gran cantidad de estudios sobre el tema, Llach et al (1999) señalan que aunque revela una bienvenida preocupación casi universal, una clara mayoría de los trabajos se ha realizado en los Estados Unidos y se ha empapado así de la problemática de ese país.

${ }^{46}$ Es interesante destacar aquí una conclusión a la que arriba Pritchett (1999) al analizar el caso de países en desarro1lo. De acuerdo con este autor, los resultados en este caso pueden diferir respecto de países desarrollados dado que en los primeros los docentes influyen en la distribución del gasto hacia insumos que incrementan su bienestar.
} 
en el país a partir de 1993, cuentan sin embargo, con diferentes niveles de cobertura y en muchos casos diferentes características ${ }^{47}$.

Uno de los principales trabajos es el de Llach et al (1999) que describe la totalidad del sistema educativo y utiliza el enfoque de la FPE para evaluar los resultados de las pruebas de 1993 y 1997. Otro, de Eskeland y Filmer (2002), también a partir de este enfoque, intenta analizar el efecto de la participación de los padres y la autonomía de la escuela sobre el desempeño de los estudiantes. Por su parte, Murillo et al (2001) y Parandekar et al (2003) utilizan regresiones lineales para estimar la FPE; en el primer caso con el objetivo de investigar el efecto de los gremios sobre la educación y a partir de los operativos de 1997 y 1999; en el segundo para evaluar el efecto de la crisis sobre el proceso educativo y a partir del operativo de 2000.

Por último tanto en Ministerio de Educación (1999) como en Abuelafia (2003), se utiliza la técnica de análisis multinivel que tiene la ventaja de identificar los diferentes niveles de los datos y consecuentemente permite obtener estimadores más eficientes de los coeficientes de la regresión. En ambos casos se utiliza el enfoque de la FPE para analizar la relación de distintos insumos con los resultados de los operativos.

Si bien la mayor parte de los análisis centran la atención sobre el nivel de educación primario, existen algunos estudios que evalúan también el nivel medio - este es el caso por ejemplo de Llach et al (1999)-.

\subsubsection{Características de los docentes}

Existe una serie de características de los docentes que habitualmente se relaciona con la calidad de la educación que reciben los alumnos, entre éstas las que han recogido mayor atención y/o mayor posibilidad de estudio a partir de los datos disponibles son: la experiencia, la educación del docente y su situación de revista y la participación en cursos de actualización docente.

El trabajo de Mayer et al (2000) resume la revisión de los textos sobre este aspecto con la siguiente afirmación: "existe un amplio acuerdo en que los estudiantes aprenden más de docentes con mayor formación académica y experiencia en la docencia de lo que aprenden de docentes con débil formación académica y menor experiencia."

En cuanto al perfil académico, Ferguson and Ladd (1996) utilizan como medida de éste las calificaciones obtenidas por los docentes en evaluaciones estandarizadas. Emplean para ello bases de datos por estados para Estados Unidos y luego de controlar por diversos factores locales, personales y distintas características de los docentes, encuentran que puntajes más altos en las evaluaciones de los docentes están positivamente correlacionados con puntajes más altos en las evaluaciones de los alumnos.

Con respecto a la experiencia, Rivkin, Hanushek y Kain (2001) encuentran que estudiantes de 4to a 6to grado con docentes con más experiencia durante un año, muestran un 0,10 de aumento en el desvío estándar en lectura y matemática comparado con sus pares en clases con docentes con menor experiencia.

La evidencia para América Latina a partir del trabajo de Velez et al (1994) se reproduce en el cuadro XXII que resume 274 coeficientes acerca de las características de los docentes. Si bien los coeficien-

\footnotetext{
${ }^{47}$ Complementariamente a las pruebas propiamente dichas, y para poder analizar los factores determinantes de la calidad, se definieron cuatro unidades de análisis a las que se aplicaron cuestionarios especiales: los alumnos, sus familias, los maestros o profesores y los directores del establecimiento estudiado. Lamentablemente, la investigación de estas distintas unidades no tuvo continuidad en el tiempo. Por ejemplo, las familias de los alumnos sólo fueron encuestadas en 1993. En el caso de la enseñanza secundaria, por su parte, no se aplicó ningún cuestionario especial en 1995 y en los años siguientes sólo se lo hizo con los directores. En el último año de este nivel se aplicaron a partir de 1997 evaluaciones con carácter censal. Con respecto al desarrollo de los operativos para los últimos años, de acuerdo con información del MECyT, en 2001 la evaluación no se llevó a cabo en ningún nivel de educación, mientras que los resultados de 2002 y 2003 aún no están disponibles.
} 
tes se centran principalmente en la formación y la experiencia docente, hay características como su domicilio (indicador aproximado del tiempo de tarea), la especialidad, las expectativas sobre el rendimiento de los alumnos y la experiencia con el material, que resultan también buenos indicadores de la calidad docente. De acuerdo a la información que surge del cuadro, la formación inicial (31 de 68 modelos) y la experiencia docente $(25 \mathrm{de}$ 62) se encuentran significativamente asociadas al rendimiento de los alumnos. Por
Cuadro XXII

Relación entre variables asociadas a los docentes y rendimiento escolar en América Latina y el Caribe

\begin{tabular}{lcccc}
\hline & $N^{\text {o Estudios }}$ & $\begin{array}{c}\text { Relación } \\
\text { positiva }\end{array}$ & Sin relación & $\begin{array}{c}\text { Relación } \\
\text { negativa }\end{array}$ \\
\cline { 2 - 5 } Años de formación inicial & 68 & 31 & 33 & 4 \\
Años de experiencia & 62 & 25 & 35 & 2 \\
Formación en servicio & 8 & 0 & 7 & 1 \\
Incentivos económicos & 5 & 0 & 3 & 2 \\
Nivel socioeconómico & 5 & 3 & 0 & 2 \\
Lugar de residencia (cerca=1; lejos=0) & 15 & 8 & 7 & 0 \\
Conocimiento de la asignatura & 19 & 9 & 9 & 1 \\
Expectativas de desempeño alumno & 2 & 2 & 0 & 0 \\
Tiempo dedicado a preparar clases & 1 & 0 & 1 & 0 \\
Sexo (masculino=1; femenino=0) & 19 & 2 & 10 & 7 \\
Satisfacción & 43 & 4 & 37 & 2 \\
Experiencia con el material & 10 & 4 & 4 & 2 \\
Experiencia en la sala de clases & 4 & 1 & 3 & 0 \\
Empleo adicional & 10 & 2 & 6 & 2 \\
Experiencia enseñanza primer grado & 1 & 1 & 0 & 0 \\
Dedicación full time (1)/ parcial $(0)$ & 1 & 0 & 1 & 0 \\
Diseña sus propios experimentos & 1 & 0 & 0 & 1 \\
\hline \hline
\end{tabular}

Fuente: Velez, Schiefelbein y Valenzuela (1994). otro lado, la capacitación a través del entrenamiento en servicio no parece mejorar el rendimiento académico de los estudiantes, siete de ocho modelos no hallaron relación alguna. Es importante mencionar que los modelos revisados no incluyen indicadores sobre la calidad de la capacitación otorgada, sino que se refieren a la experiencia en tal aspecto.

Una prueba muy interesante acerca de la influencia de la calidad de los docentes es la hallada por Hanushek et al (1996) en un estudio para Brasil, donde se aplicaron a los docentes las mismas pruebas de calidad que a los alumnos de cuarto grado. Esta investigación mostró que los resultados obtenidos por los docentes tenían una correlación significativa con los de los chicos: los alumnos de docentes con calificaciones un $10 \%$ superiores obtenían resultados un $5 \%$ mejores (elasticidad = $0,5)$.

En Unesco (2000) resulta positiva y estadísticamente significativa sobre el rendimiento, la formación del docente a cargo del curso: cada año adicional en la preparación docente postsecundaria, aumentan los resultados de los alumnos alrededor de $1 \%$. Por otra parte, el estudio no detectó influencia de la experiencia docente, ni de la capacitación docente en servicio (aunque los signos de la relación de estas variables con el rendimiento es en todos los casos positivo).

Con respecto a la evidencia argentina para estas relaciones, el Ministerio de Educación (1999) encuentra que tanto la antigüedad del docente en la escuela como la antigüedad del docente como docente del año evaluado presentan un efecto significativo sobre el rendimiento, adicional al producido por el nivel socioeconómico del alumno y de la sección.

Por su parte, Llach et al (1999) con respecto a los docentes y los directores evalúan la situación de revista y los cursos de capacitación para ambos y la antigüedad en el cargo únicamente para el caso del director. Encuentran que las variables referidas a los docentes, tal como están medidas, tienen escasísima influencia. Sólo la antigüedad del director aparece como importante, sobre todo en la enseñanza secundaria.

Además, Murillo et al (2001) y Parandekar et al (2003) encuentran relaciones positivas y significativas entre el rendimiento y la experiencia y la educación de los docentes a cargo del curso. Sin embargo Abuelafia (2003) no encuentra asociaciones significativas con estas variables, aunque sí para la situación de revista del docente.

Por último y tal como se mencionara en la sección 4.1 puede suponerse que existe una relación entre la calidad de los docentes/ calidad de la enseñanza que imparten y la satisfacción de éstos con la tarea que desempeñan. 
Esta variable ${ }^{48}$ aparece evaluada en Murillo et al (2001) y en Abuelafia (2003) quienes encuentran que los estudiantes muestran mejores resultados cuando sus docentes están más satisfechos con sus tareas (los coeficientes resultan muy significativos en las distintas regresiones que llevan a cabo).

En esta misma línea de análisis en el trabajo de UNESCO (2000) se evalúa la variable "remuneración adecuada", la cual corresponde a la apreciación del docente respecto de lo adecuado de su salario. Los resultados en este caso muestran que cuando los profesores perciben que tienen una remuneración adecuada por su trabajo, su desempeño se traduce en un aumento de entre ocho y diez puntos en el rendimiento de sus alumnos ${ }^{49}$.

De la serie de indicadores de calidad asociados a los docentes, la experiencia, formación y satisfacción de éstos ofrecen las mejores perspectivas en cuanto a capturar empíricamente cambios en la calidad.

Para obtener una medida de la experiencia docente, se construye a partir de los cuestionarios docentes de los ONE una variable que asigna valores entre 1 y 8 a los distintos tramos de años de experiencia que declara tener el docente. Dado que no se cuenta con los resultados de los ONE 2001 y 2002, estos valores se estiman suponiendo que se mantiene constante la tasa promedio de crecimiento anual registrada para el período 1998-2000. Del mismo modo se construye una variable que asigna valores entre 1 y 6 según el máximo título obtenido por el docente para reflejar la formación $^{50}$. Con respecto a la satisfacción del docente, ésta se equipara con el poder adquisitivo del salario bruto para cada año.

El cuadro XXIII presenta las tasas de crecimiento anual de las tres características. Como puede observarse la experiencia aumenta, mientras que la formación disminuye. En el caso del poder adquisitivo se evidencia un aumento entre 1998 y 1999, mientras que se registra una abrupta disminución entre 2001 y 2002.

Cuadro XXIII

Tasa de crecimiento anual en características de docentes primarios

\begin{tabular}{lrrrr}
\hline & $\mathbf{9 8 - 9 9}$ & $\mathbf{9 9 - 0 0}$ & $\mathbf{0 0 - 0 1}$ & $\mathbf{0 1 - 0 2}$ \\
\cline { 2 - 5 } experiencia & 3,16 & 6,41 & 4,77 & 4,77 \\
formación & $-1,07$ & $-1,12$ & $-1,10$ & $-1,10$ \\
poder adquisitivo salario & 13,55 & $-3,11$ & $-4,88$ & $-20,62$ \\
\hline
\end{tabular}

Fuente: elaboración propia sobre la base de MECyT e INDEC.

\subsubsection{Tamaño de la clase}

¿Es importante el tamaño de la clase? Intuitivamente si el tamaño no importara, sería perfectamente lógico aumentar una clase de 30 a 60 alumnos, o a 120. A pesar de que la intuición obliga a esta conclusión el impacto de la variación en el tamaño de la clase es un tema de debate en la literatura.

Distintos factores como la forma en que los docentes implementan los contenidos de los cursos, la pedagogía de la instrucción y el uso de tecnología en el aula, pueden estar influenciados por el número de alumnos en la clase. En este sentido existe evidencia que sugiere que los estudiantes mejoran sus resultados en clases más pequeñas.

\footnotetext{
${ }^{48}$ La pregunta del cuestionario docente es “¿Está satisfecho con sus tareas? . En este sentido la variable refleja tanto factores objetivos como subjetivos como el estado psicológico del docente. Así, si bien puede reflejar en cierta medida la percepción de un salario adecuado, refleja también la percepción de aspectos tales como el ambiente de trabajo, la respuesta de los alumnos, etc.

${ }^{49}$ Cabe aclarar que las variables relacionadas con el salario docente, en los casos donde fueron incorporadas al análisis, no resultaron significativas para explicar el rendimiento de los alumnos. Hanushek (1996) justifica este resultado a partir de que los buenos y los malos docentes ganan generalmente lo mismo.

${ }^{50}$ Las preguntas en el cuestionario docente sobre las que se construyen las variables son respectivamente: ¿Cuántos años hace que Ud. trabaja como docente? y ¿Qué títulos ha obtenido?
} 
Uno de los sustentos de esta conclusión se encuentra en un reciente y muy citado trabajo sobre el tamaño de la clase: un experimento aleatorio conducido por el estado de Tennesse ${ }^{51}$ (Krueger 1998). El estudio compara los logros de estudiantes primarios en clases pequeñas con aquellos alumnos en clases de tamaños estándar. Luego de dos años, los estudiantes en clases pequeñas se benefician con aproximadamente 0,25 de desviación estándar en los resultados de pruebas estandarizadas.

Pritchard, I. (1999) resume los resultados de algunos estudios centrales acerca del tamaño de la clase concluyendo que "el patrón de los hallazgos de las investigaciones señala más y más claramente hacia los efectos beneficiosos de reducir el tamaño de la clase." Pritchard realiza la siguiente conclusión de su análisis: "a) Las investigaciones existentes muestran que clases más pequeñas en los primeros grados derivan en mayores logros; b) reducir el tamaño de la clase de más de 20 alumnos a menos de 20 alumnos traslada al estudiante promedio del percentil 50 al percentil 60 en las mediciones de logros; y c) los estudiantes, los docentes y los padres consideran que clases más pequeñas aumentan la calidad de las actividades en el aula."

En el otro lado del debate, Hanushek (1998), basado en 277 estudios independientes, advierte que sólo el 14\% encuentra una correlación estadísticamente significativa: "La evidencia sobre mejoras en el logro de los estudiantes que pueden ser atribuidas a clases más pequeñas resulta insuficiente y poco convincente".

En el trabajo de Unesco (2000) un mayor número de alumnos por sala de clases tiene un efecto negativo y significativo, aunque de proporciones pequeñas.

En cuanto a la evidencia para la Argentina, tanto en el estudio realizado por Llach et al (1999) como en los de Murillo et al (2001) y Abuelafia (2003), no se encuentran evidencias acerca del impacto positivo de menores tamaños del aula. En el primer caso se evalúa el efecto de un tamaño del aula menor a 20 alumnos y se encuentra que no tiene impacto positivo sobre el aprendizaje, sino negativo. En el estudio de Murillo, los coeficientes relacionados con el tamaño del aula resultan positivos para las regresiones referidas a 1997, mientras que son negativos para 1999. En el caso de Abuelafia, el coeficiente que relaciona el número de alumnos por aula al rendimiento resulta positivo aunque no significativo.

Para el período analizado, la información sobre el tamaño promedio de la clase no está disponible; sin embargo sí se cuenta con el promedio para la relación alumno por cargo docente que es una proxy para el tamaño. En el cuadro XXIV se presenta la tasa anual de crecimiento para este indicador. Como puede observarse en los dos últimos años bajo análisis se advierte un incremento en la cantidad de alumnos por cargo docente.

\begin{tabular}{|c|c|c|c|c|}
\hline \multicolumn{5}{|c|}{$\begin{array}{l}\text { Cuadro XXIV } \\
\text { Tasa de crecimiento anual en la relación alumnos por cargo do- } \\
\text { cente en primaria }\end{array}$} \\
\hline & 98-99 & 99-00 & 00-01 & 01-02 \\
\hline alumnos por cargo docente & $-4,94$ & $-3,45$ & 3,67 & 3,73 \\
\hline
\end{tabular}

Si bien los resultados con respecto a la influencia de esta variable sobre el rendimiento de los alumnos son ambiguos, es probable que exista un cierto número de alumnos, a partir del cual el producto aumenta menos que proporcionalmente debido a cambios en las condiciones de provisión del servicio (punto de congestión). Este argumento se utiliza en un trabajo de Malizia (1998) para Italia, donde para representar este elemento cualitativo en el índice de producto se estima una función que transforma el número de alumnos que recibe una calidad determinada del servicio en "alumnos estándar" que reciben un servicio de "calidad estándar".

\footnotetext{
${ }^{51}$ Dado que este tipo de experimento se considera como uno de los más válidos diseños de estudios y dado que son raros en el campo de la investigación educativa, los resultados de este estudio recibieron mucha atención de parte de los investigadores, los hacedores de política y el público en general.
} 


\section{$\underline{\text { 5.3.1.3 Infraestructura y material didáctico }}$}

De acuerdo con Hanushek (1995), una de las más claras divergencias entre los hallazgos en países en desarrollo y desarrollados es el efecto de las instalaciones, sugiriendo que en los primeros las diferencias en el ambiente escolar resultan de importancia. En la revisión que realiza, el autor encuentra que el $65 \%$ de las investigaciones sustentan la provisión de edificios de calidad. Del mismo modo, la relación de los libros de texto y el material escrito con el desempeño de los alumnos resulta importante con razonable consistencia.

En el trabajo de Velez et al (1994) también aparece una asociación positiva entre los materiales educativos y el rendimiento (Cuadro XXV). Trece de diecisiete modelos encontraron una relación positiva entre la disponibilidad de libros de textos y material de lectura y el rendimiento de los alumnos. $\mathrm{El}$ acceso a otros materiales didácticos como el pizarrón, globo terráqueo y mapas, etc., posee también un efecto positivo sobre el rendimiento, pero presenta una imagen menos optimista. Por su parte, la mayoría de los indicadores de infraestructura, incluyendo no solo la calidad del edificio sino también del mobiliario y el acceso a la electricidad o agua corriente, presentan un efecto positivo sobre el rendimiento, aunque un número considerable no halló ninguna relación.

\section{Cuadro XXV}

Relación entre variables asociadas a materiales educativos y rendimiento escolar en América Latina y el Caribe

\begin{tabular}{lcccc}
\hline & N Estudios $^{\text {o }}$ & $\begin{array}{c}\text { Relación } \\
\text { positiva }\end{array}$ & Sin relación & $\begin{array}{c}\text { Relación } \\
\text { negativa }\end{array}$ \\
\cline { 2 - 5 } Acceso a libros de texto & 17 & 13 & 4 & 0 \\
Otros materiales didácticos & 34 & 14 & 17 & 3 \\
Infraestructura & 70 & 23 & 45 & 2 \\
\hline
\end{tabular}

Fuente: Velez, Schiefelbein, Valenzuela (1994).

El trabajo de la UNESCO (2000) evaluó los recursos de la escuela en términos de disponibilidad de materiales básicos para la instrucción (pizarrón, calculadoras, mapas y otros) y constató que en el ámbito regional un aumento de un ítem en el número de estos materiales, se asocia con un incremento de $0,76 \%$ en los resultados de las pruebas. Asimismo, el estudio encuentra que escuelas con bibliotecas con al menos mil libros se asocian con las que alcanzan puntajes de rendimiento superiores. La presencia de bibliotecas de más de mil libros aumenta el rendimiento en 3,8\%.

Para el caso argentino, Llach et al (1999) encuentran que los estudiantes que asisten a escuelas con buena dotación de infraestructura y equipamiento obtienen resultados hasta un $25 \%$ superiores a los de sus pares en escuelas mal equipadas. Esta diferencia es menor en los colegios secundarios, en los que alcanza a un $12 \%$.

En el estudio de Parandekar et al (2003), con respecto a los materiales escolares (mapas, libros, útiles de geometría), su disponibilidad en las escuelas evidencia un impacto positivo sobre el aprendizaje de los alumnos (demostrado por su coeficiente positivo).

Abuelafia (2003) incorpora el concepto infraestructura a partir de un índice construido sobre la opinión de los docentes respecto de cuán apropiado es el aula en términos de luz, calefacción y ventilación; y encuentra efectos positivos y estadísticamente significativos sobre los resultados de las evaluaciones. Si la infraestructura del aula se mejora desde el valor medio hasta el máximo, los resultados de los estudiantes se espera aumenten en 3,75 puntos porcentuales.

Para incorporar estos insumos se utiliza información proveniente de las Cuentas de Inversión de la Nación para los distintos años bajo estudio. El relevamiento de distintas metas físicas de programas nacionales permite identificar la cantidad de libros y útiles provistos así como la cantidad de metros cuadrados construidos y refaccionados en infraestructura escolar financiados por el gobierno nacional. 


\section{Cuadro XXVI}

Tasa de crecimiento anual en infraestructura y material didáctico

\begin{tabular}{lrrrr}
\hline & $\mathbf{9 8 - 9 9}$ & $\mathbf{9 9 - 0 0}$ & $\mathbf{0 0 - 0 1}$ & $\mathbf{0 1 - 0 2}$ \\
\cline { 2 - 5 } & $-1,95$ & 0,32 & $-5,38$ & $-5,18$ \\
metros ${ }^{2}$ construidos y refaccionados & 1,89 & $-2,58$ & 0,84 & $-0,93$ \\
provisión de libros y útiles & & & \\
\hline
\end{tabular}

Fuente: elaboración propia sobre la base de Contaduría General de la Nación.

A partir de la tasa de crecimiento de estos indicadores, se observa una importante disminución en el último período. En este sentido es interesante notar que de acuerdo con una encuesta realizada por el Banco Mundial en junio de 2002, una gran proporción de hogares reportaron haber reducido la compra de útiles escolares y materiales didácticos $(71,9 \%$ de los hogares encuestados declaran haber reducido el gasto en este concepto) ${ }^{52}$.

\subsubsection{Cantidad de días de clase}

La relación entre la cantidad de días de clase y el rendimiento de los alumnos no aparece evaluada en los distintos estudios internacionales revisados. Sin embargo, en los trabajos para la Argentina este factor cobra relevancia, sobre todo considerando que los conflictos y medidas de fuerza docentes han sido habituales en los últimos años y han derivado en pérdidas importantes en la cantidad de días de instrucción.

En este sentido, la interrupción del proceso educativo es probable que tenga fuerte impacto en el aprendizaje de los alumnos. El abandono de la "rutina escolar", la imposibilidad de fijar y corregir conocimientos, las tensiones en la relación de la escuela con las familias, son todos factores que pueden afectar seriamente el rendimiento escolar.

Murillo et al (2001) encuentran que los resultados de los alumnos mejoran cuando tienen mayor cantidad de días de clase. Los coeficientes resultan muy significativos en las cuatro regresiones que llevan a cabo. Un día adicional de clase resulta en una mejora de aproximadamente $0,4 \%$ en los resultados de los alumnos.

En Parandekar et al (2003) los días de clase también muestran un impacto positivo sobre el desempeño de los alumnos. El coeficiente, medido por cada 10 días de clases, presenta un valor de 0,22 que resulta igual a la influencia de un año de escolaridad de la madre. Esto significa un impacto relativamente importante de la variable bajo estudio.

Por último, también Abuelafia (2003) encuentra un efecto positivo y estadísticamente significativo de esta variable sobre el rendimiento. Si el número de días de clase aumenta desde la media hasta el valor máximo, se espera que los resultados aumenten en 6,4 puntos porcentuales.

Para incorporar la cantidad de días de clase al análisis, se utiliza la cantidad de conflictos y medidas de fuerza protagonizados por las organizaciones sindicales docentes que surge de un relevamiento del Centro de Estudios Nueva Mayoría ${ }^{53}$.

\section{Cuadro XXVII}

Tasa de crecimiento anual en días de clase perdidos

\begin{tabular}{lllll}
\hline & $\mathbf{9 8 - 9 9}$ & $\mathbf{9 9 - 0 0}$ & $\mathbf{0 0 - 0 1}$ & $\mathbf{0 1 - 0 2}$ \\
\cline { 2 - 5 } días de clase perdidos & $-2,56$ & $-6,58$ & $-20,42$ & 12,39 \\
\hline Fuente: elaboración propia sobre la base de Centro de & Estudios & Nueva Mayoría.
\end{tabular}

Alternativamente a esta fuente de información existen datos que recoge el Consejo Federal de Educación sobre la cantidad de días de clase previstos y efectivos en cada provincia. Si bien no se cuenta con información para el período 1998-2000, en 2001 y 2002 se registran diferencias significativas

\footnotetext{
${ }^{52}$ Parandekar et al (2003)
} 
entre las provincias. La cantidad de días de clase perdidos llega en algunos casos casi al $30 \%$ del ciclo -San Juan y Jujuy perdieron en promedio en ambos años más de 50 días de clase sobre un total anual de aproximadamente 180 días-; mientras que en otras provincias no se registran diferencias para este período entre los días de clase previstos y efectivos-es el caso de Catamarca y Corrientes -.

\subsubsection{Aplicación de los ajustes por calidad a partir de los insumos}

Los estudios reseñados en la sección anterior permiten conocer si existe relación entre distintos insumos o procesos educativos y los resultados en pruebas estandarizas. Sin embargo, a pesar de que a partir de algunos es posible obtener estimaciones para los coeficientes asociados a cada factor, traducir estos resultados en cambios en la calidad del producto educativo no resulta trivial. Así, si se obtuvo que $\mathrm{x}$ días más de clase aumentan los resultados en un $\mathrm{x} \%$ o en $\mathrm{x}$ puntos, se supone que esto significa alumnos educados con mayor calidad, pero ¿cuál es el mecanismo para incorporar esta intuición a la medida de cantidad de producto?

A pesar de que en los distintos trabajos sobre la medición del producto en educación aparece considerada la incorporación de ajustes por calidad a partir de medidas basadas en los insumos, no aparece clarificado el mecanismo para realizar esta asociación.

Sobre este punto, en un trabajo de Fraumeni (2004) para Estados Unidos, donde se incorporan indicadores relacionados con los insumos, se consideran distintos porcentajes: por ejemplo se introduce con un coeficiente igual a 1 las características de los docentes, mientras que la relación alumno por docente se incorpora con un coeficiente igual a 0,1. En el primer caso, no se justifica la selección del coeficiente; la elección del segundo se explica por la controversia que existe sobre la influencia de esa relación.

Con el objetivo de incorporar los insumos estudiados al análisis, se suma (resta) la tasa de crecimiento anual de cada factor a la tasa de crecimiento anual de la matrícula en el nivel correspondiente. Luego se incorpora para cada nivel este nuevo número al cálculo global, ajustando por costos, al igual que en el último ejercicio de la sección 5.2.

La elección de los factores a incluir en cada nivel y la ponderación que se asocia en cada caso, si bien es arbitraria, intenta basarse en la consideración de los resultados obtenidos a partir de los trabajos reseñados. De este modo se incorpora en el nivel primario la experiencia docente con coeficiente igual a 0,5 y la relación alumno por cargo docente con 0,1 ; y para los niveles primario y medio se incorpora el poder adquisitivo del salario de cada nivel con 0,5 , las variables relacionadas con la infraestructura y material didáctico con 0,1 y la cantidad de días de clase con 0,2 .

Los resultados del cálculo aparecen en el cuadro XXVIII. En línea con la evolución de las distintas variables relevadas previamente, a partir de 2001 se evidencia una caída en el producto considerando el indicador que incorpora todos los factores y el crecimiento acumulado para el período ronda en este caso, el $0,6 \%$.

Los resultados muestran que ajustar por calidad los indicadores de volumen puede tener un efecto significativo sobre el producto estimado. La diferencia entre las tasas de crecimiento del producto para la medición ajustada por calidad y para la no ajustada es en cada año $-0,4$ por ciento, 1,2 por ciento, $-3,6$ por ciento y $-3,8$ por ciento respectivamente.

\footnotetext{
${ }^{53}$ Esta organización releva la cantidad anual de conflictos laborales y medidas de fuerza que realizaron los distintos gremios en la Argentina desde 1980. Del análisis de los datos surge que más del 17\% del total de conflictos registrados entre 1980 y 2002 fueron protagonizados por los gremios docentes.
} 


\section{Cuadro XXVIII}

Gasto público consolidado en educación básica y terciaria, 1998-2002

Deflactor: matrícula total-ponderando por costos, con ajustes por calidad

\begin{tabular}{lrrrrrr}
\hline & $\mathbf{1 9 9 8}$ & $\mathbf{1 9 9 9}$ & $\mathbf{2 0 0 0}$ & $\mathbf{2 0 0 1}$ & $\mathbf{2 0 0 2}$ & $\mathbf{9 8 - 0 2}$ \\
\cline { 2 - 7 } En mill.\$ & 10.150 & 11.048 & 11.237 & 11.157 & 10.947 & \\
0,50 x características docentes & 9.850 & 10.702 & 11.143 & 11.157 & 10.353 & \\
\% var. anual & & 8,7 & 4,1 & 0,1 & $-7,2$ & 5,1 \\
0,10 x alumnos p/cargo docente & 10.466 & 10.637 & 11.054 & 11.157 & 11.232 & \\
\% var. anual & & 1,6 & 3,9 & 0,9 & 0,7 & 7,3 \\
0,10 x infraestructura y material & 10.561 & 10.702 & 11.077 & 11.157 & 11.193 & \\
\% var. anual & & 1,3 & 3,5 & 0,7 & 0,3 & 6,0 \\
0,20 x días de clase & 11.092 & 11.188 & 11.465 & 11.157 & 11.514 & \\
\% var. anual & & 0,9 & 2,5 & $-2,7$ & 3,2 & 3,8 \\
todos los factores & 10.455 & 11.339 & 11.665 & 11.157 & 10.523 & \\
\% var. anual & & 8,5 & 2,9 & $-4,4$ & $-5,7$ & 0,6 \\
\hline
\end{tabular}

Fuente: elaboración propia sobre la base de DAGPyPS y MECyT.

Es importante aclarar que los resultados están estrechamente vinculados tanto a la elección de los factores que se incorporan para considerar cambios en la calidad del producto educativo, como a los coeficientes que se aplican en cada caso. En este sentido, y teniendo en cuenta que sobre este aspecto particular de la medición del producto resta aún mucho por hacer, es probable que la mejor opción sea simplemente tener en cuenta cómo evolucionan los distintos factores estudiados al momento de evaluar los cambios en el producto. Los futuras investigaciones deberán prestar particular atención al mecanismo para incorporar los cambios en insumos y/o procesos a la medición del producto.

\subsubsection{Indicadores de resultado}

En esta sección se revisan las posibilidades de incorporar cambios en la calidad del producto educativo a partir de utilizar indicadores relacionados con los resultados.

En primer lugar es importante distinguir claramente entre resultado y producto. El resultado generalmente se refiere al nivel de conocimiento o habilidad que poseen aquellos que reciben educación. Este puede verse afectado por una cantidad de factores distintos de las escuelas, como por ejemplo la habilidad, el apoyo de los padres, la calidad de la vida en el hogar, y el capital social en general. El producto se refiere únicamente al impacto de las escuelas en el nivel de conocimiento y habilidad de los estudiantes.

De este modo, podría considerarse una medida que contemple la diferencia en el conocimiento de los alumnos entre el final y el principio del año escolar, que tendría en cuenta cambios en el nivel inicial de conocimientos. Sin embargo, a pesar de que existen datos sobre exámenes en algún punto del tiempo o indicadores de logros similares, no existe prácticamente ningún dato sobre el conocimiento que los alumnos poseen cuando empiezan el ciclo lectivo.

En este sentido, uno de los indicadores que puede proponerse para obtener una aproximación del producto considerando cambios en la calidad de la enseñanza es el número de graduados en cada nivel de educación.

Existen sin embargo, algunas desventajas en el uso del número de graduados como indicador de producto. En primer lugar, la enseñanza impartida a alumnos que no se gradúan no se contabiliza como producto. Además, existe un defasaje temporal entre las mejoras de la calidad y un posible incremento en el número de graduados (el número de graduados en un año dado refleja la calidad de la enseñanza en un año anterior a este). Por último, el tiempo que un alumno requiere para alcanzar su graduación debería ser también tenido en cuenta: el producto decrecerá si los alumnos necesitan más tiempo para graduarse. 
Algunas de estas dificultades pueden ser mitigadas utilizando el número de alumnos que completan exitosamente el año en curso. La mayor parte de la educación argentina (al menos en cuanto a la educación primaria y secundaria) se organiza en años escolares. Para cada año hay un nivel mínimo de educación que el alumno debería lograr para pasar al año siguiente. Que el alumno pase o no al curso siguiente se determina a partir de sus resultados durante el año. Si bien no existe un sistema centralizado de exámenes cada año y son las escuelas quienes deciden por si mismas qué alumno pasa al curso siguiente, el número de alumnos promovidos cada año es un indicador de producto alternativo que se ve afectado por la calidad de la enseñanza. Naturalmente, existen otros factores que también influencian la promoción, por ejemplo cambios en los estándares ${ }^{54}$.

Si se utiliza un indicador de estas características, puede asumirse que un alumno que pasó de año ha obtenido todo el conocimiento que era requerido para ese año, mientras que un alumno que no pasó se asume que no ha obtenido todos los conocimientos necesarios. La gran ventaja de un método como éste es que no existe el problema del defasaje temporal: la tasa de promoción refleja la calidad de la enseñanza en ese año.

Otra alternativa que sigue el mismo tipo de lógica, es utilizar el número "esperado" de años que los alumnos necesitan para graduarse. La duración media de la permanencia de los egresados se calcula a partir del flujo de alumnos a través del sistema educativo.

La información sobre la duración media de la permanencia de los egresados puede utilizarse para ajustar el número de alumnos utilizando la siguiente fórmula:

\# alumnos ajustados $=$ \# alumnos * duración nominal de los estudios

duración esperada de los estudios

Si por ejemplo, un curso requiere normalmente cuatro años, pero el alumno promedio requiere cinco años para completarlo, entonces cada año en promedio sólo se transfiere efectivamente el $80 \%(4 / 5)$ del conocimiento que debería haber sido transferido. Así, el número de alumnos deberá ajustarse por este factor. Este factor de ajuste es de hecho una aproximación hacia la tasa anual de promoción.

De acuerdo con Llach et al (1999) este indicador puede interpretarse como una tasa de insumoproducto. Entendiendo el año escolar como una medida de los insumos o recursos empleados para mantener a un estudiante en el sistema durante ese período. Si el estudiante repite el grado o año, este estudiante tiene un año de educación y un año adicional de sobreuso. Así, esta tasa representa la cantidad de años escolares consumidos por los graduados y se calcula como el cociente del total de años escolares consumidos sobre el total de años escolares teóricos necesarios para la graduación.

Por último otro indicador que puede utilizarse para considerar la calidad en el producto educativo es el resultado obtenido por los alumnos en exámenes estandarizados, en el caso de la Argentina, a partir de los operativos nacionales de evaluación de la calidad educativa.

Debe considerarse que este tipo de indicador es una aproximación para el producto y no el producto en si mismo: el sistema educativo produce enseñanza, no diplomas. La escuela se ocupa de transferir a los alumnos cierto nivel de conocimiento: cuánto mejor haga esto, más alumnos aprobarán, mejores serán las notas que obtengan y menos será el tiempo que consuman en educarse. A partir de esto, el número de graduados o los resultados que obtengan puede ser un mejor indicador de la cantidad de conocimiento transferida que el utilizar simplemente el número de alumnos.

Una de las principales dificultades con este tipo de indicadores es que, como se mencionó previamente, resultan influenciados por una serie de factores que están fuera del alcance de la escuela: el

\footnotetext{
${ }^{54}$ En este sentido, como resultado de los conflictos salariales que tuvieron lugar a lo largo de 2001 y 2002 , y la pérdida de días de clase derivada de esos conflictos se registran casos como el de la provincia de Río Negro, donde se promovió automáticamente a los alumnos ya que el conflicto docente impidió formar las mesas examinadoras de marzo o el de la provincia de Jujuy donde se permitió a los alumnos pasar de año con cuatro materias previas, en lugar de dos.
} 
nivel socioeconómico del hogar de donde proviene el alumno, la educación de sus padres, sus habilidades innatas, su actitud y capacidad de aprendizaje, entre otros ${ }^{55}$.

Si esta serie de factores exógenos pudiera mantenerse constante, la influencia del sistema educativo podría aislarse para averiguar cuánto representa en la explicación de los cambios en los distintos indicadores de resultado.

En relación con este punto es posible realizar una evaluación de la importancia de algunos factores socioeconómicos, en particular los relacionados con el ingreso del hogar y la educación de los padres, a partir del índice de movilidad en la educación (IME).

Este índice, calculado por el CEDLAS a partir de información de la EPH para el total de aglomerados urbanos relevados, sigue la metodología de Andersen (2001) que consiste en calcular qué proporción de la varianza en la brecha escolar se explica por el entorno familiar. La brecha escolar se define a partir de la diferencia entre el número de años teóricos que la persona debería haber empleado en la educación si hubiera ingresado al sistema a la edad teórica y hubiera avanzado un nivel cada año y el número de años dedicados efectivamente a la educación. Cuando la movilidad en la educación es escasa, el entorno familiar será importante y el índice será pequeño.

\section{Gráfico VI}

Evolución del índice de movilidad en la educación 1998-2002 $(\mathbf{1 9 9 8}=100)$

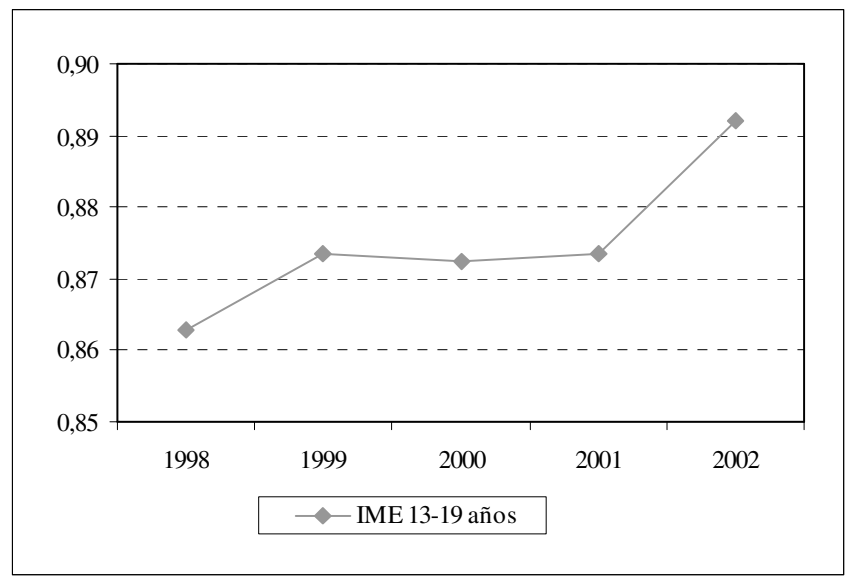

Fuente: elaboración propia sobre la base de CEDLAS.
El índice correspondiente al tramo de edad entre 13 y 19 años (lamentablemente no se dispone del cálculo para edades menores) si bien no presenta mucha variabilidad para el período estudiado, sí presenta una leve tendencia creciente (aumenta entre 1998 y 2002 $3,41 \%$ ), lo cual puede interpretarse como que a lo largo del período la importancia del entorno familiar está disminuyendo y en consecuencia los factores que están bajo el dominio del sistema educativo son cada vez más importantes o al menos no pierden relevancia.

\subsubsection{Aplicación de los ajustes por calidad a partir de los resultados}

La información básica para construir los distintos indicadores relacionados con los resultados del sistema educativo surge de los relevamientos anuales y de los ONE que realizó el MECyT a través de la Dirección Nacional de Información y Evaluación de la Calidad Educativa (DiNIECE) en el período 1998-2003. Los datos disponibles permiten construir una serie de indicadores relevantes para los niveles de educación primario y medio. Sin embargo, no se cuenta con información más allá de la matrícula para los niveles de educación inicial y terciario.

Con respecto a los resultados de los ONE, como se mencionara en la sección 5.3.1. no se cuenta con información para el período 2001-2002, por lo que al igual que en el caso de las características docentes, se supone para estos años que se mantiene constante la tasa promedio de crecimiento anual registrada para el período 1998-2000.

En todos los casos los resultados se ajustan considerando el costo asociado a cada nivel educativo.

\footnotetext{
${ }^{55}$ Con respecto a los factores socioeconómicos que son exógenos al sistema educativo y la discusión de si este sistema - la escuela, los docentes, las gestiones- puede y/o debe comenzar a aceptar esa realidad (endogeneizarla) y emprender la búsqueda de soluciones superadoras de los limitantes exógenos, se encuentra fuera de los alcances de este trabajo.
} 
En primer lugar se calcula un índice a partir del número de alumnos que completan exitosamente el año en curso; se reformula la matrícula de cada año para considerar los alumnos que promovieron al año de educación siguiente. De este modo si la matrícula total es 100 y el porcentaje de alumnos que se inscriben como repitentes al año siguiente sumado al porcentaje que no se inscribe en el año siguiente es $7 \%$, se considera para el indicador de volumen 93 alumnos en ese nivel para ese año ${ }^{56}$.

En segundo lugar se calcula un índice que contempla la tasa de variación de la duración media de la permanencia de los egresados. En este caso al número de alumnos matriculados se lo multiplica por la relación entre la cantidad nominal de años de duración del nivel respectivo y la duración teórica del mismo.

Por último se calcula un índice que incorpora los resultados de las pruebas de calidad. Aquí, a la matrícula asociada a cada nivel, se la multiplica por el porcentaje de aciertos promedio del año en las evaluaciones realizadas en los $\mathrm{ONE}^{57}$. Estos porcentajes están ajustados para contemplar los cambios en el nivel de dificultad de las pruebas ${ }^{58}$.

Los resultados se reproducen en el cuadro XXIX y en el gráfico VII. En el caso donde la matrícula se ajusta para considerar el número de alumnos promovidos, la información disponible contempla que la cantidad de éstos en la educación primaria y media, al igual que la matrícula, aumentó de manera constante en todo el período. Las únicas excepciones se registraron para la educación media en 2002 cuando el número de alumnos que aprobaron el año se redujo levemente con respecto a 2001 en 0,63\% y para la educación primaria que entre 1998 y 1999 presentó una reducción de $0,12 \%$.

\section{Cuadro XXIX}

Gasto público consolidado en educación básica y terciaria, 1998-2002

Deflactor: matrícula ajustada-ponderando por costos

\begin{tabular}{|c|c|c|c|c|c|c|}
\hline & 1998 & 1999 & 2000 & 2001 & 2002 & 98-02 \\
\hline En mill.\$ & 10.150 & 11.048 & 11.237 & 11.157 & 10.947 & \\
\hline $\begin{array}{l}\text { Matrícula ajustada por } \\
\text { promovidos }\end{array}$ & 10.500 & 10.589 & 10.901 & 11.157 & 11.210 & \\
\hline$\%$ var. anual & & 0,8 & 3,0 & 2,3 & 0,5 & 6,8 \\
\hline $\begin{array}{l}\text { Matrícula ajustada por } \\
\text { duración }\end{array}$ & 10.461 & 10.599 & 10.975 & 11.157 & 11.213 & \\
\hline$\%$ var. anual & & 1,3 & 3,6 & 1,7 & 0,5 & 7,2 \\
\hline $\begin{array}{l}\text { Matrícula ajustada por } \\
\text { resultados }\end{array}$ & 10.997 & 10.792 & 11.190 & 11.157 & 11.097 & \\
\hline$\%$ var. anual & & $-1,9$ & 3,7 & $-0,3$ & $-0,5$ & 0,9 \\
\hline
\end{tabular}

Fuente: elaboración propia sobre la base de DAGPYPS y MECyT.

Con respecto a la matrícula que no considera ajustes por calidad, la mayor diferencia en cuanto a la variación porcentual entre ésta y la cantidad de promovidos, se registró entre 2000 y 2001 para la educación media (3,42 puntos porcentuales). En este caso, el incremento en el número de alumnos

\footnotetext{
${ }^{56}$ Los porcentajes mencionados corresponden a la tasa de repitencia y a la tasa de abandono interanual que elabora el MECyT como parte de un conjunto de indicadores de proceso del sistema educativo.

${ }^{57}$ Dado que no se realizan evaluaciones para cada uno de los años de estudio, se aplica para los tres primeros años de la educación primaria los resultados que obtuvieron los alumnos evaluados en el 3er grado, para los restantes alumnos de primaria los resultados de los de 6to y para la educación media en el primer tramo los resultados de los alumnos en 3er año y para el resto, los del último año. A su vez, se realiza un promedio entre los porcentajes de acierto en las evaluaciones de Lengua y Matemática.

${ }^{58}$ Debido a que la dificultad de las pruebas se va modificando año tras año, los puntajes, expresados como porcentaje de aciertos, no deberían ser comparados con el objetivo de inferir el grado de avance o retroceso del desempeño académico de los alumnos en el tiempo. Para analizar las tendencias de los resultados en un período determinado, las puntuaciones necesariamente deben "equipararse".La equiparación de puntuaciones es un procedimiento estadístico que permite ajustar diferencias en la dificultad de distintas pruebas. Una vez realizado este proceso, la variación en
} 
que promovieron al año siguiente pudo haberse debido al cambio en los requisitos de aprobación que fueran comentados en secciones anteriores. A partir de esto, es probable que el incremento en el indicador esté sobreestimado.

Con respecto a la matrícula ajustada por duración, el número de años promedio que le requiere a un alumno graduarse en la educación primaria, aumentó levemente a lo largo del período $(0,54 \%)$ mientras que en el caso de educación media disminuyó $(-0,50 \%)$. Dado que la variación porcentual no fue muy importante en este indicador, su aplicación arroja resultados similares al caso en donde se utiliza la matrícula sin ajustar por calidad.

Por último, con respecto al indicador que considera los resultados en las pruebas de los ONE, se registró en el porcentaje de aciertos comportamientos disímiles entre los niveles primario y medio. Mientras que en el primer caso el desempeño de los alumnos registró una caída entre 1998 y 1999 y se recuperó en el período siguiente aunque sin alcanzar los niveles iniciales, en el caso de la educación media la evolución de los resultados mostró el comportamiento inverso. El supuesto de

Gráfico VII

Evolución de indicadores de volumen 1998-2002 (1998=100)

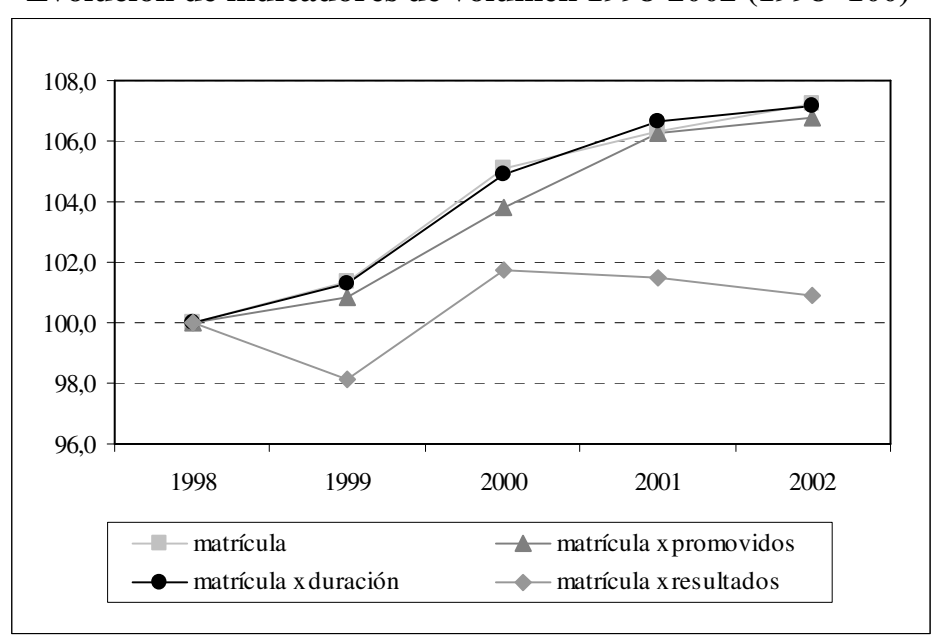

Fuente: elaboración propia sobre la base de DAGPyPS e MECyT.

crecimiento constante para este indicador en el período 2000-2002, dado que las variaciones promedio entre 1998 y 2000 fueron negativas en todos los casos, implica asumir que el porcentaje de aciertos disminuyó a tasas de alrededor de $2 \%$ anual.

\section{La productividad del gasto público educativo}

\subsection{Medición directa: diferencia entre producto e insumos}

Medir la productividad del gasto educativo puede relacionarse con la medición del producto expuesta en la sección anterior. La productividad física relaciona una medida de volumen - el producto del gobierno para un período dado- a los insumos utilizados para producirlo. Para tomar un ejemplo, un aumento en la cantidad de producto mientras se mantiene el nivel de los insumos físicos constante genera, por definición, una mejora en el nivel de productividad física.

Si el comienzo de la serie es el gasto público y el final es la medida de productividad, el orden de los sucesos y las series intermedias que deben generarse puede expresarse a partir del gráfico VIII, basado en el desarrollo de Pritchard (2003).

Tal como se expusiera en secciones previas, el producto y el gasto destinado a él son conceptos diferentes. Un ejemplo simple es la incorporación de un alumno extra a una clase de 10: esto no agrega 10 por ciento al gasto pero si agregará 10 por ciento al producto siempre que la calidad de la educación provista no se vea alterada.

las puntuaciones sí puede interpretarse como consecuencia de distintos niveles de aptitud o conocimientos de los alumnos examinados. El ajuste realizado se basa en estimaciones del MECyT. Ver Perusia (2001). 


\section{Gráfico VIII}

Gasto en insumos que generan el producto educativo

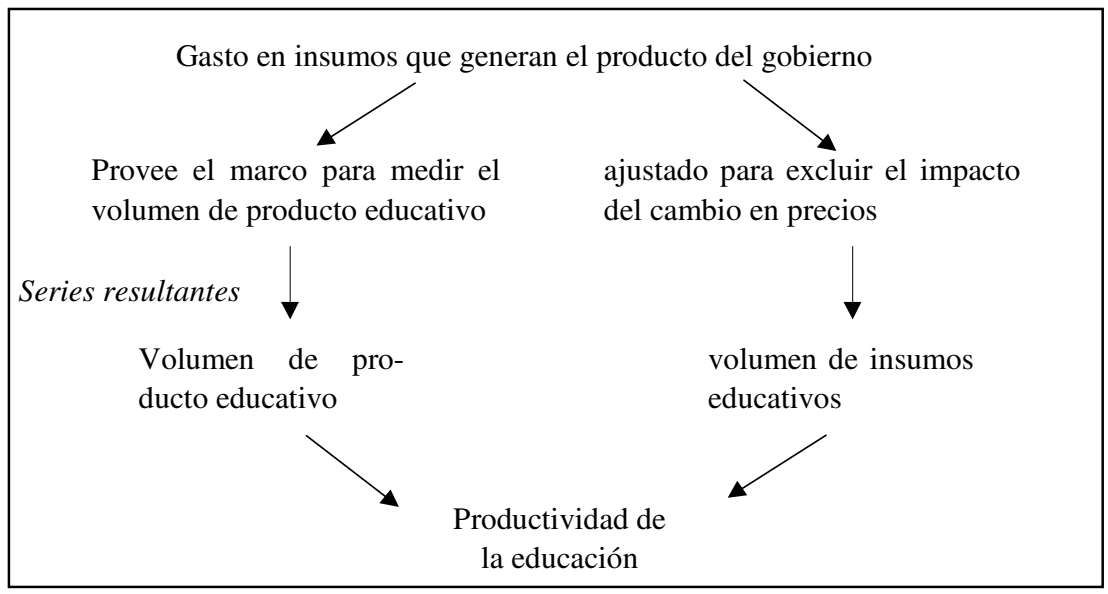

Si el volumen de producto educativo no varía de manera lineal con el gasto, su costo unitario de producción no permanecerá constante, sino que aumentará o se reducirá. Con esto, la relación gasto en el producto de la educación y volumen de producto de la educación resulta de interés. Esta relación, que se conoce habitualmente como el "deflactor implícito", mide el costo por unidad de producto. Es una medida similar a un índice de precios y se interpreta usualmente como una medida de la inflación del sector público. Sin embargo, difiere de un índice de precios como el IPC en un aspecto importante: no es una medida del precio de mercado y no puede ser observada o medida directamente.

El cuadro XXX muestra que entre 1998 y 2002 el gasto en el producto de la educación aumentó $7,9 \%$. En el mismo período, el volumen de producto a partir del número de alumnos promovidos aumentó en 6,8\%. Con lo cual, el deflactor implícito que surge de esta relación aumentó en 1,0\%. Es decir, el costo de producir una unidad de producto creció $1,0 \%$. Sin embargo, este índice no brinda información acerca de cuán eficientemente los recursos se transforman en producto.

Cuadro XXX

Gasto público consolidado en/ producto de la educación básica y terciaria, 1998-2002

\begin{tabular}{|c|c|c|c|c|c|c|}
\hline & 1998 & 1999 & 2000 & 2001 & 2002 & 98-02 \\
\hline $\begin{array}{l}\text { Gasto en educación básica y } \\
\text { terciaria }\end{array}$ & 10.150 & 11.048 & 11.237 & 11.157 & 10.947 & \\
\hline$\%$ var. anual & & 8,9 & 1,7 & $-0,7$ & $-1,9$ & 7,9 \\
\hline $\begin{array}{l}\text { Producto de la educación básica } \\
\text { y terciaria en mill.\$2 } 2001\end{array}$ & 10.500 & 10.589 & 10.901 & 11.157 & 11.210 & \\
\hline$\%$ var. anual & & 0,8 & 3,0 & 2,3 & 0,5 & 6,8 \\
\hline Costo por unidad de producto & 0,97 & 1,04 & 1,03 & 1,00 & 0,98 & \\
\hline
\end{tabular}

Fuente: elaboración propia sobre la base de DAGPyPS y MECyT.

Con respecto al costo por unidad de producto, pueden destacarse los siguientes aspectos:

- Al estar expresado en términos monetarios, reflejará cambios en los precios de los insumos así como cambios en la eficiencia con que éstos se convierten en producto.

- Es posible que, aún cuando los costos por unidad de producto estén aumentando, los recursos puedan ser utilizados más eficientemente año tras año.

- El uso eficiente de los recursos físicos sólo puede ser aislado si se miden los insumos excluyendo el efecto de cambios en precios. 
Surge de aquí la necesidad de relacionar el producto con los insumos que lo generan. Un aumento en el volumen del producto de la educación entre dos años puede resultar de cualquiera de los siguientes escenarios:

- $\mathrm{x} \%$ más de producto se produce utilizando $\mathrm{x} \%$ más de insumos; $\mathrm{o}$

- $\mathrm{x} \%$ más de producto se produce utilizando menos de $\mathrm{x} \%$ más de insumos; $\mathrm{o}$

- $\mathrm{x} \%$ más de producto se produce utilizando más de $\mathrm{x} \%$ más de insumos.

En el primer caso no hay cambios en la productividad, en el segundo hay un aumento y en el tercero una disminución. Para medir la productividad, entonces es necesario conocer dos cosas: el producto y los insumos.

El cuadro XXXI presenta el volumen de producto a partir del número de alumnos promovidos, el volumen de insumos calculado a partir del índice de Paasche encadenado y una estimación indicativa de la variación porcentual de la productividad anual del gasto educativo. El gráfico VIII presenta la evolución de estas variables entre 1998 y 2002.

\section{Cuadro XXXI}

Volumen de producto, volumen de insumos y estimación del cambio anual de la productividad en la educación básica y terciaria, 1998-2002

\begin{tabular}{lrrrrrr}
\hline & $\mathbf{1 9 9 8}$ & $\mathbf{1 9 9 9}$ & $\mathbf{2 0 0 0}$ & $\mathbf{2 0 0 1}$ & $\mathbf{2 0 0 2}$ & $\mathbf{9 8 - 0 2}$ \\
\cline { 2 - 7 } & & 10.589 & 10.901 & 11.157 & 11.210 & \\
$\begin{array}{l}\text { Volumen de producto en } \\
\text { mill.\$ 2001 }\end{array}$ & 10.500 & 0,8 & 3,0 & 2,3 & 0,5 & 6,8 \\
$\%$ var. anual & & 10.012 & 10.583 & 11.157 & 10.760 & \\
$\begin{array}{l}\text { Volumen de insumos en } \\
\text { mill.\$ 2001 }\end{array}$ & 10.210 & $-1,9$ & 5,7 & 5,4 & $-3,6$ & 5,4 \\
$\%$ var. anual & & & & & & \\
$\begin{array}{l}\text { Productividad anual - } \\
\text { estimación indicativa de } \\
\text { la var. en \% }\end{array}$ & 2,8 & $-2,8$ & $-3,1$ & 4,0 & 0,8 \\
\hline
\end{tabular}

Fuente: elaboración propia sobre la base de DAGPyPS y MECyT.

Los resultados indican que la productividad medida de este modo aumentó a lo largo del período $0,8 \%$, registrando variaciones positivas entre 1998 y 1999 , y entre 2001 y 2002 únicamente. En ambos casos se evidenció una disminución en el volumen de insumos mientras que el producto educativo aumentó levemente. Por su parte, entre 1999 y 2001 la caída en la productividad estuvo relacionada con que el aumento en el volumen de insumos superó al que se registró para el producto.
Gráfico VIII

Evolución de volumen de producto, volumen de insumos, productividad 1998-2002 $(1998=100)$

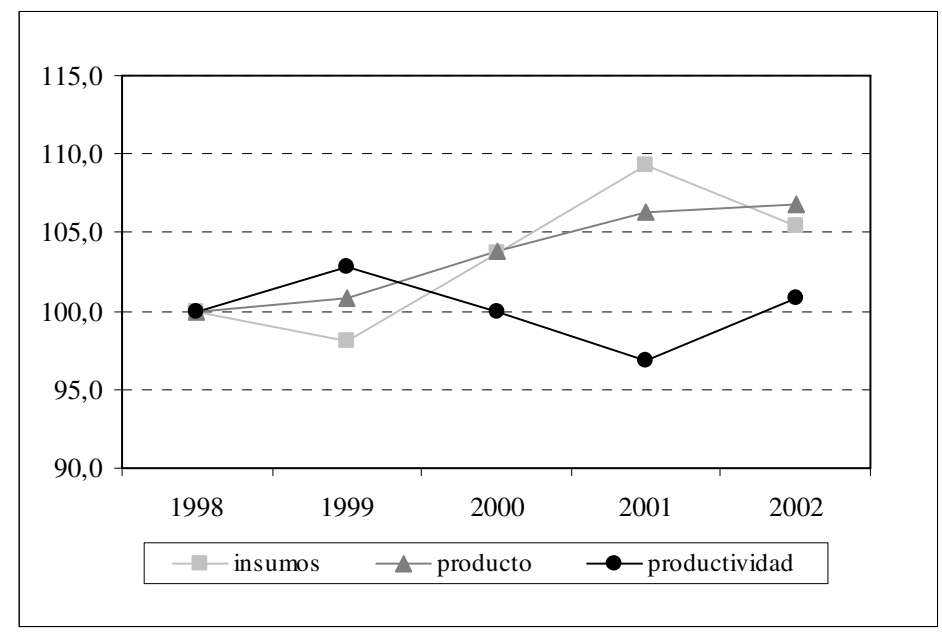

Fuente: elaboración propia sobre la base de DAGPyPS y MECyT.

\section{Consideraciones Finales}

El presente trabajo intenta en primer lugar estudiar cuán sensibles son las estimaciones del gasto público educativo en términos constantes a los deflactores utilizados para calcularlas. En particular, 
a partir de analizar las dificultades asociadas a la utilización de los deflactores habituales, surge que los resultados basados en ellos pueden derivar en conclusiones erróneas ${ }^{59}$.

En este sentido, mientras que a partir de los índices usuales el gasto en términos constantes cae significativamente en el período 1998-2002, los resultados de las distintas alternativas evaluadas muestran en todos los casos que los recursos reales destinados a la educación presentaron un aumento entre esos años.

De este modo, si bien la elección de alguna metodología particular está íntimamente relacionada con la disponibilidad de información y con los objetivos que se persigan en cada caso, es posible extraer algunas consideraciones interesantes sobre esta parte del análisis.

En primer lugar, resulta fundamental para evaluar la evolución de los recursos reales destinados al sector educativo, considerar los bienes y servicios involucrados en su producción. Surge del análisis que no resulta suficiente con aproximar el cambio en los precios a partir de índices que consideran canastas construidas atendiendo otros objetivos.

Por otro lado, también es relevante considerar las fluctuaciones en la estructura del gasto (la canasta educativa), en especial cuando se analizan períodos alejados en el tiempo. En este sentido, la alternativa más eficiente es un índice que considere cambios frecuentes en las ponderaciones. En el desarrollo de este punto, se observa que los resultados son similares tanto si se utiliza un índice encadenado de Laspeyres, de Paasche o de Fisher.

La construcción de índices idóneos, requiere a su vez, disponer de una completa estratificación de los datos. La disponibilidad de información desagregada evita incluir en el componente precios, cambios en la calidad y composición de los insumos que deberían incluirse en el volumen.

Este requerimiento es particularmente importante para la porción del gasto que se destina al personal. En este caso, tener en cuenta cambios en la calidad, implica considerar tanto aspectos objetivos como subjetivos. Los primeros se relacionan con características observables tales como la antigüedad en el cargo y la formación académica de los docentes; los segundos se asocian a aspectos más difíciles de cuantificar, como la satisfacción del docente con respecto a la tarea que desempeña o la interrelación del docente con el ámbito en el que desarrolla su actividad.

En este sentido, es interesante también la atención hacia la calidad de los docentes que surge del trabajo de Roshtein y Miles (1995). Los autores argumentan que cuando los salarios docentes aumentan en relación con los salarios de trabajadores comparables en otras áreas, puede presumirse que las escuelas están aumentando la calidad de su fuerza de trabajo. Un índice de precios de la educación podría por tanto tener en cuenta para esta porción del gasto, no sólo el salario asociado al sector sino también la relación de éste con los salarios de sectores comparables.

El trabajo también considera de manera separada las diferencias en el poder de compra real del gasto educativo entre diferentes jurisdicciones. Si el costo de la educación en distintas jurisdicciones difiere, entonces una cantidad dada de gasto en una localidad comprará diferentes cantidades de recursos reales que el mismo gasto en otra localidad. Del análisis planteado, surge que el costo de los docentes, que da cuenta de más del $80 \%$ del gasto, difiere sustancialmente entre las provincias. Se destacan las provincias de la región patagónica con costos muy superiores a la jurisdicción promedio, y en el otro extremo, con costos inferiores la Ciudad de Buenos Aires y la Provincia de Buenos Aires.

En cuanto a la segunda parte del estudio, se encuentra en primer lugar que el producto de la educación puede diferir tanto del gasto destinado a producirlo como de los insumos reales utilizados en su producción. Sin embargo, el gasto en educación en términos constantes estimado a partir de considerar la evolución del producto del sector, también evidencia un aumento para el período analizado.

Los resultados muestran que la aplicación de distintos ajustes para considerar cambios en la calidad puede tener un efecto significativo sobre el producto estimado. El análisis de distintos factores relacionados con insumos y/o procesos educativos, si bien permite tener una noción de cómo la evolu-

\footnotetext{
${ }^{59}$ La controversia acerca de qué índice debe utilizarse para deflactar las series de gasto público aparece considerada
} en Dirección de Análisis de Gasto Público y Programas Sociales (2005). 
ción de cada uno puede influir en la calidad de la educación, y los ejercicios realizados intentan una primera aproximación hacia esto, resta aún avanzar en la investigación sobre el mecanismo a través del cual el cambio en estos factores se traduce en cambios en el producto educativo.

Con respecto a las medidas que incorporan consideraciones de calidad a partir de los resultados, se destaca la influencia que sobre estas puede tener una serie de factores que están fuera del alcance de los prestadores del servicio educativo. A pesar de ello, estas medidas son las que presentan las mejores perspectivas en cuanto a capturar empíricamente cambios en la calidad; y son de hecho, las más utilizadas en los desarrollos a nivel internacional. Una aproximación que puede ser considerada en el futuro es partir de una medida de resultado como índice base, y luego transformar esta medida en una medida de producto a partir de aislar el impacto de factores exógenos al sistema educativo.

En la última parte del trabajo se presenta, a partir de los resultados obtenidos en las secciones previas, una estimación de la productividad del gasto educativo. El cálculo realizado tiene el objetivo de brindar un primer acercamiento sobre este aspecto, por lo tanto los resultados deben tomarse con cautela. Sin embargo, es interesante notar que contar en el futuro con mejores estimaciones del volumen de insumos y particularmente el avance sobre el desarrollo de medidas de producto, permitirán mejorar esta estimación y obtener resultados progresivamente más confiables.

Por último, es importante mencionar dos aspectos: en primer lugar, si bien el estudio está enfocado hacia el gasto público en educación básica y terciaria, y al comportamiento de éste para un cierto período, resulta necesario extender el análisis hacia las restantes funciones del gasto público. Esto es, tanto con respecto a la medición del gasto real que se destina a cada sector, como a la evaluación de las prestaciones que el Estado brinda en cada caso.

Por otro lado, se destaca que la disponibilidad de información resulta un factor limitante para el desarrollo de este tipo de estudio. Sobre este punto, puede mencionarse una serie de iniciativas, generadas desde distintos ámbitos, que probablemente permitan lograr en el futuro un avance considerable en cuanto a los temas abordados. En particular: el desarrollo del índice de salarios de INDEC, especialmente si se contara en un futuro con la desagregación del mismo por ocupación, rama de actividad y jurisdicción; la disponibilidad de las Paridades de Poder de Compra del Consumidor para distintos puntos del tiempo; la disponibilidad de los datos que surgen de los Operativos Nacionales de Evaluación de 2002 y 2003 y del Censo Nacional Docente 2004; la disponibilidad de datos de gasto con mayor desagregación para las provincias; el avance sobre los puntos incorporados en el Régimen Federal de Responsabilidad Fiscal ${ }^{60}$; y el avance internacional en la investigación sobre medidas basadas en el producto.

\footnotetext{
${ }^{60}$ El artículo $8^{\circ}$ de la Ley $N^{\circ} 25.917$ (Régimen Federal de Responsabilidad Fiscal) establece que "Los gobiernos provinciales, de la Ciudad Autónoma de Buenos Aires y el Gobierno nacional, tomarán las medidas necesarias para calcular parámetros e indicadores homogéneos de gestión pública que midan (...) eficiencia en materia de gasto público, a los efectos de que permitan realizar comparaciones interjurisdiccionales,..." Asimismo, en el Decreto 1731/2004 que reglamenta la citada ley, se establece que las medidas deberán tener una periodicidad anual como mínimo y preverse un cálculo inicial para el año 2006. Con relación a la gestión del gasto público, el decreto prevé la generación de "indicadores significativos que permitan captar la economicidad, es decir, el costo de los insumos utilizados; así como la eficiencia, esto es, la relación entre los insumos y productos que muestre la combinación de los elementos utilizados en los procesos de producción de bienes o servicios. En la construcción de tales indicadores se considerarán al menos los servicios y bienes derivados de la prestación de seguridad interior, defensa, justicia y función legislativa, que prestan los gobiernos, y las funciones que forman parte de los servicios sociales y económicos."
} 


\section{Bibliografía}

- Abuelafia, E. (2003). Estimating the scope for governmental interventions to improve education performance. University of Cambridge.

- Burke, G. y White, P. (2003). Price measures in education and training: opening a discussion. Monash University-ACER Centre for the Economics of Education and Training, Australia. WP N`53.

- Centro de Estudios Distributivos, Laborales y Sociales (2005). Estadísticas Argentina - Education Mobility (1992-2004). Universidad Nacional de La Plata, La Plata.

- CEPAL (1994). Panorama social de América Latina. Edición 1994, Santiago de Chile.

- Chambers, J y Fowler, W. (1995). Public School Teacher Cost Differences across the United States. Washington, DC: U.S. Department of Education, National Center for Education Statistics, NCES 95758.

- Contaduría General de la Nación (1998, 1999, 2000, 2001 y 2002). Cuenta de Inversión. Ministerio de Economía y Producción, Buenos Aires, Argentina.

http://www.mecon.gov.ar/hacienda/cgn/cuenta/default1.htm

- Coordinación General de Estudio de Costos del Sistema Educativo (2005). Informe Indicativo de Salarios Docentes. Ministerio de Educación, Ciencia y Tecnología, Buenos Aires.

- Dehn, J., Reinikka, R. y Svensson, J. (2002). Survey Tools for Assessing Service Delivery. Development Research Group, World Bank Institute.

- Delfino, J. (2002). Introducción a la teoría económica de los números índices. Documento de trabajo $\mathrm{N}^{\circ}$ 14. Facultad de Ciencias Económicas, Universidad Nacional de Córdoba.

- Dirección de Análisis de Gasto Público y Programas Sociales (2005). Informe sobre los programas de empleo de ejecución provincial 2003. Documento de Trabajo N GP/15. Ministerio de Economía y Producción, Buenos Aires.

- Dirección de Análisis de Gasto Público y Programas Sociales (2005). Series de Gasto Público Consolidado por finalidad-función (1980-2003). Ministerio de Economía y Producción, Buenos Aires.

- Dirección de Evaluación Presupuestaria (2005). Indicadores de la Administración Pública Nacional 1994-2002. Oficina Nacional de Presupuesto. Ministerio de Economía y Producción, Buenos Aires.

- Dirección de Índices de Precios de Consumo (2002). Paridades de Poder de Compra del Consumidor. INDEC, Buenos Aires.

- Dirie, C. y Oiberman, I. (2001). La profesión docente en el mercado de trabajo actual. Estudios del Trabajo, $\mathrm{N}^{\circ}$ 22, Asociación Argentina de Especialistas de Estudios del Trabajo, Buenos Aires.

- Eskeland, G. y Filmer, D. (2002). Autonomy, Participation, and Learning in Argentine Schools: Findings, and their Implications for Decentralization. Development Research Group, World Bank Institute.

- European Commission (2003). UK price and volume (ESA95) inventory. EUROSTAT, Luxembourg.

- European Commission (2001). Handbook on price and volume measures in national accounts. EUROSTAT, Luxembourg.

- European Commission (1998). Final Report of the Task Force "Prices and Volumes for Education". EUROSTAT, Luxembourg.

- Fowler, W. J. Jr. y Monk, D. (2001). A Primer for making cost adjustments in education. Washington, DC: U.S. Department of Education, National Center for Education Statistics, NCES 2001-323. 
- Fraumeni, B., Reinsdorf, M., Robinson, B. y Williams, M. (2004). Real Output Measures for the Education Function of Government: A First Look at Primary \& Secondary Education. Presented at the Public Services Performance Workshop National Institute of Economic and Social Research, London, UK.

- Hanushek, E. (1995). Interpreting Recent Research on Schooling in Developing Countries. The World Bank Observer, 10 N² (August), pp. 227-246.

- Hanushek, E. A., Kain, J. F. y Rivkin, S. G. (1998). Teachers, Schools and Academic Achievement. National Bureau of Economic Research Working Papers. W6691.

- Hanushek, E. (2002). The failure of input-based schooling policies. National Bureau of Economic Research Working Papers. W9040.

- Hanushek, E. (2000). Publicly Provided Education. En Auerbach, A. y Feldstein, M. (ed.), Handbook of Public Economics, Amsterdam: North-Holland, pp. 2047-2143.

- Hughes, A. (2002). General government consumption at constant prices. ONS, United Kingdom.

- Jenkinson, G. (2003). Measuring the volume of government outputs. OECD Meeting of National Accounts Experts, Paris. STD/NA(2003)14.

- Jorgenson, D.W. y Slesnick, D.T. (1983) Individual and Social Cost of Living Indexes. En W.E. Diewert y C. Montmarquette, eds., Price Level Measurement (Statistics Canada, Ottawa) pp. 241-323.

- Konijn, P. y Kleima, F. (2000). Volume Measurement of Education. OECD Meeting of National Accounts Experts, Paris. STD/NA(2000)27.

- Krueger, A. (2002). Economic considerations and class size. Economic Journal.

- Llach, J.J., Montoya, S. y Roldán F. (1999). Educación para todos. Instituto de Estudios de la Realidad Argentina y Latinoamericana. Córdoba.

- Lódola, A., Busso, M. y Cerimedo, F. (2001).Sesgos en el Índice de Precios al Consumidor: El Sesgo Plutocrático en Argentina. Universidad Nacional de La Plata y Ministerio de Economía de la Provincia de Buenos Aires.

- Malizia, R. (1998). The estimation of general government services at constant prices: Methodology and application proposal for Italy. Joint OECD/ESCAP meeting on National Accounts - 1993 System of National Accounts: Five Years On. Bangkok, 4-8 May 1998.

- Mayer, D. P., Mullens, J. y Moore, M. (2000). Monitoring School Quality: An Indicators Report .Washington, DC: U.S. Department of Education. National Center for Education Statistics, NCES 2001-030.

- Ministerio de Cultura y Educación (1999). Factores asociados al logro escolar / 3: Características institucionales y rendimiento escolar en Matemática, Alumnos de $7^{\circ}$ año - Escuela urbana -Operativo Nacional de Evaluación 1995-1997.

- Ministerio de Cultura y Educación (2000). Factores asociados al logro escolar / 4: La Institución Educativa de Nivel Medio y el Rendimiento en Matemática, Directores del Nivel Medio - 1997/1998.

- Morduchowicz, A. (1995). Alcances, limitaciones y alternativas al gasto por alumno: qué nos dice la experiencia argentina. Programa Estudio de Costos del Sistema Educativo. Secretaría de Programación y Evaluación Educativa. Ministerio de Cultura y Educación. Buenos Aires.

- Morduchowicz, A. (1997). La estructura salarial docente en la Argentina: conceptos, dificultades y evidencia empírica. Programa Estudio de Costos del Sistema Educativo. Secretaría de Programación y Evaluación Educativa. Ministerio de Cultura y Educación. Buenos Aires.

- Morduchowicz, A. (2002). El financiamiento educativo en Argentina: Problemas estructurales, soluciones coyunturales. IIPE - UNESCO - Sede Regional Buenos Aires. 
- Murillo, Ronconi, Sanguinetti y Tommasi (2001). The economic effects of unions in Latin America: teachers' unions and education in Argentina. Centro de Estudios para el Desarrollo Institucional (CEDI, Fundación Gobierno y Sociedad), Doc. № 56.

- Naciones Unidas (1979). Manual de cuentas nacionales a precios constantes. Informes Estadísticos, Serie M N ${ }^{\circ} 64$, New York.

- Parandekar, S., España, S. y Savanti, M.P. (2003). El impacto de la crisis en el proceso educativo en Argentina. Documento de Trabajo N.3/03. Oficina del Banco Mundial para Argentina, Chile, Paraguay y Uruguay.

- Perusia, J. C. (2001): Evolución de los resultados de los operativos de evaluación de la calidad educativa. Puntuaciones equiparadas de las pruebas de lengua y matemática. Instituto para el Desarrollo de la Calidad Educativa, Ministerio de Educación. Documento de trabajo $\mathrm{N}^{\circ} 13$.

- Porto, A. (2002). Microeconomía y Federalismo Fiscal. Serie Economía I. Editorial de la Universidad de La Plata, La Plata.

- Pradhan, S. (1996). Evaluating Public Spending, A Framework for Public Expenditure Reviews. World Bank Discussion Papers $N^{\circ} 323$.

- Pritchard, A. y Powell, M. (2001). Direct measures of government output: a few conceptual and practical issues. OECD Meeting of National Accounts Experts, Paris. STD/NA(2001)28.

- Pritchard, A. (2003). Understanding government output and productivity. Economic Trends $\mathrm{N}^{\circ} 596$, pp. 27-40.

- Pritchard, I. (1999). Reducing Class Size. What Do We Know?. National Institute of Student Achievement, Curriculum and Assessment. Office of Educational Research and Improvement, U.S. Department of Education.

- Pritchett, L. and Filmer, D. (1999): What Education Production Functions Really Show: a Positive Theory of Educational Expenditures. Economics of Education Review 18, pp. 223-239.

- Rothstein, R. y Miles, K. H. (1995). Where's the Money Gone? Changes in the Level and Composition of Education Spending. Washington, DC: The Economic Policy Institute.

- Rothstein, R. y Mishel, L. (1997). Alternative Options for Deflating Education Expenditures over Time. En W. J. Fowler, Jr. (ed.), Developments in School Finance, 1996. Washington, DC: U.S. Department of Education, National Center for Education Statistics, NCES 97-535.

- Tuke, A. (2004). The Atkinson Review of Measurement of Government Output. Conference on Measuring Performance in the Public Sector, March.

- Unesco (2000). Primer Estudio Internacional Comparativo sobre lenguaje, matemática y factores asociados, para alumnos del tercer y cuarto grado de la educación básica - Segundo Informe. Laboratorio Latinoamericano de Evaluación de la Calidad de la Educación, Oficina Regional de Educación para América Latina y el Caribe, Santiago de Chile.

- United Nations (1993). System of National Accounts 1993.

- Velez, E., Schiefelbein, E. y Valenzuela, J. (1994). Factores que afectan el rendimiento académico en la educación primaria: revisión de la literatura de América Latina y el Caribe. Revista Latinoamericana de Innovaciones Educativas n. 17, vol. 6. Argentina. Ministerio de Educación y Justicia; OEA.

- Wolff L., Schiefelbein E. y Valenzuela J. (1994). Mejoramiento de la Calidad de la Educación Primaria en América Latina y el Caribe: Hacia el Siglo XXI. World Bank Discussion Papers N 257. Washington, DC, World Bank.

- Zhao, S. y Jones, M. (2001). The output of the government education sector: experimental estimates and issues. Australian Bureau of Statistics. 


\section{Anexos}

\subsection{Ley Federal de Educación}

En 1993, la Ley Federal de Educación No 24.195 (LFE) modifica la estructura del sistema educativo y el nuevo sistema queda conformado por los siguientes niveles:

- Educación inicial: constituida por el jardín maternal -3 y 4 años- y el jardín de infantes -5 años-.

- Educación general básica: obligatoria, de nueve años de duración a partir de los 6 años de edad, organizada en tres ciclos.

- Educación polimodal: impartida por instituciones específicas de tres años de duración como mínimo.

En el siguiente esquema se compara este sistema con el anterior. A partir de la reforma educativa, la educación inicial para los niños de 5 años se convierte en obligatoria; la educación primaria se reemplaza por la EGB y su obligatoriedad se extiende de 7 a 9 años, y la educación secundaria o media se transforma en polimodal. De este modo, la normativa actual establece, en el ámbito nacional, 10 años de escolarización obligatoria que culminan con el último año de la Educación General Básica e imponen una permanencia en el sistema escolar hasta los 14 años de edad. En relación con el segundo punto, se estipula una correspondencia entre edades y niveles: 6 a 11 años para EGB 1 y 2; 12 a 14 para EGB 3 y 15 a 17 para polimodal.

\section{Comparación de estructuras educativas}

$\begin{array}{lllll}\text { Edad } & 3 & 6 & 13 & 18\end{array}$

\begin{tabular}{|c|c|c|c|}
\hline Antes LFE & Inicial & Primaria & Secundaria \\
\hline Después LFE & Inicial & Escuela General Básica & Polimodal \\
\hline
\end{tabular}

Nota: los niveles obligatorios se distinguen mediante el tramado.

Fuente: elaboración propia sobre la base de Ley Federal de Educación. 


\subsection{Variables utilizadas en la estimación del modelo de salarios hedónicos}

\begin{tabular}{|c|c|c|c|c|c|}
\hline variable & descripción & fuente & año & media & desvío \\
\hline $\ln$ (salarios) & $\begin{array}{l}\text { salario bruto de docentes con } 10 \text { años de } \\
\text { antigüedad para maestros de grado de } \\
\text { jornada simple/ profesores hora cátedra } \\
\text { en escuelas de educación común }\end{array}$ & $\begin{array}{l}\text { Coordinación General de } \\
\text { Estudio de Costos del Sistema } \\
\text { Educativo-MEyCT }\end{array}$ & 2002 & 6,317 & 0,244 \\
\hline $\begin{array}{l}\text { paridad de poder de com- } \\
\text { pra del consumidor }\end{array}$ & $\begin{array}{l}\text { relación entre el costo de una canasta de } \\
\text { bienes y servicios representativos del } \\
\text { consumo de una región y el costo de la } \\
\text { misma canasta a los precios medios de } \\
\text { otra región de referencia }\end{array}$ & INDEC & 2001 & 89,588 & 3,118 \\
\hline densidad de población & cantidad de habitantes por $\mathrm{km} 2$ & Censo-INDEC & 2001 & 582,1 & $2.789,8$ \\
\hline tasa de desocupación & $\begin{array}{l}\text { relación entre la cantidad de desocupados } \\
\text { y la cantidad de población económica- } \\
\text { mente activa }\end{array}$ & EPH-INDEC & 2002 & 14,867 & 4,244 \\
\hline tasa de crimen & $\begin{array}{l}\text { cantidad de hechos delictuosos cada } 1000 \\
\text { habitantes }\end{array}$ & $\begin{array}{l}\text { Sistema Nacional de Informa- } \\
\text { ción Criminal }\end{array}$ & 2002 & 40,442 & 14,287 \\
\hline temperatura & $\begin{array}{l}\text { temperatura media anual en grados } \\
\text { celcius }\end{array}$ & $\begin{array}{l}\text { Servicio } \quad \text { Meteorológico } \\
\text { Nacional }\end{array}$ & 2002 & 16,963 & 3,994 \\
\hline distancia de CBA & $\begin{array}{l}\text { distancia de la capital provincial a la } \\
\text { Ciudad de Buenos Aires en kilómetros }\end{array}$ & $\begin{array}{l}\text { Atlas Clarín de la Rep. Ar- } \\
\text { gentina }\end{array}$ & - & $1.140,9$ & 699,1 \\
\hline formación docente & $\begin{array}{l}\text { promedio provincial para un índice que } \\
\text { otorga a cada docente un puntaje ( } 0 \text { a } 100 \\
\text { puntos) en base a su situación respecto a } \\
\text { variables significativas de su formación: } \\
\text { máximo nivel educativo alcanzado, } \\
\text { títulos obtenidos, acreditación de forma- } \\
\text { ción docente, asistencia a cursos de } \\
\text { capacitación y estudios en curso. }\end{array}$ & $\begin{array}{l}\text { Censo Nacional de Docentes y } \\
\text { Establecimientos Educativos- } \\
\text { MEyCT }\end{array}$ & 1994 & 74,117 & 1,818 \\
\hline experiencia docente & $\begin{array}{l}\text { antigüedad promedio de los docentes en } \\
\text { actividad }\end{array}$ & $\begin{array}{l}\text { Censo Nacional de Docentes y } \\
\text { Establecimientos Educativos- } \\
\text { MEyCT }\end{array}$ & 1994 & 9,413 & 1,082 \\
\hline matrícula & $\begin{array}{l}\text { cantidad de alumnos en educación común } \\
\text { en la provincia, en relación con el total } \\
\text { del país }\end{array}$ & $\begin{array}{l}\text { Dirección Nacional de Infor- } \\
\text { mación y Evaluación de la } \\
\text { Calidad Educativa-MEyCT }\end{array}$ & 2002 & 0,042 & 0,075 \\
\hline sindicatos & $\begin{array}{l}\begin{array}{l}\text { cantidad de sindicatos cada } 10.000 \\
\text { docentes }\end{array}\end{array}$ & $\begin{array}{l}\text { Murillo et al (2001) sobre la } \\
\text { base de Dirección Nacional de } \\
\text { Asociaciones Sindicales }\end{array}$ & 1999 & 5,075 & 7,127 \\
\hline participación gremial & $\begin{array}{l}\text { porcentaje de docentes que declaran } \\
\text { partipación en sindicatos docentes }\end{array}$ & $\begin{array}{l}\text { Murillo et al (2001) sobre la } \\
\text { base de información de la } \\
\text { Encuesta de Desarrollo Social }\end{array}$ & 1997 & 4,613 & 3,941 \\
\hline transferencias nacionales & $\begin{array}{l}\text { relación entre transferencias presupuesta- } \\
\text { rias desde el gobierno nacional y el gasto } \\
\text { provincial }\end{array}$ & $\begin{array}{l}\text { Dirección de Análisis de } \\
\text { Gasto Público y Programas } \\
\text { Sociales - MEyP }\end{array}$ & 2002 & 0,010 & 0,004 \\
\hline $\begin{array}{l}\text { erogaciones netas nacio- } \\
\text { nales }\end{array}$ & $\begin{array}{l}\text { relación entre gasto ejecutado por el } \\
\text { gobierno nacional en cada provincia y el } \\
\text { gasto ejecutado por cada provincia }\end{array}$ & $\begin{array}{l}\text { Dirección de Análisis de } \\
\text { Gasto Público y Programas } \\
\text { Sociales - MEyP }\end{array}$ & 2002 & 0,035 & 0,016 \\
\hline
\end{tabular}

